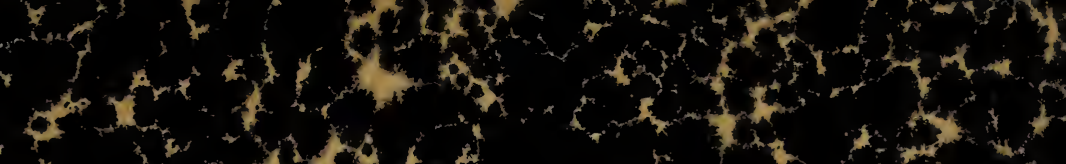

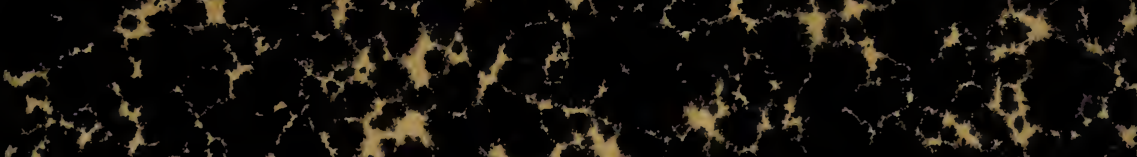

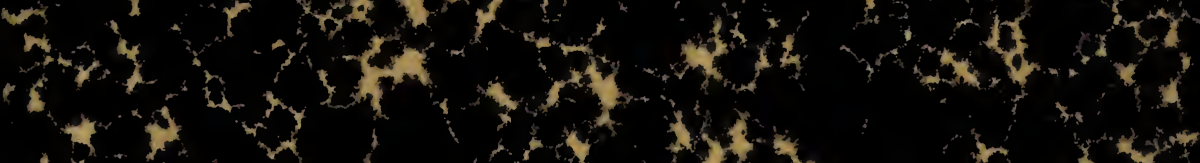

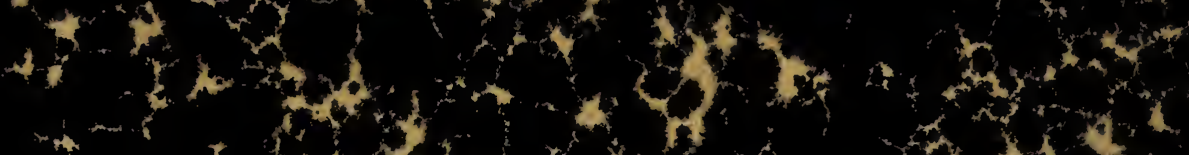

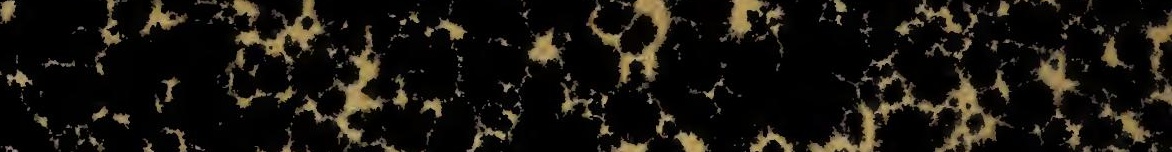

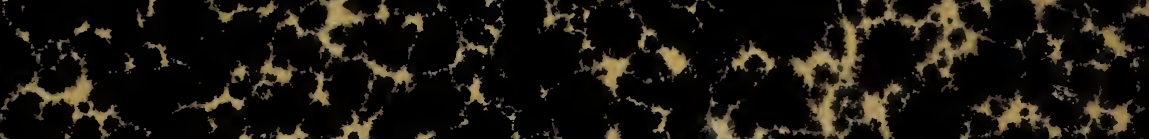

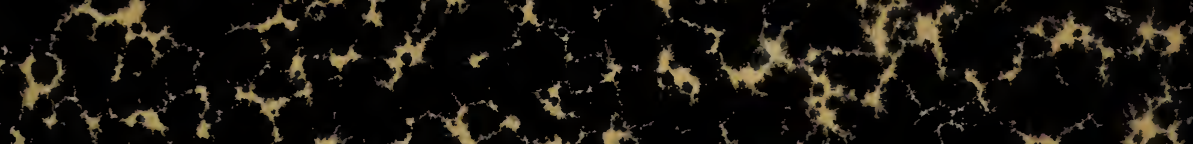

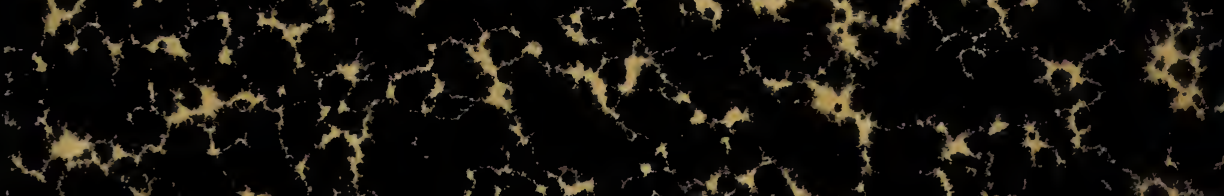

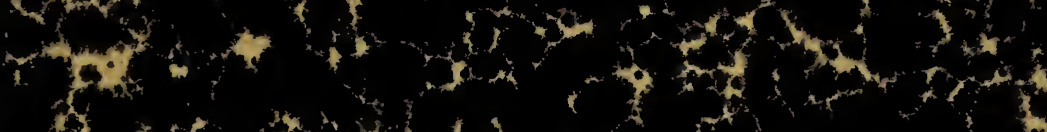

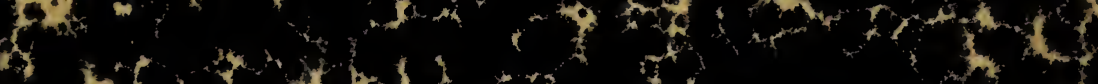

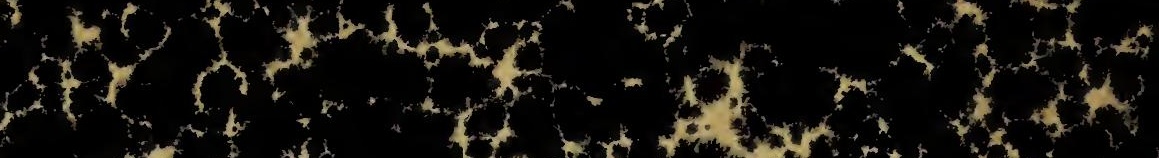

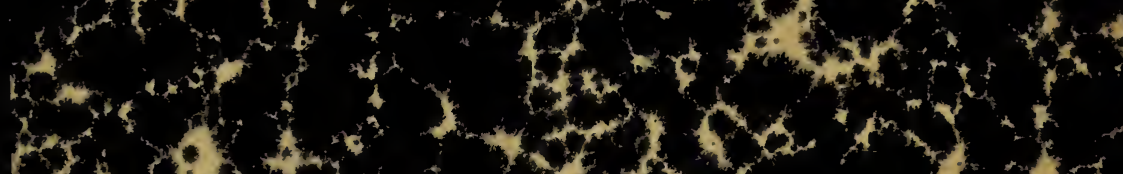

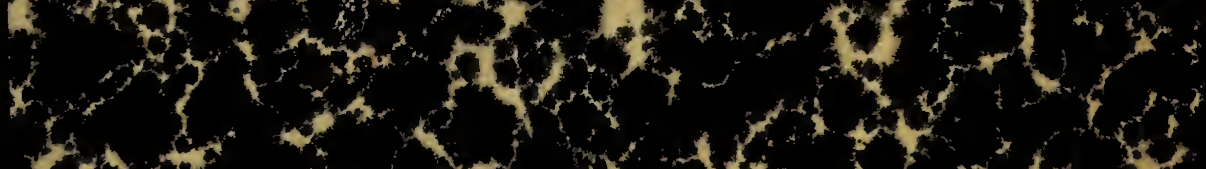

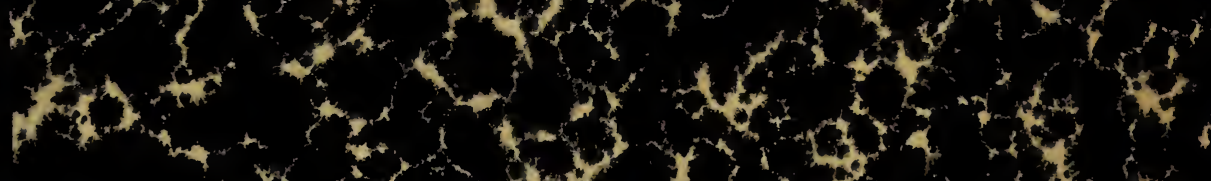

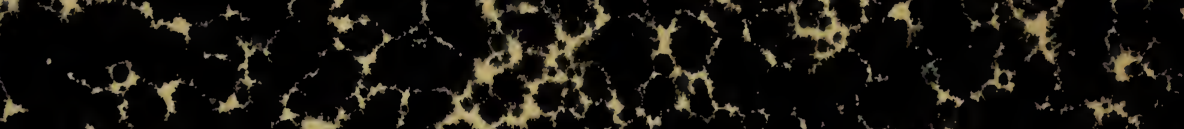

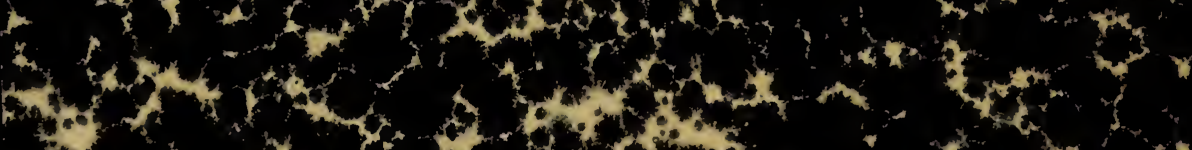

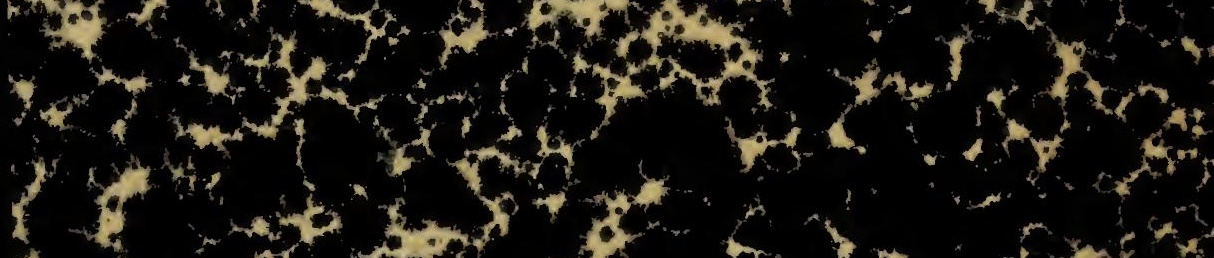

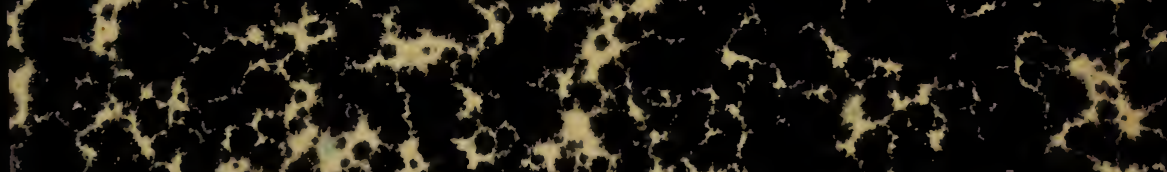

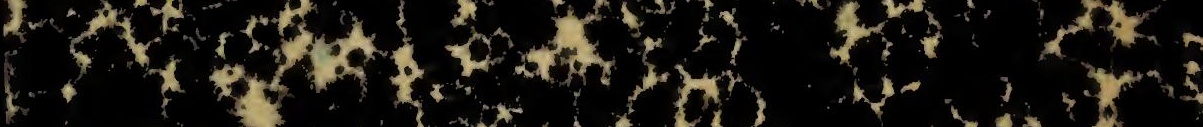

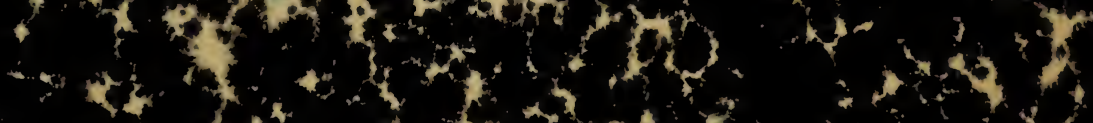

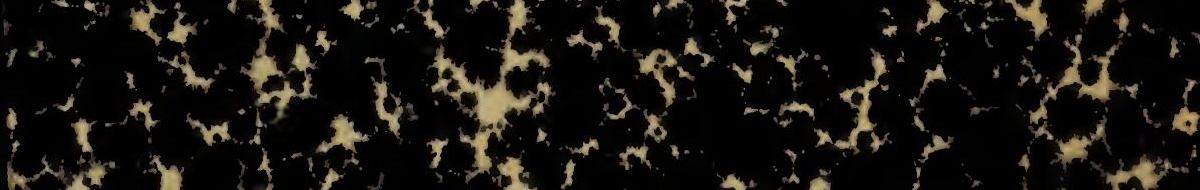

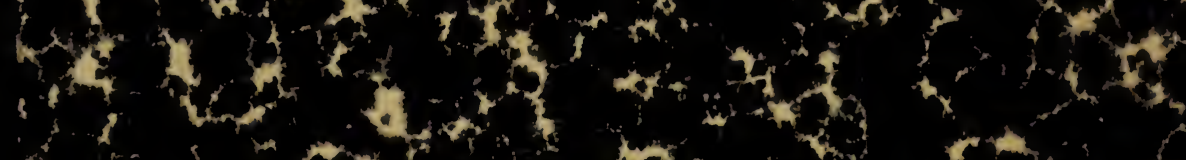
$y+x$ 


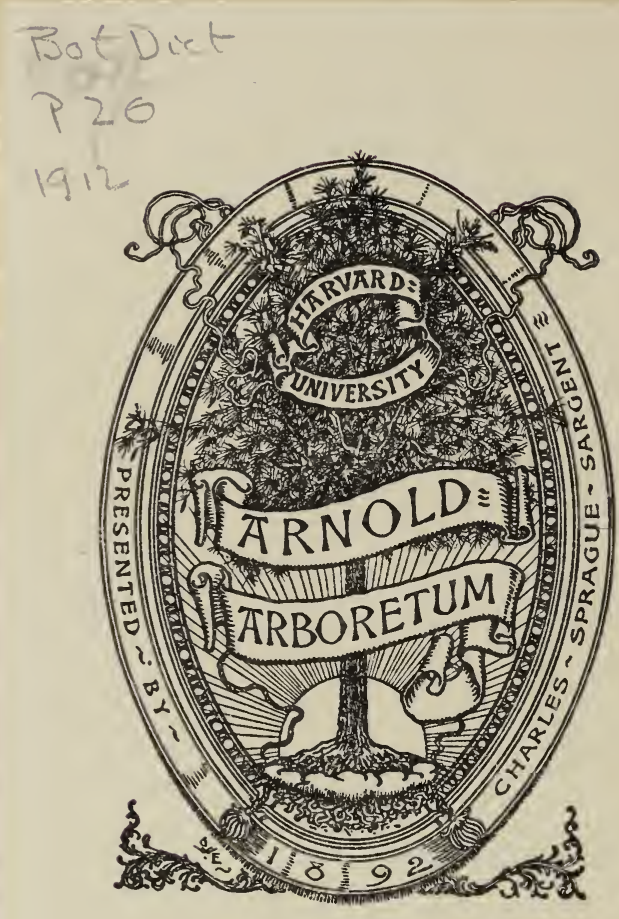






\title{
DE VLAAMSCHE
}

\section{VOLKSNAMEN DER PLANTEN}

vax

België, Fransch-Vlaanderen, Noord-Brabant, Hollandsch-Limburg, enz.

MET AANDUIDING DER TOEPASSINGEN EN DER GENEZENDE EIGENS(HAPPEN IDER PIANTEN

\author{
DOOR \\ E. PAQUE, S. J.
}

Ondervoorzitter van het Kruidkundig Genootschap van België

Gewezen leeraar aan de Faculteit van Wetenschappen te Namen

Werk hekroond door het Kruidkundig Genootschap van België Goedgekeurd door den Verbeteringsraad

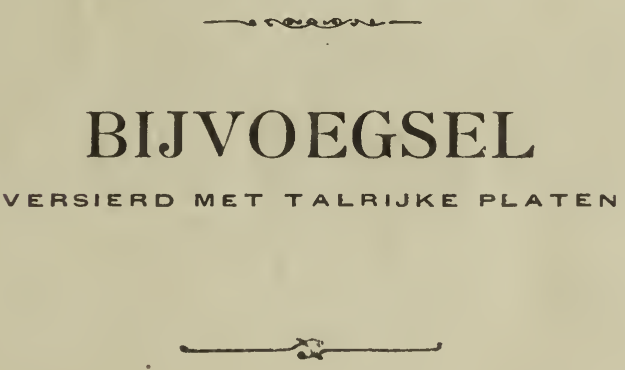

BRUSSEL

WETENSCHAPPILIJKE DRUKKERIJ

KARE, BULANS, UITGEVER

75 , Nieuw-Landstraat

$$
\text { ז }
$$



DE VLAAMSCHE

\section{VOLKSNAMEN DER PLANTEN}


Digitized by the Internet Archive in 2017 with funding from BHL-SIL-FEDLINK 


\section{DE VLAAMSCHE}

\section{VOLKSNAMEN DER PLANTEN}

rax

België, Fransch-Vlaanderen, Noord-Brabant, Hollandsch-Limburg, enz.

MET AANDUIDING DER TOEPASSINGEN EN DER GENEZENDE EIGENSCHAPPEN DER PLANTEN

DOOR

$$
\text { E. PAQUE, S. J. }
$$

Ondervoorzitter van het Kruidkundig Genootschap van België Gewezen leeraar aan de Faculteit van Wetenschappen te Namen

Werk bekroond door het Kruidkundig Genootschap van België Goedgekeurd door den Verbeteringsraad

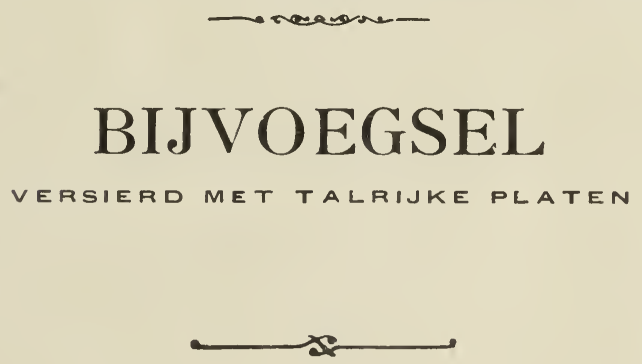

BRUSSEL

WETEXSCHAPPELIJKE DRUKKERIJ

KAREI, BCLANS, UITGEVER

75. Nieuw-Landstraat

I 912 


$$
\begin{aligned}
& \operatorname{Nov} 1913 \\
& 28846
\end{aligned}
$$




\section{INLEIDING}

In 1896, verscheen ons boek : De Vlaamsche Volksnamen der Planten van België, enz., dat door het publiek buitengewoon goedgunstig onthaald werd.

' $t$ Is met genoegen dat wij de huidige gelegenheid te baat nemen om aan al onze geachte medewerkers en aanmoedigers de uitdrukking van onzen innigen dank aan te bieden.

Bijzondere erkentenis zijn wij ook verschuldigd aan de opstellers der dagbladen en tijdschriften die, door hunne welwillende verslagen, niet weinig hebben bijgebracht om de kennis van ons boek te verspreiden en zijnen bijval te verzekeren.

Onder de talrijke getuigschriften, die wij zouden kunnen aanhalen, ontleenen wij eenige regels aan den diepbetreurden Fr. de Potter, secretaris der Koninklijke Vlaamsche Academie.

In de Bibliographische Aanteekeningen welke hij, in de Uitgaven der Academie (1896), neerschreef, lezen wij onder anderen :

... « Deze korte ontleding van het werk des heeren Pâque bewijst genoeg, meenen wij, zijn groot nut en ongemeene waarde. Schrijver is een alleszins bevoegd man, die aan zijne studie de meeste zorg heeft besteed. Ten bewijze hiervan zij gezegd, dat de volksnamen der planten verzameld zijn in niet min dan 271 gemeenten of gehuchten van Zuid-Nederland...

»De geleerde Opstellers van het Woordenboek der Nederlandsche Taal zullen het boek des heeren Pâque met vrucht raadplegen; althans men vindt er vele plantenen bloemennamen, levende in den mond des volks en 
alleszins verdienende bewaard te blijven. Enkele zijn in de reeds verschenen afleveringen vergeten, zooals :...

»Laten wij den heer Pâque dankzeǵgen voor het verbazend vele, dat hij op den weligen akker der Belgische Flora en Pomona heeft saamgelezen...

» Ten slotte : is het boek hoogst verdienstelijk te achten voor den liefhebber der kruidkundige wetenschap en voor den beoefenaar onzer taal, niet minder dienstig zal het zijn aan de liefhebbers van Folklore, uithoofde der talrijke wetenswaardige bijzonderheden, sprookjes, legenden, volksbijgeloof, enz., enz., die men er vereenigd vindt.

»Den heer Pâque zij lof gezegd voor het openbaar maken van de belangrijke vrucht zijner studie, alsmede voor de bereidwilligheid met welke hij die aan de Koninklijke Vlaamsche Academie ten geschenke heeft geboden. »

Wij zouden ook de vriendelijke en aanmoedigende getuigenissen van den alom bekenden hoogleeraar, Ed. Martens zaliger en van vele anderen kunnen vermelden... Maar, genoeg daarover!

$$
* *
$$

Toen wij, over vijftien jaar, de Inleiding tot ons werk opstelden, zeiden wij ten slotte : «Alvorens te eindigen, verzoeken wij onze medewerkers en al de personen die medewerkers zouden kunnen worden, ons hunne ondersteuning, in het toekomende, niet te ontzeggen. Ons werk is ver van volledig te zijn. Veel tijds en de medewerking van velen is noodig om ons doel ganschelijk te bereiken. De toekomstige bijdragen zouden in eene tweede uitgave of in een Bijvoeg'sel kunnen benuttigd worden. »

Het hoog getal exemplaren der eerste uitgave is de oorzaak dat deze nog niet is uitgeput. Van den anderen kant, is het aantal nieuwe inlichtingen zoo aanzienlijk geworden, dat wij, volgens veler begeerte, niet langer willen vertoeven een Bijvoeg'sel in 't licht te geven. 
Wij zijn bijzondere dankbaarheid verschuldigd aan de volgende heeren, die ons ijvervol ter zijde hebben gestaan om de inzameling onzer volksnamen immer nog meer uit te breiden. (1)

MM. Boeckx, J.-A, voor de namen van Oostmalle en omstr.

Butaye, R., voor Stavele en omstr.

COENEGRACHT, Th., voor Reckheim, Oostham, Nederland.

Cousinne, V., Pepinghen (bij Halle) en omstr.

DE COCK, Alph., Denderleeuw, Lebbeke, Herdersem,...

De Haes, Jul., Heyst-op-den-Berg.

DE JAEGHER, A., Poperinghe, Oost-Roosebeke; Kortrijk, Ledeghem, enz.

Derboven, Westerloo.

Ghysebrechts, E., Oeleghem, Schilde.

GHYSEBRECHTS, L., Diest en omstr.

Gielen, J., Maaseyck.

HEUKELS, H., Nederland.

Jaspers, A., Berchem (Antwerpen).

Lambrecht, Berthem.

L. R., Heyst-op-den-Berg.

MARTENS, Ed., Leuven, Kerkom, Lubbeek, Nederland, Duitschland, Oostenrijk, Denemarken, enz. MULDER, J.-J., Antwerpen, Lillo, Leuven, Maastricht, Prov. Brabant.

PAELIN'CK, Jos., Zwijnaarde, Seeverǵhem, Eecke, Sint-Denijs-Westrem, De Pinte,...

SAMIJN, J., Kruidw. (W.-V1.).

Steppe, Em., Oultre (bij Ninove) en omstr.

(1) De namen der heeren wier bijdragen zich door het getal of door de verdienstelijkheid onderscheiden, staan in HOOFDLETTERS gedrukt. - Onder deze komt, bij uitstek, de eerste plaats toe aan den diepbetreurden Ed. Martens, weleer hoogleeraar aan de katholieke Universiteit van Leuven. 
Van Nerom, Diest en omstr.

Van Schoor, O., Herenthals en omstr:

VAN WILDER, Hugo, Denderwindeke en omstr.

VITS, J.-D., Vilvoorde en talrijke gemeenten van - België.

VRANCKEN, Beeringen en omstr.

Willems, F.-J., Herenthals, Moll, Sluis (bij Moll),...

De werken die ons nuttig waren bij het navorschen der genezende eigenschappen der planten en dezer toepassingen, alsook bij het nagaan der taalkundige waarde en gescbiedenis van eenige volksnamen, werden opgegeven in ons eerste boekdeel : De Vlaamsche Volksnamen der Planten, bl. 9 en 10.

Als weleer, doen wij een oproep aan alle mannen van goeden wil. Er valt wellicht nog te oogsten op het terrein der vlaamsche volksnamen. - Alle nieuwe vonden, die men ons zal gelieven in te zenden (1), zullen met groote erkentenis ontvangen en later (indien 't God belieft) in de tweede uitgave ingelascht worden.

(1) Ons adres : ... Sint-Michiels College Ursulinnenstraat, 14, Brussel. 


\section{Verklaring eeniger verkortingen}

Alg. Vl. Idio. Schuermans, Algemeen

Vlaamsch Idioticon.

bedr. werkw. bedrijvend werkwoord.

Belg.-Limb. Belgisch-Limburg.

bet. beteekenis, beteekent.

bijv. bijvoegelijk naamwoord.

(Bijv.) Z. ons Bijvoegsel.

bl. bladzijde.

boekd. boekdeel.

d. duitsch of hoogduitsch.

d. i. dat is.

deen. deensch.

eng. engelsch.

enkelv. enkelvoud.

f. féminin.

Fam. Famille.

fig. figuur.

fr. fransch, fransche.

Fr.-V1. Fransch-Vlaanderen.

gebr. gebruik, gebruikt.

gr. grieksch.

gram. grammen.

ibid. ibidem, op dezelfde plaats of plaatsen.

id. idem, hetzelfde, dezelfde beteekenis.

$i_{n}$ 't algem. in het algemeen.

ital. italiaansch.

klemt. klemtoon.

Kruidw. Samyn, Kruidwoordenboek.

lat.

lettergr.

latijn, latijnsch.

$\mathrm{m}$.

lettergreep.

mannelijk zelfstandig naamwoord.

Mèm. cour. inéd. Mémoire couronné inédit. Mèm. inéd. "Utile sit" Mémoire inedit "Utile sit".

mv. meervoud.
N. B. Nota Bene; opmerking.

o. onzijdig zelfstandig naamwoord.

omstr. omstreken.

onz. werkw. onzijdig werkwoord.

opmerk. opmerking.

O.-Vl. Oost-Vlaanderen.

port. portugeesch.

Prov. Provincie, Provinciën.

scherpl. scherplang.

sp. spaansch.

uitspr. uitspraak.

v. vrouwelijk zelfstandig naamwoord.

variëteit; eene verscheidenheid.

verbastering, verbasterd.

vglk. vergelijk.

vl. vlaamsch, vlaamsche.

(V1. Wk.) Z. het Vlaamsch Woordenboek van ons werk: De Vl. Volksn. der Planten.

vlkspr. in de volkspraak; fr. vulgairement.

vklw. verkleinwoord.

volg. volgende.

volksn. volksnaam.

voorg. voorgaande.

vulg. vulgairement; in de volksspraak.

w. woord.

ww. woorden.

W.-V1. West-Vlaanderen.

Z. Zie.

zachtl. zachtlang.

Zuid. Belg.-Limb. Zuidelijk Belgisch-Limburg.

zw. zweedsch.

dat is. 


\section{Naanverkortingen der Plantenkundigen}

\begin{tabular}{|c|c|c|c|}
\hline Adans. & Adanson. & L. & Linné. \\
\hline Ag. & Agardh. & Lmk. & Lamarck. \\
\hline Ait. & Aiton. & Ledeb. & Ledebour. \\
\hline All. & Allioni. & Lehm. & Lehmann. \\
\hline Aschs. & Ascherson P. & Lej. & Lejeune. \\
\hline Babingt. & Babington. & Lem. & Lemaire. \\
\hline Baill. & Baillon. & L'Hér. & L'Héritier. \\
\hline Balb. & Balbis. & Lindl. & Lindley. \\
\hline Benth. & Bentham. & Loud. & Loudon. \\
\hline Bellk. & Bellynck. & Lour. & Loureiro. \\
\hline Bor. & Boreau. & Mart. & Martins. \\
\hline R. Br. & Robert Brown. & M. en $\mathrm{K}$. & Mertens en Koch. \\
\hline rongn. & Ad. Brongniart. & Mich. & Michaux. \\
\hline $\begin{array}{l}\text { Coss. } \\
\text { Cout. }\end{array}$ & $\begin{array}{l}\text { Cosson. } \\
\text { Coulter. }\end{array}$ & Mill. & Mille \\
\hline Cout. & Coulter. & Miq. & Miquel. \\
\hline $\begin{array}{l}\text { Crép. } \\
\text { Curt. }\end{array}$ & Fr. Crépin. & Moq. & Moquin-Tandon. \\
\hline $\begin{array}{l}\text { Curt. } \\
\text { Cyr. }\end{array}$ & Curtis. & F. Müll. & F. Müller. \\
\hline Cyr. & Cyrillo. & Murr. & rray. \\
\hline D C. & P. de Candolle. & Naud. & Naudin. \\
\hline Desf. & Desfontaines. & Neck. & Necker. \\
\hline Desv. & Desvaux. & Nees. & Nees von Esenbeck. \\
\hline Dmrt. & Dumortier. & Nestl. & Nestler. \\
\hline Ehrb. & Ehrenberg. & Nutt. & Nuttal. \\
\hline Ehrh. & Ehrhart. & Pall. & Pallas. \\
\hline Endl. & Endlicher. & Parl. & Parlatore. \\
\hline Fr. & Fries. & Pav. & Pavonl. \\
\hline Gärtn. & Gärtner. & Paxton. & Paxt. \\
\hline Gaud. & Gaudin. & P. Beauv. & Palisot de Beauvois. \\
\hline Germ. & Germain de S'-Pierre. & Pers. & Persoon. \\
\hline Gmel. & Gmelin. & Pfeiff. & Pfeiffer. \\
\hline Godr. & Godron. & Plum. & Plumier. \\
\hline Good. & Goodenough. & Poir. & Poiret. \\
\hline Gray. & Asa Gray. & Pourr. & Pourret. \\
\hline Gren. & Grenier. & Rchb. & Reichenbach. \\
\hline Griseb. & Grisebach. & Red. & Redouté. \\
\hline Hall. & Haller. & Relh. & Relhan. \\
\hline $\begin{array}{l}\text { H. B. en K. } \\
\text { Hoffm. }\end{array}$ & $\begin{array}{l}\text { Humboldt, Bonpland en Kunth } \\
\text { Hoffmann. }\end{array}$ & $\begin{array}{l}\text { R. en S. } \\
\text { Retz. }\end{array}$ & $\begin{array}{l}\text { Rœmer en Schultes. } \\
\text { Retzius. }\end{array}$ \\
\hline Hook. & Hooker. & Rich. & Richard (L.-C.). \\
\hline Hort. of Hort & ul. Hortulani; de Hoveniers. & Riss. & Risso. \\
\hline Huds. & Hudson. & Roxb. & Roxburg. \\
\hline H. en B. & Humboldt en Bonpland. & A. Saint-Hill. & A. Saint-Hillaire. \\
\hline Jacq. & Jacquin. & Salisb. & Salisbury. \\
\hline Jord. & Jordan. & Scheidw. & Scheidweiler. \\
\hline $\begin{array}{l}\text { Juss. } \\
\text { Kit. }\end{array}$ & Jussieu. & Sch. & Schimper. \\
\hline & & & \\
\hline
\end{tabular}




\begin{tabular}{ll|ll} 
Schm. & Schmidt. & Thuill. & Thuillier. \\
Schreb. & Schreber. & Thunb. & Thunberg. \\
Scop. & Scopoli. & Tournef. & Tournefort. \\
Ser. & Seringe. & Tritt. & Trattinick. \\
Sibth. & Sibthorp. & Trinius. \\
Sieb. & Siebold. & Vail. & Vaillant. \\
Sims. & Simson. & Vill. & Ventenat. \\
Sm. & Smith. & W. en K. & Wallars. \\
Soy.-Will. & Soyer-Willemet. & Wahl. & Wahlenberg. \\
Spreng. & Sprengel. & Wallr. & Wallroth. \\
Stev. & Stevens. & Willd. & Willdenow. \\
Sutt. & Sutton. & With. & Withering. \\
Sw. & Swartz. & Zucc. & Zuccarini. \\
Ten. & Tenore. & &
\end{tabular}

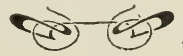





\section{BIJVOEGSEL}

\section{A}

Aalranken, v. mv. - Te Eecke, Nazareth en omstr. Solanum Dulcamara L.; fr. Morelle Douce-Amère; vl. Bitterzoet, Alfsrank. - Aal, Ale, v., beduidt, in Vlaanderen, den Solanum nigrum L.; fr. Morelle noire; vl. Zwarte Nachtschade. Deze plant gelijkt zeer (door bladeren, bloemen, enz.) op den Solanum Dulcamara L., maar, aangezien deze zich onderscheidt door zijnen rankachtigen stengel (fr. tige sarmenteuse), heeft hij den naam van Aalranken gekregen. - Fig. I en 2.

Aalst, m. - Nederland. - Id. als Alsem (Vl. IVk.).

Aalstekels, m. inv. - Nederland. - Stratiotes aloides L.; fr. Stratiote Faux-Aloès; vl. Valsche Aloës; vulg. Scheeren. - De plant groeit in de waters, waar de alen (fr. anguilles) verblijven en hare bladeren zijn van stekels (fr. piquants, épines) voorzien. - Men zou 't woord ook als

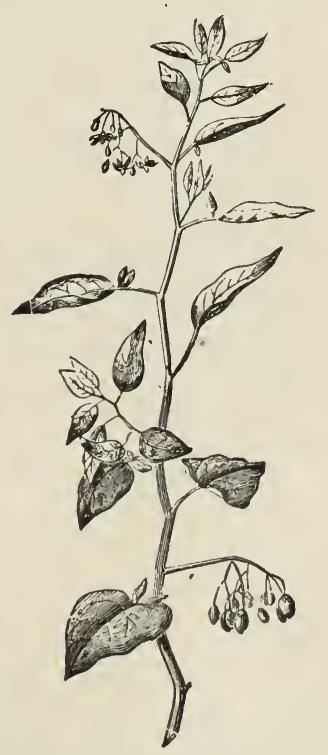

Fig. 1. - Solanum Dulcamara. eene verb. van Aalstekers (fr. foìne; eene vork om aal te stelien) kunnen aanzien. 
Aambeiwortel, v. - Nederland. - Scrophularia nodosa L.; fr. Scrophulaire noueuse; vl. Helmkruid. - De knobbelige wortel werd gebruikt om de aambeien of gezwollen speenaders (fr. hémorroüdes) te genezen.

Aankampaan, Z. Anekapane (Bijv.).

Aardeikel, m. - Nederland. - Lathyrus tuberosus L.; fr. Gesse tubéreuse; vl. Knollige Platerwt. - De wortel dezer plant vormt, onder de aarde, eetbare knollen die op eikels (fr. glands) gelijken : vandaar de naam van Aardeikel. Men zegt ook : Aardnoot, Aardaker (Aker =eikel).

Aardnoot, v. - Nederland.-'Z.'t voorg. w.

Aardrook, m. - Id. als DUIVE(N)KERVEL (V1. Wk.). - In 't looog. duitsch vindt men ook Erdrauch.

A a ronskelk, Z. Aronskelk (Bijv.).

Aarsgat, 0. - Z. IsGAT (Bijv.).

Achtschaai, v. - Herenthals en omstr. Id. als NachtschaA en Nachtscinade (Vl. Wk.)

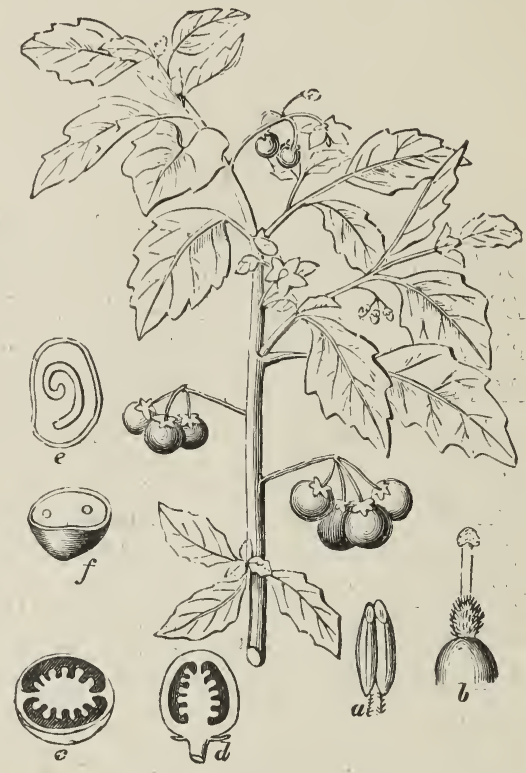

Fig. 2. - Solanum nigrum. $a$, Meeldraad; $-b, c, d$, vrucht (gansch en doorgesneden); $-e, f$, zaad (doorgesneden).

Adam-en-Eva. - Nederland. - Wordt, in 't algemeen, gezegd van het geslacht Aconitum Tournef.; fr. Aconit; vl. Monnikskap (fig. 3). Zinspeling op de twee kroonbladen die grooter zijn dan de andere, eenen bijzonderen vorm hebben (fig. 4) en onder het opperste kelkblad insgesloten liggen (fig. 5).

Adderkruid. - Nederland. - $\mathrm{I}^{\circ}$ Pteris aquilina L.; fr. Pléride Aigle-impérial; vl. Adelvaren. - De plant leeft 
in de vochtige bosschen, waar de adderen (slangen) hun verblijf houden. - $2^{\circ}$ Sagittaria sagittifolia L. ; fr. Sagittaire Flèche-dleau; vl. Pijlkraid. - Het blad der plant heeft den vorm (fig. 6) dien men gewoonlijk aan de slangen-

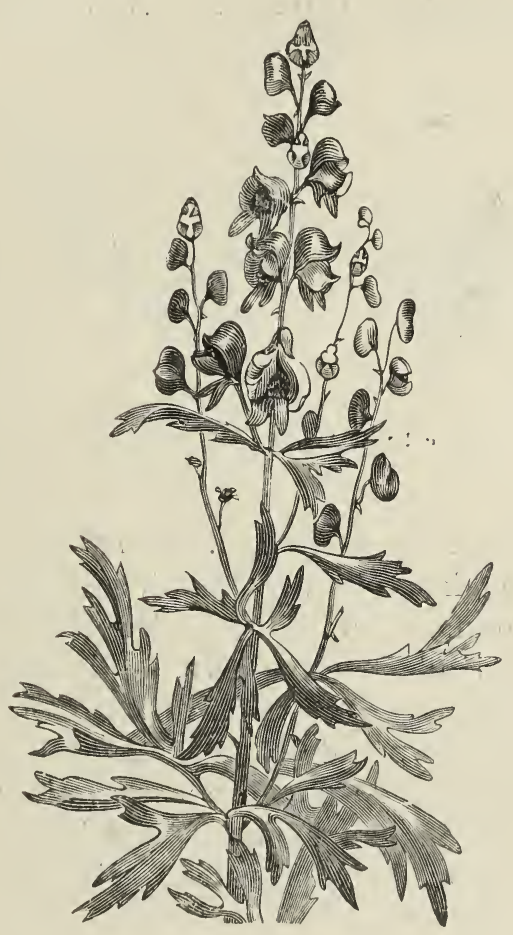

Fig. 3. - Aconitum Nupellus.
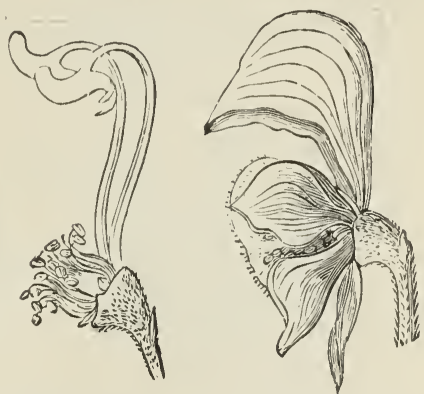

Fig. 4. - Bloem Fig. 5. - Het bin(natuurlijke groote). nenste der bloem.

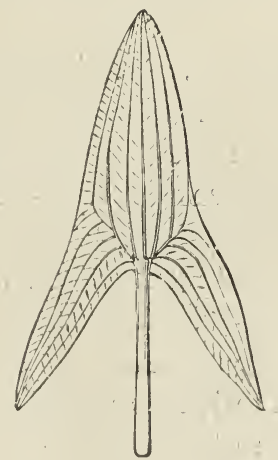

Fig. 6. - Blad van Sagillaria.

tongen (adderen-) toeschrijft; vandaar wordt de plant elders ook Serpentstongen geheeten.

Addertong. - Nederland. - Ophioglossum vulgatum L.; fr. Ophioglosse commune; vulg. Langue-dle-serpent; vl. Gemeene Slangentong. - Het blad der plant heeft eenige gelijkenis met eene slange- of addertong.

Addervaren, v. - Nederland. - Polystichum Thelypteris Roth; fr. Polystichum Thélyptère; vl. Moeras-Nier- 
varen. - Groeit in voch tige, moerasachtige plaatsen waar de adderen, volgens de meening van 't volk, hun gewoonlijk verblijf houden.

Ahorn, m. - Nederland. - Acer L.; fr. Erable; vl. Eschdoorn (fig. 7, 8 en 9).

Ajuin-bloemekens. - Lebbeke en omstr. - Astrantia
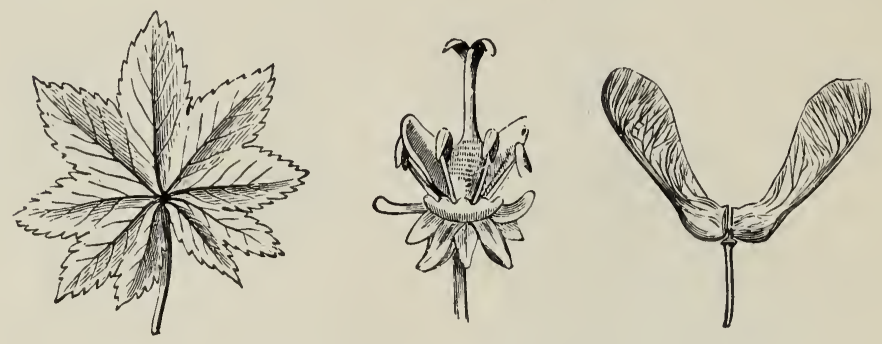

Fig. 7, 8 en 9. - Blad, bloem en vrucht van Acer Pseudo-Platanus.

major L.; fr. Astrance à grandes fleurs; vl. Sterrekruid. - De bloemtjes, boven een kraagje verzameld, gelijken niet slecht, in hunnen samenhang, op die van den Ajuin.

Alfsrank, v. - Denderwindeke en omstr. - Id. als Aalranken (Bijv.). - Alfsrank is eene verb. van Elfrank; Z. Elfrank (Bijv.). - De Elfen, in de Noordsche mythologie, waren kleine rondzwervende natuurgeesten, die of als goede en schoone wezens in den hemel, of als kwade en leelijke onder de aarde woonden. Zij waren bijzonder gekend als vloed- en watergeesten. - Onze plant is rankachtig en groeit veel lang's de waters, waar de Elfen (of Alfen) voornamelijk machtig waren.

Algoede, v. - Nederland. - Blitum Bonus-Henricus Rchb.; fr. Blite Bon-Henri; vl. Goede-Hendrik Sapkelk; ook Brave-Hendrik genaamd.

Allerheiligenbloem. - Heyst-op-den-Berg. - Id. als STER (Vl. Wk).

Alpenroos. - Nederland. - Id. als Alproos (Vl. Wk.). Altheeplante. - Poperinghe, Oost-Roosebeke en omstr.

-- Id. als 't volg. w. 
Altheewortels, m. mv.-Poperinghe, Oost-Roosebeke en omstr. - Wortels van de Witte Maluwe. - Althaea officinalis L.; fr. Guimanve officinale of alleenlijk Guimauve (fig. In). - Althee is de verb. van den lat. naam Althaea; de wortels zijn bijzonder gekend onder 't volk, omdat zij veel gebruikt worden als weekmakend geneesmiddel.

Amerikaansche-Spinazie. - Nederland. - Id. als Wilde Porselein (V1. Wk). - De plant is afkom. stig uit Amerika en kan gegeten worden op dezelfde wijze als Spinazie.

Amerikaansch-Vergeet-mij-nietje, o. - Nederland. - Omphalodes verna Mönch; fr. Om-

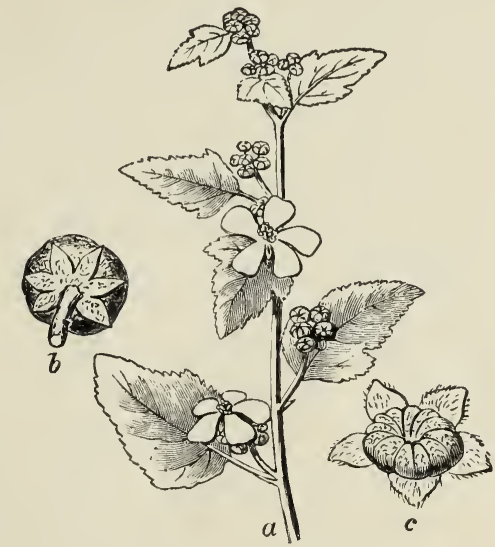

Fig. 10. - Althaea officinalis. $a$, Bloeiende tak; $-b, c$, vrucht. phalode printanière; vl.

Lente-Omphalode. - Eene sierplant uit Oostenrijk; soms verwilderd nevens de tuinen. - De schoone blauwe bloem. kroon gelijkt op die van 't Vergeet-mij-nietje (Myosotis); amerikaansch = eene vreemde, eene ingevoerde plant.

Anekampane, v. - Z. 't volg. w.

Anekapane, v. - V.-Vl. - Inula Helenium L.; fr. Inule A ınée; vl. Alant; eng. Elecampane. - Te Kortrijk, zegt men inekampane.

Anijskruid. - Denderwindeke.-Id.als A viJs (Vl. Wk.). Anjer, v. - Nederland. - Id. als ANGelier (Vl. Wk.). Wordt ook gebr. om de Anjelieren in 't algem. te beduiden.

Antonisraapje (Sint-). - Nederland. - Z. SinT-. - (Bijv.)

Aposteemkruid. - Nederland. - Knautia arvensis Coult., fr. Knautie des champs; vulg. Scabieuse des champs; v1. Aktier-Knautia. - Werd eertijds reel als geneesmiddel gebruikt, bijzonder om de aposteemen (zweren) en wonden te verzorgen. 
Araainden. - Zwijnaarde en omstr. - Id. als EEKAPPEL (Vl. Wk.). - Verb. van Oranjen, w. dat men, in V'laanderen, dikwijls Araanjen hoort uitspreken. De Eekappels of valsche galnoten gelijken op kleine Oranjeappels.

Arenkruid. - Tongerloo (bij Gheel) en ornstr. - Polygonatum multiflorum All.; fr. Polygonatum multiflore, vulg. Sceau de Salomon; vl. Salomonszegel. - Aren is eene samentrekking van Adderen (fr. vipères) : de plant groeit in de bosschen, waar de adderen hun verblijf plegen te houden.

Arme-Klaren, v. mv. - Oost-Roosebeke en omstr. - Id. als NAAKTEBegiJnen (Vl. Wk.). - Arme Klaren (fr. Pauvres Claires): soort van nonnen door de H. Klara gesticht, die zeer arm leven. - Onze plant ziet er ook zoo arm en zoo naakt, omdat de bloemen uit den grond opschieten vóór de bladeren (fig. I I).

Armoede. - Heyst-op-den-Berg en omstr: - Myriophyllum verticillatum L.; fr. Myriophylle verticillé; vl. Gekransd Duizendblad. - Men beweert dat waar deze waterplant groeit, de grond arm is aan voedstoffen.

Aronskelk, m. - Nederland. - Arum

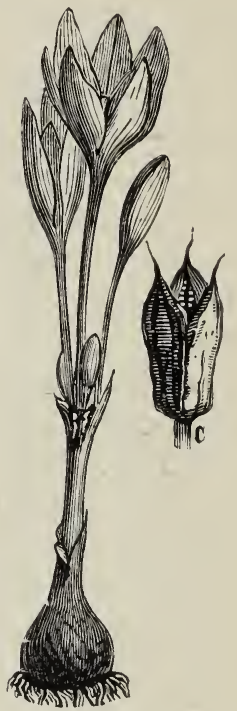

Fig. 11.

C)lchicum autumnale. Bloem en vrucht. maculatum L.; fr. Gouet tacheté, vulg. Pied de veau; vl. Gevlehte Kalfsvoet of Aronskelk (fig. I2). - Arons = verb. van den lat. naam Arum. - De bloeischeede heeft den vorm van eenen kelk.

Aronstaf, m. - Nederland. - Id. als 't voorg. w. Verb. van den lat. naam Arum en staf (fr. bâton, crosse) : de bloeikolf is boven in een knotsvormig uitsteeksel verlengd, dat op eenen staf gelijkt (fig. I2, b.).

Arteeze, v. - Proven, Watou, enz. (West-V1.). - Z. Bamespruim (Bijv:).

Aruikela, v.-West-Vlaanderen.-Primula Auricula L.; 
fr. Primevère Auricule, vulg. Auricule en Oreille d'ours: vl. Berenoor. - Aruikela = eene verb. van 't lat. Auricula of van 't fr. Auricule. - Z. ook ArikeL (Vl. Wk.).

Aschgrauw, v. - Oultre (bij Ninove). - idd. als Aschalle -(Vl. Wk.), naam die waarschijnlijk maar eene verminking van Nachtschade is (vl. naam der plant). De bladeren der plant zijn een weinig groen-grijsachtig : vandaar Aschgrauw (fr. gris cendré).

Aschoenje, r. - Oost-Roosebeke en de omstr. vain Kortrijk. - Naam der groote witte Kers; fr. guigne. - Volgens M. Samyn, zegt men in W.-Vl:- ook Gaskoenje (Gaschoenje), hetgeen aan Gasconje (fr. Gascogne) zou doen denken, als zijnde misschien de streek van waar deze kers bij ons zou ingevoerd zijn.

Ate, z. Wilde-Ate (Bijv.).

Augustus, m. Nederland. - Ligustrum vulgare L.; fr. Troëne commun; vl. Gewoon Mondhout.

Aurikel, v. - Nederland. - Z. A RIKEL (Vl. Wk.).

Avermoenie, v.

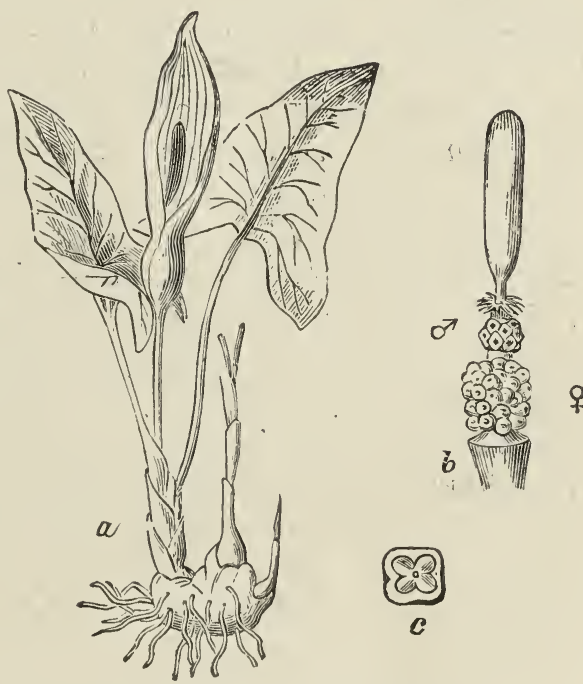

Fig. 12. - Arum maculatum.

$a$, Gansche plant; $b$, mannelijke bloemen boven de vrouwelijke; $c$, een meeldraad of mannelijke bloem, vergroot.

\section{- Poperinghe en}

omstr. - Agrimonia Eupatoria L.; fr. Aigremoine Eupatoire; vl. Agrimonij. - Avermoenie = verb. van Agrimonij.

Avron, v. - Beeringen. - Z. Averon (Vl. Wk.). 


\section{B}

Bagaaize, z. BlagaAize (Bijv.).

Bakkerinnetjes. - Poperinghe en omstr. - Id. als BaквLоем (Vl. Wk.), en, volgens A. De Jaegher, bijzonder de gekweekte soorten van Primula.

Bakkertjes. - In Vlaanderen. - Id. als 't voorg. w.

Bakkruid. - Nederland. - Id. als de twee voorg. ww.

Ballemine, v. - Z. Bellemine (Bijv.).

Bamespruim. - Oost-Roosebeke en omstr. - Uitspr. - prime. - Bames, voor Bamis : verkorting van St-Baafsmis of St-Bavo's mis, d. i. het feest van St-Bavo (1 I $^{\text {sten }}$ October). - Soort van pruim die omstreeks Bamis, d. i. in 't begin van October rijp is. Men noemt ze ook Bakpruim (z. Vl. WVk.), Arteeze en Alteeze. Deze laatste naam is waarschijnlijk eene verb. van Altesse, fransche naam dezer pruim.

Bargebloem. - Nederland. - Trifolium pratense L.: fr. Trèfle des prés; vl. Roode Klaver. - De bloemkroon heeft den vorm eener barge (oudtijds : bargie), d. i. eener trekschuit.

Bargegras. - Nederland. - Id. als ZwiJntJESGERst en Verkenges' (z. Vl. Wk.). - Een barg is een gesneden mannetjesverken. Dit gras is zeer gezocht door de bargen, d. i. door de zwijnen in 't algem.

Beefgras. - Nederland. - Id. als Bevennelleke(N)s (Vl. Wk.) en zelfde uitleg.

Beekpunge, v. - Nederland. - Naam, die men reeds bij Dodoens vindt, en nog de hedendaagsche vl. naam is van de Veronica Beccabung*a L.; fr. Véronique Beccabung*a : hij schijnt maar eene grove verb. te zijn van 't lat. Beccabung'a.

Beeksalade, v. - Denderwindeke en ornstr. - Id. als Waterkers (z. Vl. Wk.).

Beenbreek, v. - Nederland. - Eene vergiítige moerasplant, Narthecium ossifragum Huds.; fr. Narthécie des marais; vl. Moeras-Narthecium of Sipelgras.-Beenbreek is de letterlijke vertaling van 't lat. ossifrag'um. 
Beenhouwershout. - W.-Vl. - Id. als Potroodenhout (Vl. Wk.). - De takken hebben de roode eigenaardige kleur met dewelke de beenhouwers hunne huizen doen verven : bloedrood, bloedkleur. Vandaar ook de lat. naam : Cornus sanguinea L. en de fr. Cornouiller sanguin.

Begijnenthee, v. - Seeverghem. - Id. als GELE-The en Gele-Kenrs (Vl. Wk.). - De begijnen of nonnen plegen deze thee veel te gebruiken. - Voor de anwending van dit geneesmiddel, z. Verbascum Thapsus, in 't lat. Wk.

Begijnenvoorschoot, v. - Reckheim en omstr. - Veratrum nigrum L. en $V$. album L.; fr. Vératre noir en $V$. blanc; vl. Zwart en Wit Nieskruid. - De bladeren dezer gekweekte plantsoorten zijn fijn en regelmatig geplooid als de voorschoot eener begiin.

Begijntje. - Nederland. - Arabis alpina L.; fr. Arabette des Alpes; vl. Alpische Scheefkelk, Randjesbloem.Veel gekweekt als sieraadplant, bijzonder om de bloemperken te omzoomen (vandaar : randjesbloem geheeten), en de bloeiende plant ziet er zoo net en zindelijk uit als een begijntje.

Bekelaar, m. - Coursel, Zeelhem. - Juniperus communis L.; fr. Genévrier commun; vl. Gemeene Jeneverboom.

Belle-Dame, v. - Poperinghe en omstr. - Atriplex hortensis L.; fr. Arroche des jardins, vulg. Bonne-Dame; vl. Hofmelde. - Belle-Dame is warschijnlijk maar eene verb. van den fr. volksn. Bonne-Dame.

Bellemine, v. - In W.-Vl. - Men zegt ook Ballemine en Belzemine. - Z. Balzamien (Vl. Wk.).

Belzemine, v. - Z. 't voorg. w.

Bengelkruid. - In Vlaanderen. - Id. als SchiJtkruid. (V1. IVk.).

Ben'rik. - Heyst-op-den-Berg en omstr. - Id. als BraAu (Vl. Wk.). - Ben = een teenen mandje. De stengels der Bramen zijn rankachtig, dun en taai, als de teenen die men gewoonlijk gebruikt om de bennen of mandjes te vlechten. Het volk onderscheidt niet.

Bent. - Nederland. - I Het geslacht Carex Mich., in 't algem., fr. Carex of Laiche; vl. Zegge. In dien zin, 
gebruikt men ook, in Nederl., het w. Bund. $-2^{\circ}$ Deschampsia caespitosa P. Beauץ.; fr. Deschampsie gazonnante; vl. Veen-Boendergras

Bentgras. - Nederland. - Molinia ccerulea Mönch; fr. Molinie bleue; vl. Blauwe Molinia. - Vglk. Bunt, in ons Vl. Wk.

Berbelle, v. - In Fr.-Vl. - Men zegt ook Barbelle (z. Vl. Wk.), Borbelle en Verbelle in W.Vl. - Id. als Baarnoot, dat te Exaarde en te Saffelare gezegd wordt (z. Vl. Wk.). Voor verderen uitleg, z. BaARnotenboom (Vl. Wk.). - Barbelle komt van 't fr. barbe : 't is eene var. van hazelnoot, die baard draagt op het uiterlijk schaaltje der vrucht, 't geen ook aangeduid wordt in baar(d)noot. - Berbelle, Borbelle, enz., zijn verb. van Barbelle.

Bergknop, m. - Nederland. - Sedum acre L. ; fr. Orpin âcre; vl. Scherp Vetgroen; Muurpeper. - De plant groeit dikwijls op bergen en het uiteinde des stengels gelijkt op eenen ronden knop (fr. bouton).

Berkhouterklaver, m. - Nederland. - Potentilla Anserina L.; fr. Potentille Ansérine; vl.Zilverschoone Ganzerik. - De bladeren zijn gewoonlijk wit, gelijk het hout (de stam) van den Berk (fr. Bouleau).

Berstbezie, v. - Denderleeuw, Lebbeke. - Id. als Berstkruid (Vl. Wk.).

Berstebollen, m. mv. - Lebbeke en omstr. - Id. als 't voorg. w.

Berwin, v. - Gronsveld (bij Maastricht). - Id. als Wivin (Vl. Wk.).

Beschaamde-Meiske(n)s. Roosebeke en omstr. - Id. als Bernagie(Vl. Wk.). - De bloemen der plant hangen naar beneden, als of zij beschaamd waren (fig. I3).

Bessemhout. - Antwerpsche Kempen. - Id. als Gagel (Vl.

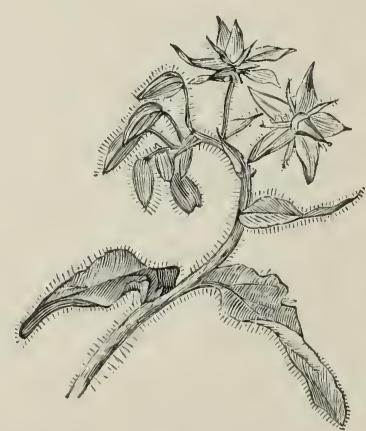

Fig. 13. - Bovrago officinalis. Wk.). - Men gebruikt de takken ran dit struikgewas om bessems (fr. balais) te maken. 
Bessemrijs, o. - Heyst-op-den-Berg en omstr. - Id. als BERK (Vl. Wk.). - Het rijs (fr. petites branches) dient om bessems (fr. balais) te vervaardigen.

Bessemtakken. - Antwerpsche Kempen. - Id. als de twee voorg. woorden.

Bêstebezen, v. mv. - Oost-Roosebeke.- $\mathrm{I}^{\circ}$ De vruchten van Solanum nigrum L.; fr. Morelle noire; vulg. Crèvechiens; vl. Zwarte Nachtschade.-Verb. van Berstbeziën : zinspeling op de giftige eigenschappen der vruchten (fig. 2); $-2^{\circ}$ De vruchten van Rhamnus Frangula L.; fr. Nerprun Bourdaine, vulg. Bourdaine; vl. Pijl Spork. - Deze vruchten zijn zwart en bolvormig gelijk die der vorige plant, maar zijn niet vergiftig : ' $t$ is dus ten ourechte dat het volk ze bêstebezen noemt.

Bevertjes. - Nederland. - Id. als Bevennelieke(N)s (Vl. Wk.).

Bewinde, v. - Nederland. -- Beduidt het geslacht Convolvulus, L.; fr. Liseron; vl. Winde, in 't algem. Het werkw. bewinden $=\mathrm{id}$. als omwinden. De stengel dezer planten is meest windend ( $\mathrm{fr}$. voluble en niet volubile, gelijk wen dikwijls, ten onrechte, hoort zeggen).

Bezuring, v. - Nederland. - Algemeene naam die het geslacht Typha L.; fr. Massette; vl. Lischdodde, aanduidt.

Bijenkorfjes. - Nederland. - Id. als PEerde(N)BeE'T (Vl. Wk.). - De bloeiwijze der plant heeft den vorm vall een bijenkorfie ( $\mathrm{fr}$. petite ruche).

Bijtnettels, v. mv. - Poperinghe en omstr. - Id. als BraNdetel (Vl. Wk.).

Bijvoet, m. - Nederland. - Id. als Bievoet (Vl. Wk.).

Bikbeeren, v. mv. - Nederland. - Id. als KrakeBEZEN (Vl. Wk.). - Beeren of beziën die goed zijn om te bikken (fr. becqueter), d. i. om te eten (in de volkstaal).

Bikkeboom. - Beeringen en omstr. - Verb. van Beukenboom en dezelfde bet. - Z. Vl. Wk.

Bilzenkruid. - West-Vl. - Hyoscyanuss niger L.; fr. Jusquiame noire; vl. Zwart Bilzenkruid. - Vergiftige plant. 
Binde, v. - Poperinghe en omstr. - Id. als KoorNWINDE (Vl. Wk.).

Bitterkers, v. - Nederland. - Id.als HoFkers (Vl. Wk.). - Deze Kers, die in de tninen gekweekt yordt, beeft eenen bijzonder bitteren of prikkelenden smaak.

Bitterplant. - Nederland. - Polygänum Fy.dropiper L.; fr. Renouée Poivre-d'eau; vl. Waterpeper-Duizendknoop. - Deze plant groeit aan 't water of in de slooten en heeft eenen bitteren, brandenden, peperachtigen smaak.

Blaaskeshout. - Beeringen. - Id. als BLAAsвоом (Vl. Wk.).

Blagaaize. - Z. Roode - ; Witte -, (Bijv.).

Blauwbes, v. - Nederland. - Id. als Krakebezen (Vl. Wk.). - De rijpe vruchten hebben eene zwarte-blanwachtige kleur.

Blauw-Erwtjes, o. mv. - Nederland. - Viccia Cracca L.; fr. Vesce en épi; vl. Aar-IVikke of--Vitse; VogelWikke of--Vitse. - De bloempjes zijn blauwachtig en de vruchten (peulen) gelijken op erwtjes (kleine erwtpeulen).

Blauw - Korenbloem. - Denderwindeke en omstr. - Id. als Blauwbloem (Vl. Wk.), (fig. 14). -De bloem wordt op witten wijn gesteken : bij oogontsteking, wordt er het zieke deel mede gedoopt. Dit gebruik bestaat op vele plaatsen.

Blauw-Porselein, o. - W.- Vl. - Id. als VERGEeT-MIJ-NIET (Vl. Wk.). - De bloempjes zien er uit als of zij van blauw-porselein gemaakt waren.

Blauw-Torretjes, - Torre-

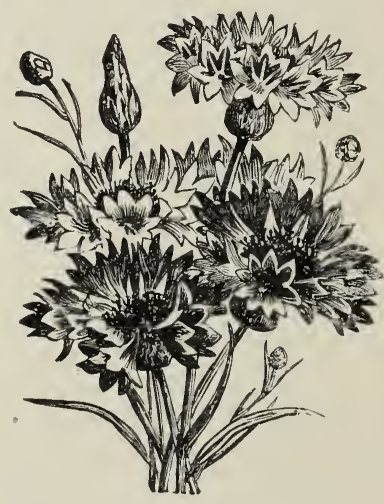
ke(n)s. - Kortrijk en omstr. -

Id. als BLAUw-Druifke(N)s (Vl. Wk.). - Verb. van - Torentjes. De bloeiwijze heeft den vorm van een torentje (fr. petite tour).

Blauwe-Druifjes. - Nederland. - Id.als BLAUw-Druif- 
$\mathrm{KE}(\mathrm{N}) \mathrm{s}(\mathrm{Vl}$. Wk.). - De bloemen zijn blauw, bolvormig en de bloeiwijze gelijkt aan een druiventrosje.

Blauwe-Hanekam, m. - Denderwindeke en omstr. Iris germanica L.; fr. Iris d'Allemagne; vl. Blauwe of Duitsche Lischbloem. - Voor de toepassingen : z. Iris germanica, in ons lat. Wk.

Bleeken. - Nederland. - Id. als KrakeBEzen (V1. Wk.). Bleinezaad. - W.-Vl. - Lepidium sativum L.; fr. Cresson alénois; vl. Hofkers. - De naam beduidt het zaad en ook de plant. - Men maakt er een afkooksel van voor de koeien die de drooge bleine hebben, d. i. aan melkloosheid onderhevig zijn (fr. agalaxie). (Kruidw.).

Blijvers, m. mv. - W.-Vl. - Jonge boompjes die blijven staan, als men een bosch afkapt, opdat ze tot groote boomen zouden kunnen opgroeien; (fr.baliveaux; réserves).

Bloedhout. - Nederland. - Id. als BloedziJKenhout (Vl. Wk.) en zelfde uitleg.

Bloedplant, z. 't volg. w.

Bloedplante, v. - Poperinghe en omstr. - Eupatorium cannabinum L.; fr. Eupatoire chanvrine; vl. Boelkenskruid. - Wordt gebruikt voor de koeien die bloed wateren, zegt het Kruidw. - Op azijn gekookt, dient zij tegen den cholera (ibid.)

Bloedwortel, m. - W.-V1. - Potentilla sylvestris Neck. (P. Tormentilla Neck.); fr. Potentille sauvag'e; vl. Wildeof Bosch-Ganzerik. - De plant, en bijzonder de wortel, bevat looistof, die samentrekkend is (fr.astringent) : men maakt er eene thee van, tegen het bloedspuwen.

Bloedzuigersbloem. - W.-V1. - Papaver Rhœas L.; fr. Coquelicot; vl. Klaproos, Kolbloem. - De'kleur der bloem is rood als bloed; men voegt er het gedacht van bloedzuiger bij, om de kinderen er eenen afkeer van in te boezemen en ze aldus te beletten in de akkervruchten te loopen om ze te plukken (Kruidw.).

Bloedzuipersbloem. - IV.-Vl. - Id. als 't voorg. w.

Bloembies, v. - W.-Vl. - Id. als Torenbies ( Vl. Wk.). - Deze plant gelijkt min of meer op eene Bies, maar draagt grootere en ware bloemen (volgens het begrip dat het rolk van eene bloem heeft). 
Bloemkauwel, ook - kouwel, m. - IV.-Vl. - Id. als BLoEmkool ( Tl. WVk.).

Boekeet, m. - Zwijnaarde en omstr. - Id. als BoEkWEIT (Vl. Wk.).

Boekel, m. - Zwijnaarde en omstr. - Id. als BEUK (Vl. Wk.). - De vruchten heeten Boekelnoten.

Boekelnoten, z. 't voorg. w.

Boekent, m. - Nederland. - Id.als Boekweit(Vl. WVk.).

Boeklis(ch), o. - W.-Vl. - Id. als Grachtuisch (Vl. Wk.). - Waarschijnlijk eene verb. van Broeklisch : de plant groeit in de broeken (fr. marécages) en langs de waters.

Boekweit, m. - Tlaamsche naam van Fagopyrum esculentum Mönch; fr. Sarrasin comestible; duitsch, Buchweizen; eng. Buck-wheat; deensch, Boghvede. Boek = verb. van Beuk (fr. hêtre) : de vrucht is driekantig gelijk die van den Beuk. - Weit=oudvlaamsch w. en bet. tarwe, graan, als ook het d. Weizen, het eng. wheat en het deensch hvede.

- De lat. naam Fagopyrum komt van den griekschen : Фryor (Phêgou) rupos (puros) en beide beteekenen ook : Beuktarwe, Beukgraan. De plant werd in Spanje ingevoerd door de Saracenen (fr. Sarrasins) ; vandaar hare fr. benaming: Sarrasin (fig. I5).

Boerenbalsem, m. - $\mathrm{Ne}$ derland. - Mentha aquatica L.; fr. Menthe aquatique; vl. Watermunt. De plant heeft eenen balsemachtigen geur en is zeer gemeen.

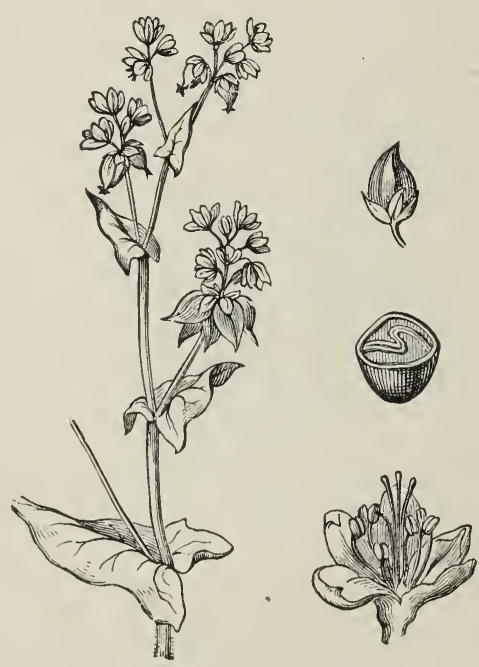

Fig. 15. - Fagopyrum esculentum.

Boerenpronker, m. - Nederland. - Dianthus barbatus L.; fr. OEillet barbu ; vulg. 
QE. des poètes, Bouquet parfait, Bouquet tout fait (in België); vl. Baardanjelier. - De bloemen leggen een zekeren pronk roor den dag en zijn niettemin in bijna alle boerentuinen te vinden.

Boerenwormkruid. - Nederland. - Id. als Reinevaren (Vl. Wk.). - Wordt gebruikt, bijzonder bij de boeren, als wormkruid.- Voor de manier van deze plant te gebruiken, z., in ons lat. Wk., TANAcetum vulgare.

Boerinnekes. - Denderwindeke en omstr. - Id. als Bernagie (Vl. Wk.). - De bloeiende plant ziet er zoo wat boerinnekesachtig uit. - Wordt gekweekt als sieraadplant, doch meer als sla (fig. I3).

Boerkes-en-Boerinnekes. - Oost-Roosebeke en omstr. - Centranthus ruber DC.; fr. Centhrante rouge; vulg. Valériane rouge; vl. Roode Spoorvaleriaan. - Zinspeling op de bijzondere roode kleur der bloemen, gelijkende op de kleur die gewoonlijk de wangen van Boerkes en Boerinnelies kenmerkt. - Z. ook .MAnNetJes-EN-WiJvetJes (Bijv.).

Boertjens-en-Boerinnetjes. - In eenige gemeenten van W.-V1. - Id. als 't voorg. W.

Bok, m. - IV.-V'. - $\mathrm{I}^{\circ}$ Tros; fr. trochet, bouquet, touffe. Een bok noten, peren, krieken, bloemen ; $2^{\circ}$ Kraaksteen van krieken, pruimen, perziken, enz.; fr. noyau d'une drupe. - Meest gebruikt in 't Poperingsche, waar het mv. van éénlettergrepige woorden gemeenlijk met $s$ gevormd wordt, b. v. boks, honds, kats, tands, enz. (Kruidw.).

Boksdoorn, m. - Nederland. -. Lycium barbarum L.; fr. Lyciet de Barbarie; vl. Boksdoorn. - Een Oostersche heester, van doornen voorzien, die nog al dikwijls gekweekt wordt en soms als verwilderd voorkomt; hare bloemen vormen boks of trossen (fr. bouquets). Z. 't voorg. W.

Bol, m. - Nederland. - Id. als IEgeL (Vl. W'k.).

Boldert, m. - Nederland. - Id. als 't voorg. W.

Bol(1)aard, m. - W.-Vl. - Een boom wiens kruin afgehouwen is; fr.têtard. - De jonge takken die uitschieten vormen een bolachtig hoofd 
Bolle, v. - Zwijnaarde en omstr. - Id. als IEgeL (Vl. $\mathrm{IT}_{\mathrm{k}}$.). - Beduidt de zwarte zaadkorrels die men in het graan vindt (fr. graines de nielle) en ook de plant zelve.

Bombeliereken. - Oultre (bij Ninove). - Id. als MADELIEFJE (Vl. Wk.).

Booghout, o. - Nederland. - Acer campestre L.; fr. Érable champêtre; vl. Kleine Eschdoorn. - Somtijds gebruikt om boogen te maken.

Boom-des-Levens. - Oost-Roosebeke, Oyghem en omstr. - Rhus coriaria L.; fr. Sumac des corroyeurs; vl. Looiersboom. - Misschien alzoo genoemd om rede der talrijke scheuten (fr. jets), die op de onderaarsche wortels ontstaan en overal rondom den boom te voorschijn komen.

Borbelle, z. Berbelle (Bijv.).

Boschhanevoet, m. - Id.als Duivelsklauwen (V1. Wk.). - De bladeren en de wortels hebben eenige gelijkenis met een hanevoet en de plant leeft vooral in de bosschen.

Boschhorde, v. - Nederland. - Melampyrum pratense I.; fr. Mélampyre des prés!; vl. Weide-Zwartkoorn.

Boschpeem, m. - Zwijnaarde en W.-V1. - Meestal Holcus mollis L.; fr. Houlque molle; vl. Zacht Zorggras. - De plant gelijkt op de pemen (z. V1. Wk.) en groeit veel in de bosschen.

Boschpelmkes. - Beeringen en omstr. - Verb. van -palmkens. - Id. als Boschpalm (V1. Wk.).

Boschratels, m. mv. - W.-V1. - Melampyrum arvense L.; fr. Mélampyre des champs; vulg. Rougeole; vl. VeldZwarthoorn. - De plant gelijkt eenigzins op de Ratels (Rhinanthus) en groeit veel op den rand der bosschen.

Boschroosje. - Oultre (bij Ninove). - Melandryum diurnum Dmrt.; fr. Mélandre diurne; vulg. Compagnon rouge; vl. Dao-Koekoeksbloem. - De bloem is rood als een roosje en groeit bijzonder in de bosschen.

Bosirebezen, v. mv. - Zwijnaarde en omstr. - Id. als Aardbei (Vl. Wk.). - Verb. van Bosch-sier-bezen, d. i. Bezen die in bosschen groeien en passen om goeden sier te maken : zinspeling op den lekkeren smaak der boschbezekens. 
Boterbloem. - Moll en omstr. - Id als Pissebloem (V1. Wk.). - De bloemen zijn geel van kleur gelijk die welke men elders Boterbloemen (fr. Renoncules) noemt. Ook soms gebruikt om de boter te kleuren.

Boterkarn, v. - Nederlaud. - Nuphar luteum Sm.; fr. Nuphar jaune; vulg. Nénuphar jaune; vl. Gele Nuphar; ook Gele Plomp. - De dikke ronde vrucht met haren langen steel gelijkt op eene boterkarn (fr. baratte); de bloemkroon, daarenboven, heeft eene gele-boterkleur.

Boterständekes, o. mv. - Beeringen. - Id. als 't voorg. w. - Boterstande $=$ ook in 't fr. baratte.

Boterstijlen, m. mv. - Oevel, Oolen, Tongerloo (bij Gheel), Norderwijck, Morckhoven, Moll en omstr. - De inlandsche soorten van Geranium L., bijzonder G. molle L.; fr. Geranium mollet; vl. Zachte Ooievaarsbek en G. Robertianum L.; fr. G.Herbe-à-Robert; vl. Stinkende O. (fig. I6). - De vruchten dezer planten gelijken niet slecht aan den houten stamper of stijl (in Belg.Limb.: boterstooter), waar'mede men de boter in de boterstande verzamelt.

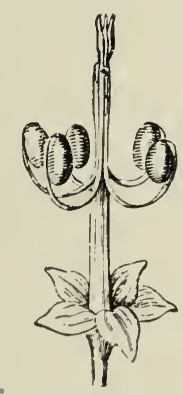

Rijpe vrucht.

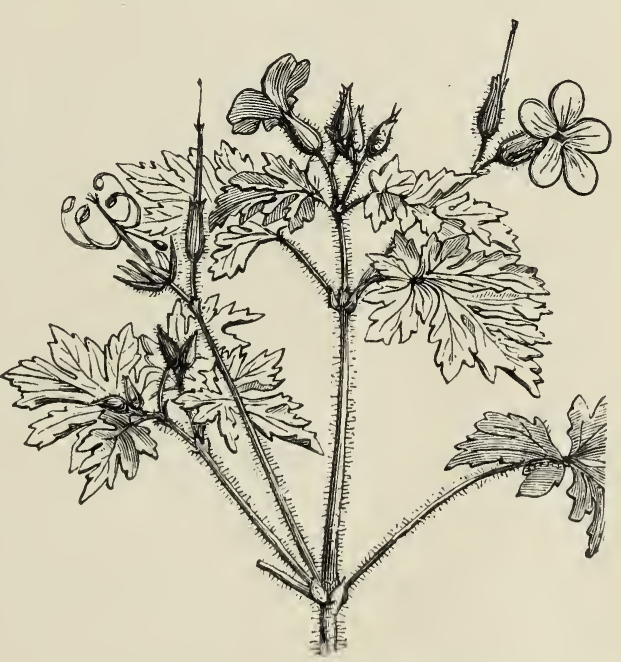

Fig. 10. - Geranium Robertiunum.

Bothol, o. - Nederland. - Enanthe Phellandrium L. ; fr. Enanthe Phellandre; vl. IVater-Torkruid. - Eene waterplant, die in slooten en moerassen groeit en wier. 
onderste einde of bot des stengels buitengewoon dik en hol is.

Bottebremen, m. inv. - Perck en omstr. - Verb. van Bottelhremen. - Z. 't rolg. w.

Bottelbremen, m. mv. - Vollezeele en omstr. - I ${ }^{\circ}$ Rosa canina L.; fr. Rose de chien, Églantier; vl. Hondsroos of Egelantier (fig. I 7): $2^{\circ}$ Rosa arvensis I.; fr. Rose des champs; vl. Veld-Roos. - Bottelbremen, zegt M.' Vits, is samengesteld uit bottel en bremen = bramen (fr. ronces). Bottel is het rerkleinw. van het oude botte, butte, dat nog bij Kiliaan voorkomt in de beteekenis van vat (oud fransch : boute; duitsch : Bütte, Botte, Bottich; eng. bottle). - Bottel beteekent : Io flesch (fr. bouteille $=$ petite boutte); $2^{\circ}$ fleschvormige vrucht van den wilden Rozelaar of Egelantier. Het komt voor, niet alleen in Bottelbraam = braam waaraan bottels groeien, maar ook in rozenbottel = fleschvormige vrucht van den Rozelaar; bottelbier (eng. : bottle-ale, enz.) = bier dat men op flesschen
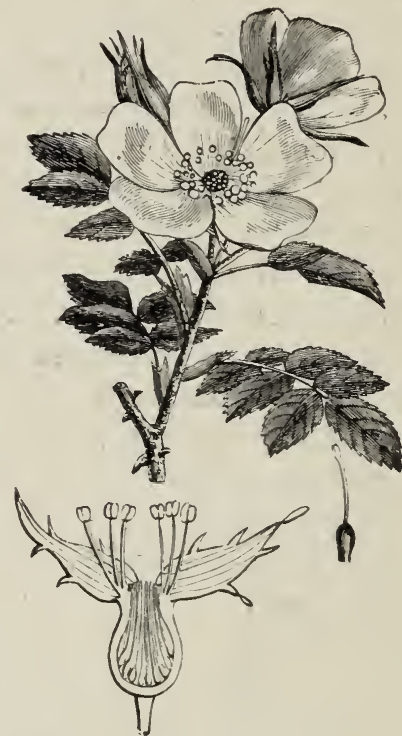

Fig. 17. - Rosa canina.

heeft getrokken; bottelen (eng. : to bottle, enz.) = bier op flesschen trekken en bottelier (eng. : bottler, enz.) $=$ keldermeester.

Bottelievekens. - Herdersem. - Id. als MAdELIEvEKExs (T1. Wk.).

Boumisbloemen. - Lebbeke en omstr. - Verb. van Bamis-. Bamis = St-Bavo's mis of St-Baafsmis, d. i. het feest van St-Baro of den I October. - Pyrethrum sinense DC.; fr. Pyrèthre de Chine; vulg. Chrysanthème; vl. Chineesche Ganzebloem. - Herfstbloem; die bloeit rond den I October. 
Boveest, v. - Brugge en omstr. - Id. als Boevenst (Vl. Ik.).

Braambulle, r. - Cruyshautem. - Id. àls BraAmBEZEN (Vl. Wk.). - Bulle = verb. van buil, d. i. eene zwelling : de vrucht der Braınen ziet er uit als eene verzameling van kleine $\mathrm{zwellingen} \mathrm{van} \mathrm{den} \mathrm{tak.} \mathrm{-} \mathrm{Elders} \mathrm{zegt}$ men (in W.-VI.), Braambuil.

Brandwortel, m. - Denderwindeke en omstr. - Id. als IUURWortel (Vl. W'k.). - Het gebruik dezer plant, als geneesmiddel roor zekere veeziekte, dat in ons $\mathrm{Vl}$. Wk. aangeduid staat, is ook in voege te Denderwindeke en zelfs in bijna gansch België (ook bij de Walen), zooals onze laatste navorschingen het ons bewezen hebben.

Breem, m. - Beeringen. - Id. als Breм (Vl. IVk.).

Brekebeen. - Nederland. - Id. als HolpiJPEN ( $\mathrm{r} l$. Wk.): - De stengel is uit talrijke gewrichten samengesteld; deze breken gemakkelijk aan de aanschakelingspunten.

Bremtol, m. - Oolen en omstr. - Orobanche minor Sutt.; fr. Orobanche mineure; vl. Kleine Bremraap. Eene woekerplant die, onder anderen, op de Brem leeft en wier knollige wortel (of het onderste deel des stengels) op eenen tol (fr. toupie) gelijkt.

Bretelleblad. - Pepinghen (bij Halle). - Verb. van Bordelleblad : z. Bordellewortel (Vl. Wk.). - Bordelle is zelf eene grove verb. van brobbelen (I) (in Zuid.Limb. : broebbelen), dat puist, uitslag, enz., beteekent. De bladeren en de wortels dezer planten worden gebruikt tegen de brobbelen en uitslag van allen aard, als zijnde bloedzuiverend, waterafzettend, versterkend... Men maakt er een opgietsel (thee) of een afkooksel mede. - Deze planten zijn : Rumex Patientia I. en R. obtusifolins L.; fr. Rumex Patience of kortaf Patience en $R$. à feuilles obtuses; vl. Tuin-Patik of Tuin-Patientiekruid en Stompbladig. Patientieliruid.

Brieole, v. - Oost-Roosebeke. - Id. als Brien.ol ( $\mathrm{T} 1 . \mathrm{Wk} \mathrm{k}$.$) .$

(1) De $e$ wordt kort uitgesproken. 
Broeinetel, v. - Nederland. - Deze algem. naam beduidt de twee soorten van Brandnetels. - Broeien hier heet worden, heet maken : het bijzonder vocht, dat de haren der plant vervult, brandt in de wonden welke deze haren, bij naraking, veroorzaken. Z. fig. I8.

Broekkraut, o. - Ketzingen (bij Tongeren). - Marrubium vulgare L.; fr. Marrube commun; vl. Gemeene Malrove. - Een broek (of een broekland) beteekent, in Zuid. Belg.Limb., eene min of meer verlaten plaats; gewoonlijk moerasachtig, ten minste hier en daar, waar weinig goed gras, maar veel biezen, enz. groeien. - Kraut = verb. van Kruid. Onze plant is dus een kruid dat veel in de broeken voorkomt. $\mathrm{Zij}$ verkiest er de droogste plaatsen.

Brom, m. - IV.-Vl. - Id. als Brem, $2^{\circ}$ ) (Vl. IVk.).

Broodjeskruid. - Antwerpen, Lillo en

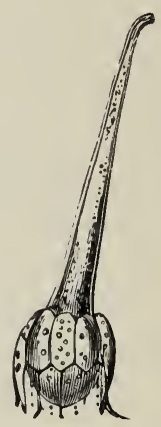

Fig. 18. Brandhaar (der Netels), met een brandend vocht vervuld. omstr. - Id. als KaAskenskruid (Vl. Wk.).

- De vruchten hebben den vorm van broodjes (fr. petits pains).

Brugsche-Meiske(n)s. - Oost-Roosebeke en omstr. Eene vroegrijpende en blozende peer, die ook Keizerinnekes genoemd wordt (A. De Jaegher).

Bruinettekens. - Nederland. - Adonis aestivalis L.; fr. Adonide d'été; vl. Zomer-Adonis.

Bruis, m. (Uitspr. Bruus). - Poperinghe, Oudenburg. - Id. als DARING (Vl. Wk.).

Brummels, v. mv. - Nederland. - Id. als Brommelen (Vl. Wk.). - De vruchten van den Braam. - Wordt ook gebr. om den heester zelf te beduiden.

Bruwin, v. - Maastricht en omstr. - Id. als BERwiN (Bijv.). - Men zegt soms ook Brulvind.

Bruwind, v. - Z. 't voorg. w.

Bullepees, v. - Nederland. - Typha latifolia I.; fr. Massette à larges feutlles; vl. Breedbladige Lischdod. $-B u l=$ stier (fr. taureau); Bullepees = in 't fr. nerf de 
bouf. - Zinspeling op den vorm en de taaiheid des stengels en der bladeren, die, desnoods als bullepees zouden kunnen dienen.

Bult, m. - Brugge en omstr. - Id. als Bonveest (VI. Wk.). - Deze Paddestoel is bultvormig.

Bund. - Nederland. - Het geslacht Carex Mich., in 't algem.; fr. Carex of Laiche; vl. Keg'ge. - Planten die op gras gelijken en gewoonlijk in vochtige of moerasachtige plaatsen groeien.

Buschpeme, v. - IV.-Vl. - Id. als Boschperm (Bijv.), waarvan dit w. maar eene verb. is.

Buschratels, m. mv. - Poperinghe en omstr. - Id. als Boschratels (Bijv.), waarvan dit w. maar eene verb. is.

Buzekeskruid. - Zwijnaarde en omstr. - Id. als BEURZEKENSKRUID, I ${ }^{\circ}$ ) ( $\mathrm{Vl}$. Wk.)

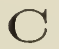

Clementine, v. Poperinghe en omstr. - Id. als DuI$\operatorname{VE}(\mathrm{N}) \mathrm{KRUID}(\mathrm{Vl} . \mathrm{WVk}$.) - Clementine = verb. van den fr. naam Clématite (fig. I9).

Corinthe boom, z. KORINTHEBOOM (Bijv.).

Grompiere(n), v. mv. - Z. Tl. IVk., bl. 79. - Dit w. schijnt eene verb. te zijn van Grondperen (fr. poires de terre). - Vergelijk aardappelen (fr. ponmes de terre).

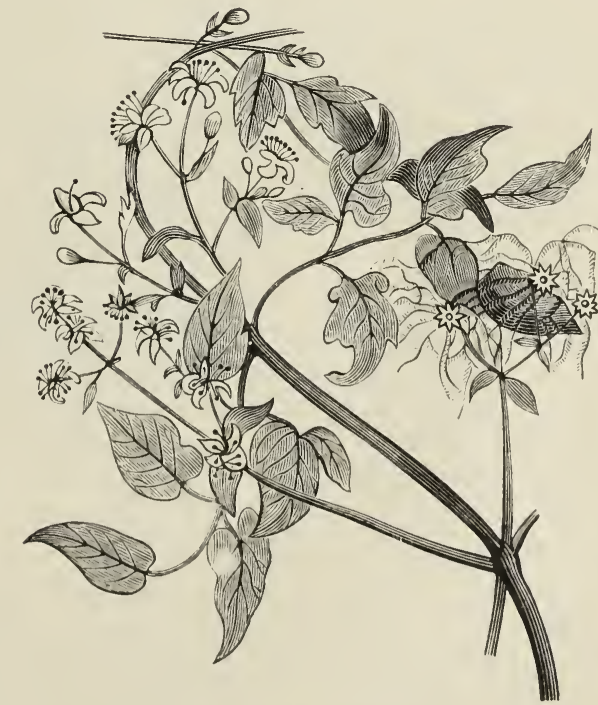

Fig. 19. - Clematis Vitalba. 
Dagsterre, v. - Oost-Roosebeke. - Convolvulus tricolor L.; fr. Liseron tricolore; vl. Drịklenrige Winde. De bloemen openen zich gewooulijk gedurende den dag. en dragen binnenst eene soort ran gekleurde ster.

Dauwkoolen, m. mv. - Oost-Roosebelie. - Io Chenopodium album I.; fr. Ansérine blanche; vl. Witte Ganzevoet. $-2^{\circ} \mathrm{Id}$. als Daumdistel ( $\mathrm{Tl}$. W $\mathrm{k}$.).

Dennekruid. - IV.-VI. - Hippuris vulgaris L.; fr. Pesse commune; vl. Gemeene Lidsteng, ook Watersparretje genoemd. - De bladeren van dit waterkruid staan gerangschikt gelijk de Dennetakken.

Dennenspellen, v. mv. - Reckheim en omstr. - Verb. van - spelden. - De bladeren der Dernen en Pijnboomen. die aan spelden (fr. épingles) gelijken.

Devote-Katoen, o. - W.-Vl. - Malcolmia maritima R. Br.; fr. Julienne de Mahon; Giroflée de Mahon.Eene gekweekte plant : de bloemen hebben allerlei kleuren en herinneren aan de veelkleurige katoenen stoffen zoo als de devoten (en andere ook) ze eertijds droegen.

Diamantbloem. - W.-V1. - Scabiosa atropurpurea L.; fr. Scabieuse noirpourpre; vulg. Fleur des veuves (fig. 20). Eene hofplant met donkerpurpere bloemen, die van verre gelijken aan diamanten booten, zegt 11. Samyn.

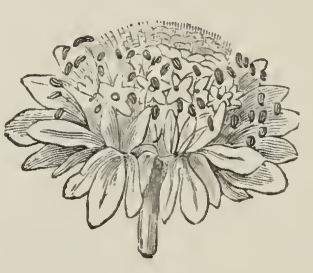

Fig. 20. - Scabiosa.

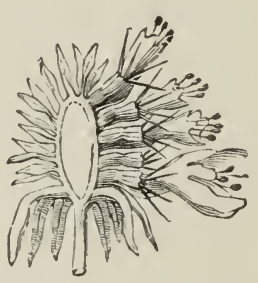

1)oorgesseden bloemhoofd.

Diptam, m. - Nederland. - Dictamnus albus L.; fr. Dictame blanc; rl. Esschenkruid. - Diptam = eene verminking van den lat. of den fr. naam der plant.

Djoezeballen, m.mr. - Zwijnaarde, Seeverghem, Eecke, 
Sint-Denijs-Westrem. - Zaadballen (d. i. vruchten) van den Aardappel. - Waarschijnlijk, zegt J. Paelinck, eene verbast. van zoe/ballen. Het werkw. zoeven wordt in die streek gebr. voor : ronken, snorren. Nu de kinders nemen een zaadbal, steken hem op een gescherpt buigzaam takje en slingeren hem aldus ver in de lucht. De bal zoeft dan, d. i. maakt een licht geronk of gesnor. - Hetzelfde kinderspel bestaat ook in Zuid. Belg.-Limb. en waarschijnlijk in meer andere streken.

Dobbel-Pijljoen, o. - Poperinghe en omstr. - Id. als Madelein (Vl. Wk.). - Pijljoen of Enkel Pijljoen beduidt, te Poperinghe, den Tijm (z. Tl. Wk.). - Pijljoen, zegt M. Samyn, schijnt eene verb. te zijn van het fr. pouliot, dat de naam is van eene welriekende plant, de Mentha Pulegium L.; fr. Menthe Pouliot. Er is ook eene die den rolksn. van Pouliot-Thijm draagt, d.i. de Mentha arvensis L.; fr. Menthe des champs. - Al deze planten hebben bijna denzelfden welriekenden geur.

\section{Dokkebladen.-}

Denderwin deke. -Id.als Koe KePs (Vl. Wk.). - Voor uitleg, z. DOKKEBLAD (Vl. WK.).

Dokkeblaren.-

Denderhautem.Id. als 't voorg. w.

Dolappel, m. Nederland. - Id. als DOORNAPPEL (Vl. Wk.). - Dol, dul; fr. furieux, enragé. - D e vrucht der plant gelijkt op eenen appel. Dol wijst

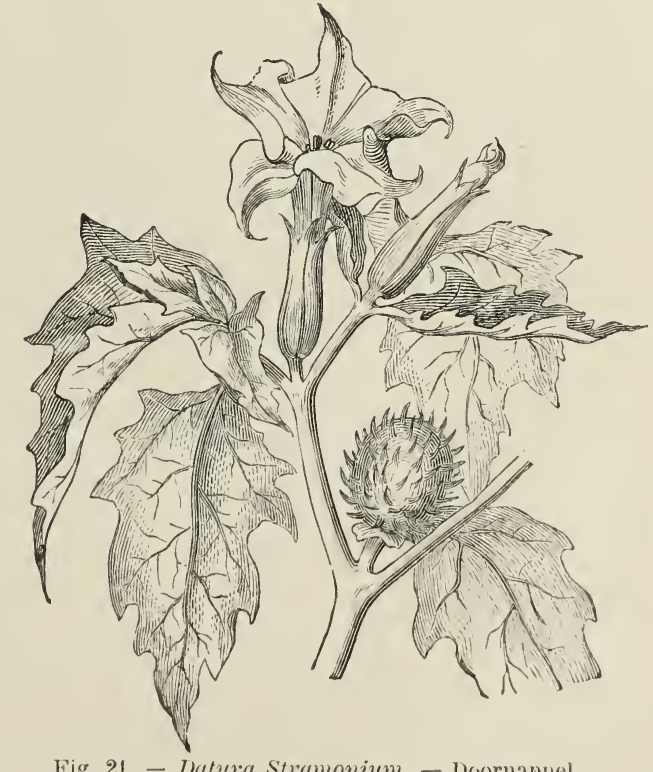
Fig. 21. - Datura Stramonium. - Doornappel. terug op de vergiftige eigenschappen (fig. 2r). 
Dolbes, r. - Nederland. - De vrucht van Solanum nigrum L.; fr. Morelle noire; rl. Zwarte Nachtschade. Beduidt ook dikwijls de gansche plant. - Bes, fr. baie; (lol zinspeelt op de vergiftige eigenschappen der vruchten (fig. 2).

Dolbessenhout.- - Nederland.-Solanum Dulcamara L.; Morelle Douce-A mère; vl. Bitterzoet (fig. I). Z. 't voorg W., roor uitleg. - Houl, duidt aan dat de stengel dezer laatste soort houtachtig. is, 't geen het geval niet is met de voorg. soort.

Dolkruid. - Nederland. - Id. als Bilzexkrtid (Bijr.). - Tergiftige plant. - Toor nitleg ran dol, z. DoldppeL (Bijv.).

Dollebeien, v. mr. - Nederland. - Id. als Dolbes (Bijv.). - Bei = bes (fr. baie).

Dolmuiskruid. - Beeringen en omstr. - Euphorbia Lathyris L.; fr. Euphorbe Épurge; rl. Kruisbladige Wolfsmelk. - De dol, m. (ook dolmuis geheeten), is hetzelfde als aard-of veldmuis; eene soort ran muis die zeer spits gebekt is (fr. musaraigne). - Deze plant wordt veel in de tuinen gekweekt, om de dolmuizen te dooden : men is orertuigd dat, indien ze aan de wortels knagen, zij er den dood vinden, door rergiftiging. - Tandaar de naam der plant.

Dolwortel, m. - Tederland. - Id. als WATERscheerLixg (Tl. Wk.). - Zeer rergiftige plant. - Voor uitleg van dol, z. Dol.APPEL (Bijr.).

Donderbladeren. - Denderwindeke en omstr. - Id als DoxDERBAARD (VI. Wk.). - Onder het rolk dezer streek is nog altijd het rooroordeel rerspreid dat het Donderblad het dak berrijdt. waarop het groeit, tegen donder en bliksem (II. Van Wi.der).

Donderbloem. - Nederland. - Naam gegeren aan 't geslacht Valeriana L.; fr. Valériane; rl. Valeriaan, in 't algem., zonder onderscheid ran soorten.

Donka, v. - W.V1. - Asperula odorata L.; fr. Aspérule odorante; rl. Welriekend Ruwhruid; rulg. Mottekruid. - De bloeiende plant rordt gedroogd om de klee- 
deren tegen de motten (fr. teignes, mites) te beschutten : vandaar Mottekruid. - Donka is misschien eene verb. van Donk (z. Alo. I'l. Idio.) dat eenen " natten, rottachtigen, vetten grond s beteekent: 't is juist in zulken grond dat onze plant gevonden wordt.

Doodaal, m. - Men zegt ook Doode-Aal. - W-Vl. Id. als Doode-Auve of Doole Aar; fr. Epi mort. - Er is veel doodaal in die tarwe.

Doodbloem - Denderwindeke en omstr. - Нyoscyamus niger L.; fr. Jusquiame noire; vl. Zwart Bilzenkruid. - De plant is zeer vergiftig en kan gemakkelijk den dood veroorzaken.

Doode-Aal. - WT.-Vl. - Z. DoodiAL (Bijv.).

Doodskeerse, v. - I ${ }^{\circ}$ Poperinghe en omstr. - Id. als Kinfspoo'T (Vl. Wk.). - De bloeikolf der plant gelijkt aan eene keers of kaars (z. fig. I2) en de plant is vergiftig, d. i. kan den dood veroorzaken. - $2^{\circ}$ Volgens Samyn, wordt dezelfde naam in $\mathrm{I}^{\top}$.-Vl. ook gebruikt, om den Paardestuart, in 't algem. te beduiden : Equisetum L.; ir. Prêle; vl. Paardestaart, ook dikwijls Kattesteert geheeten (z. Vl. Wk.). Bijna al de soorten van dit plantengeslacht hebben lange, rechte stengels, op keersen gelijkende, en daar ze een akelig en droevig voorkomen hebben, heeft men er doodskeersen van gemaakt.

Doorn, m. - Nederland.- Cirsium lanceolatum Scop.; fr. Cirse lancéolé; vl. Speer-Vederdistel. - De plant is rijkelijk met doorns of stekels voorzien.

Doornappel, m. - Denderwindeke en omstr. - Datura Stramonium I. ; fr. Iatura Stramoine; vulg. Pomme épineuse; vl. Doornappel (fig. 2I). - Een onkruid wiens vrucht omtrent den vorm heeft van een appel en gansch met stekels of doorns bezet is. De droge bladeren worden door de kortborstigen als tabak gerookt om de ademhaling te vergemakkelijken. - De bladeren van Atropa Belladona L.; fr. Atrope Belladone; vl. Wolfkers, worden dartoe ook gebruikt. - De beroemde " Poudres antiasthmatiques Escouflaire» zijn niets ander's dan de bladeren dezer twee planten, gedroogd, in eene salpeteroplosing gedoopt 
(om gemakkelijker te branden), en eindelijk fijn gewreren. Men verkoopt deze poeders ook onder vorm van cigaretten.

Doornbes, v. - Nederland. - Id. als Stekelbezex ( Vil. Wk.).

Doorndistel, v. - Nederland. - Id. als DAcwdister (Vl. Wk.).

Doornstekel, m. - Nederland. - Carduus cı ispus L.; fr. Chardon crépul ; vl. Gekrulde Distel. - De plant is van (loornstekels (fr. épines) voorzien.

Dopheide, v. - Friesland. - Id. als BoendernheI (Vl. Wk.). Dop = in deze streek, theepotje. Vandaar Dopheide, om de bolvormige gedaante der bloemkroon.

Dorre, v. - W.-Vl. - Id. als DaAlder (Vl. Wk.).

Dost. - Nederland. - Id. als Orego (V'l. Wrk.).

Draadjesbloem. - Denderwindeke en omstr. - Eupatorium cannabinum L.; fr. Eupatoire chanvrine; vl. Boelkenskruid. - Talrijke, fijne draadjes hangen aan de bloemhoofdjes (fr. capitules).

Draai, v. - Nederland. - Id. als Hagiwinde (Vl. Wk.). - De plant draait zich, windt zich om de andere planten.

Draft, m. - Beeringen. - Id. als DraAf (Vl. Wk.).

Dravik, m. - Kerkom en in 't Hageland. - Id. als DratiF ( $\mathrm{T}$ l. Wk.).

Dreesem, m. - W.-V1. - Glechoma hederacea L.; fr. Gléchome Lierre terrestre; vulg. Lierre terrestre; vl. Hondsdraf en Aardsveil. - Waar'schijnlijk verb. van Reesem : de plant rormt zeer dichte groepen; de neerliggende stengels schieten overal wortel en schijnen als aan malkander geregen.

Drentsche-Thee, v. - Nederland. - Id. als GAGEL ( Vl. Wk.). - De bladeren dienen, in eenige noordelijke streken, alsook in de Drentsche provincie, om thee op te gieten : deze wordt aanzien als een prikkelende drank. Elders (ook in 't Noorden) worden de bladeren benuttigd in het bierbrouwen.

Drieblad. - Nederland. - Z. Drijblad (Vl. Wk.).

Drievuldigheidsbloempje. - Nederland. - Viola tricolor L.; fr. Violette tricolore; vulg. Pensée sauvage; 
vl. Driekleurige Viool. - De drie verschillende kleuren, die de bloemkroon versieren, hebben aan de H. Drievuldigheid doen denken.

Dronkert, in. - Nederland. - Chaerophyllum temulum L.; fr. Cerfeuil enivrant; vulg. C. bâtard; vl. Dronkenmakende Kervel. - Dronkert is eene verb. van dronkaard: de plant is vergiftig en, gelijk haar fr. nasm het ook aanduidt, een harer nitwerksels is duizelig en als dronken te maken.

Droogbloeier, m. - Nederland. - Id. als NAAKTEBEGIJNEX (Vl. Wk.). - De bladeren der plant ontbreken gedurende den bloei; zij schijnt dus zonder sap te bloeien; vandaar : droogbloeier.

Druie, v. - IJperen en omstr. - Wordt aldaar gebruikt voor Druif; fr. raisin. -- Dedruiën zijn rijp (Samyn).

Duikelaar, m. - Nederland. - Id. als Don (Vl. Wk.). - Duikelaar $=\mathrm{fr}$. plongeur : deze plant groeit altijd met den voet in 't water en schijnt te duikelen.

Duikers, m.mv. - Nederland. - Id. als DuiL (Vl. Wk.). - Duiker $=$ fr. plongeur. Dezelfde uitleg als voor 't voorg w.

Duinbessen, r. mv. - Nederland. - Id. als R.ıniss (VI. Wk.). - Zoo geheeten, omdat deze struik, in Nederland, nog al dikwijls in de duinen gevouden wordt.

Duindoorn, in. - Nederland. - Id. als 't voorg. w. - De struik is van doorns voorzien.

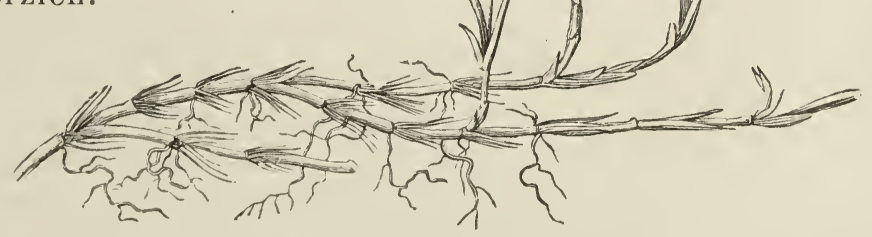

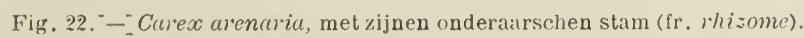

Duinreep, m. - Nederland. - Carex arenaria L.; fr. Carex of Laiche des sables; vl. Zand-Zegge. - De fijne 
onderaardsche stam (fr. rhizome), die waterpas en rechtlijnig kort bij de oppervlakte van den grond locpt, is zeer lang en is taai, gelijk een reep (fr. corde); daarenboven zijn de duinen de geliefkoosde verblijfplaats dezer plant (fig. 22).

Duitsche-Pijp, v. - Nederland. - Z. Vl. Wk.

Duivehertjes. - Poperinghe en omstr. - Id. als HeILIGHART (V1. Wk.). - De naam zinspeelt op den vorm (hart) en de schoonheid der bloemen.

Duiveljong, o. - W'.-Tl. - Z. GalgerJorg (Bijv.).

Duivelsbedstroo, o. - Poperinghe en omstr. - Id. als STEkвввем ( $\mathrm{V}$ l. Wk.). - Een bellstroo gelijk de duivel er cen verdient, met talrijke en machtige stekels.

Duivelsbeet, in. - Nederland. - Scabiosa Succisa L.; ¡r. Scabieuse Succise; vulg. Mors-du-diable; vl. Duivelsbeet. - Zoo men ziet, is de fr. volksn. de letterlijke overzetting van den vl. naam. - De plant wordt gebruikt tegen de huidziekten en bijzonder het schurft; vandaar haar lat. en fr. naam: scabies (in 't lat.) = schurft; daarom in 't vl. ook Schurfikruid geheeten.

Duivelsbenders, m. mv. - Beersel, Kinroy en omstr. Typha latifolia L.; fr. Massette à larges feuilles; vulg. Roseau de la Passion; vl. Dodderiet; ook Kruisriet. Wordt dikwijls verbeeld bij de werktuigen van de Passie van Onzen Heer; onder den vorm van den Ecce Homo draagt Hij dit riet als schepter in de liand. 't Is daarom waarschijnlijk dat, in 't gedacht van 't rolk, de plant gebruikelijk zou zijn om kwade geesten te verjagen, om duivels te verbannen.

Duivelsgras. - Denderwindeke. - Id. als MARExtAK (V1. W K.). - Deze naam doet aan den drü̈dischen godsdienst onzer voorouders denken : de druïden gebruikten de plant in de plechtigheden van hunnen afgoden- of duivelsdienst. - " Heden, zegt H. Van Wilder, wordt zij in Vlaanderen gebezigd, wanneer, bij het kalven van het vee, de zuivering niet gemakkelijk geschiedt. »

Duivelsnaairanken, v. mv. - Berthem (bij Leuren). Id. als Dieve(x)kris) (Vl. Wk.). - De ranken (fr. sar- 
ments) van dit struikgewas zijn zeer buigzaam en zeer taai ; daarenboven zijn zij gewoonlijk zeer verward. - Het zijn dus ranken die zouden kumnen dienen om te naaien (dienen als naaigaren), maar alleen gebruikelijk voor den duinel (fig. I9).

Duivelsoog, o. - In Vlaanderen. - Idonis aestivalis L.; fr. Adonide d'été; vl. Zomer-Adonis. -- De bloemkroon is vuurrood : het volk heeft er eene gelijkenis gezien met een duivelsoog.

Duivelspluim, v. - $\mathrm{W} .-\mathrm{V} 1$. Polypodium vulgare L.; fr. Polypode commun; vl. Gemeene Naaktvaren; ook Boomvaren (fig. 23). Dus genaamd om den vorm der bladeren die aan pluimen gelijken; deze bladeren zijn zeer hard en taai, vergeleken met de gewone pluimen : vandaar de naam van duivelspluim.

Duivelsvel, o. - Te Eecloo en omst., noemt men aldus de rekgom (fr. cauntchouc). - In 't gedacht van 't volk, moet het vel van den duivel zoo iets zijn : taai als leder, rekbaar, slechtriekend, enz.

Duivenkrop, m. - Maaseyck, Kessenich, Eelen. - Vglk. DuIVE(N)KERVEL (Vl. Wk.). - Fumaria officinalis L.; fr. Fumeterre officinale; vl. Genezende Aardrook. -

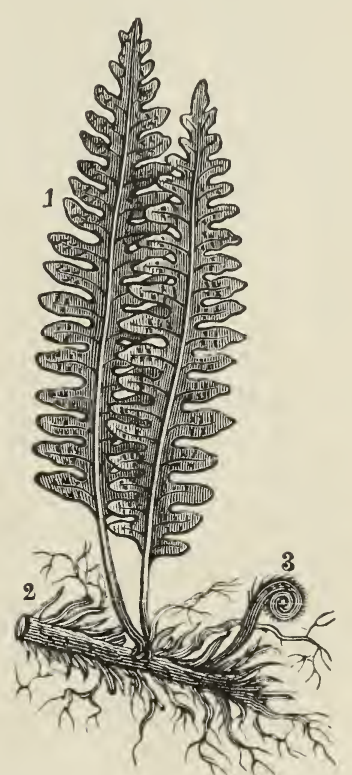

Fig. 23.-Polypodium vulgare. 1. Bladeren; -2 .Onderaardsche stam; - 3. Jong blad. De duiven, zegt men, zijn zeer verzot op de bloemen en het zaad der plant. Daarenboven eindigt de bloemkroon, langs beneden, buik- of kropvormig (fr. en forme de jabot).

Duizendgraan, o. - Nederland. - Radiola linoides Gmel.; fr. Radiole Faux-Lin; vl. Vlasvormig Duizendgraan. - Dit klein plantje draagt eene buitengewone hoeveelheid kleine, bolvormige vruchtjes, met zeer fijn rilad vervuld : vandaar duizendyrian geheeten. 
Duizendtak, in. - Nederland. - Achillea Millefolium L.; fr. Ichillée Millefenille; vulg. Millefenille; vl. Duizendbladig. Ichilleskruid; vulg. Duizendblad. De bladeren zijn buitengewoon fijn doorgesneden en als vertakkeld; vandaar : Duizendtak.

Dulle-Kamare, v. - W.-V1. - Z. AALraxkex (Bijv.). Dulle-Kamare is niet anders dan eene grove verb. van den lat. naam Dulcamara (fig. I).

Dullen, v. mv. - Nederland. - Id. als Dor (Vl. Wk).

Dult. - Brugge en omst. - Verb. van Bult. (Z. Bijv.).

Dunsel, o. - Reckheim en omstr. - De kleine boompjes die men uitkapt om de andere meer plaats en meer lucht te geven. Men zegt: dennendunsel, enz.

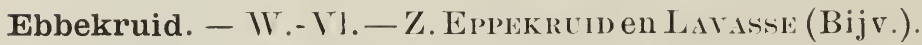
Echelenkruid. - Beeringen en omstr. - Id. als SpEcxKRUI1 (Vl. Wk.). - Echel = bloedzuiger, fr. sangsue. Deze plant groeit in vochtige plaatsen, waar men ook veel grijze slakken vindt, die niet slecht op bloedzuigers gelijken. Vandaar, door verwarring, werd de plant Echelenkruid genaamd. - De ware Echelen leven in 't water.

Echelenslaad, v. - Beeringen en omst. - Id. als 't voorg. w. - Slaad, gezegd voor salade, bet. dat de plant gegeten wordt door de gewaande echelen.

Eenboontjes. - W.-VI. - Phaseolus vulgaris I., var. nanus; fr. Haricot commun, var. naine; vulg. IIaricol nain. - Waarschijnlijk, verb. van Neinboontjes; zijnde nein, naan hetzelfde als 't fr. nain; lat. nanus (Kruidw.). - Deze boonen zijn zeer klein van gestalte.

Eendenmoes, o. - Z. Endekroos (Bijv.).

Eerappelkruid. - Oost-Roosebeke. - Verb. van Aardappelkruid. - Id. als PatatenkRuid (Vl. Wk.).

Eerdveilbladeren. - Denderwindeke en omstr. - Id. als Ee(r)DsveL ( $\mathrm{V}$. Wk.). 
Eerdveilranken, v. mv. - Denderwindeke en omstr. Id. als 't voorg. w.

Eering, m. - Berthem. - Id. als Hering en Harink ( $\mathrm{V}^{\mathrm{T}} \mathrm{l}$. ITk.).

Eernte, v. - Poperinghe, Oost-Roosebeke, Roeselare. - Id. als Heentenhout ( $\mathrm{Vl}$. Wk.).

Eersgat, o. - In Brabant. - Z. IsGat (Bijv.).

Eeuwige-Klaver, r.-Nederland.- Medicago sativa L.; fr. Luzerne cultivée; vl. Gehweekte Rupshlaver; Luzerne. - De plant gelijkt veel op de Klaver, en daar de Luzernelanden zes à zeren jaren kunnen duren, zonder herzaaid te worden, heeft 't volk er den hoedanigheidsnaam van eeuwig' bijgevoegd.

Eeuwige-Leven. - Nederland. - Id. als RiJstpap (Tl. Wk.). - Gelijk al de Vetplanten (fr. Plantes grasses), is deze ook zeer taai en vol levenskracht; zij is bijna niet dood te krijgen : vandaar de naam.

Egelgras, o. - Nederland. - Ranunculus Flammula L.; fr. Renoncule Flammette; vl. Kortbladige Ranonkel; Egelboterbloem. - De egel is eene ziekte, die bestond, volgens de Ouden, in eenen inwendigen en meestal doodelijken brand : de schapen die voornoemde plant afgraasden kregen den egel (of eghel). Vandaar de naam.

Egelkoolen, v. mv. - Nederland. - Ranunculus Ling'ua L.; fr. Renoncule Lang'ue; v]. Tongladige Ranonkel. - Dezelfde uitleg als bij 't voorg. w.

Eglentier, m. - V'erb. van Egelantier. - Vlamertinghe en omstr. - Id. als HaAgroze (V1. Wk.). - Egelantier (tegenstrijdig met 'tgeen wij schreven, Vl. Wk., bl. I04) komt van egel (fr. hérisson) en teer $=$ boom; dus = stetiel boom (zinspeling op de stekels der Haagroze). - Het fr. Églantier = verb. van 't vl. Egelantier. - Teer $=$ oud vl. woord dat boom beteekende; 't is in 't engelsch bewaard in tree = boom, met verplaatsing der $r$. - Voor verderen uitleg, z. 'TeEr (Bijv.).

Eiberbek, in - Nederland. - Id. als NAALDEKLNsk RuiD (Vl. Wk.). - Eiber = dichterlijk w. dat synoniem is ran Ooievaar. - De lange puntige vruchten der plant gelijken aan den bek van eenen Eiber. 
Eierboom. - IT.-VI. - Id. als Eıkñsboon (VI. Wk.). De vruchten van dit gekweekt struikgewas gelijken op kleine witte eiers.

Eierdoren, m. - Meerv. van Eierdor, gebruikt voor Eierdooier, te Seeverghem. - Trollius europaeus I.; fr. 'Trolle d'Europe; vl. Europeesche Trollius. - Fene verdienstelijke tuinplant, wier ronde gele bloem aan een eierdooier gelijkt door haren vorm en hare kleur.

Eierpruim, v. - Oost-Roosebeke en omstr. - Groote, bruine, langachtige pruim, op een ei gelijkende.

Ekstersnot, m. - Uitspr. A kistersnote. - Zwijnaarde en omstr. - Id. als KraAisnot (Vl. Wk.).

Elfrank, v. - Nederland. - Id. als Alfsiank (Bijv.) en dezelfde uitleg.

Elf-U re(n)-Kloksken. - Herenthals en omstr. - Id. als Elf-Ure-bionm (Vl. Wk.). - De bloem is meestal een weinig klokvormig.

Eller, m. - Nederland. - Algem. naam die de verscheidene soorten van Alnus Tournef.; fr. Alune; vl. Els beduidt. - Eller is de duitsche naam van den Els.

Emerkoorn, o. - Nederland. - Triticum dicoccum Schrk.; fr. Froment à deux grains; vl. Tweekoorn; Tweekorrelige Tarwe. - Men zegt ook Emer, alleen.

Endekroos, o. - Nederland. - Id. als Eendenmoes (V1. Wk.). - Ende= verb. van Eenden (fr. canards); kroos en kroost bet., onder anderen, winst, profijt : de eenden voeden zich zeer geerne met deze kleine waterplantjes. Vandaar ook de naam van Eendenmoes (z. V1. Wk.).; in 't.deensch Andemad, dat Eenden-eten beteekent.

Ende(n)groen, o. - Id. als 't voorg. w. - In 't duitsch vinden wij : Entegrïn (te $\Lambda$ ugsburg en in Oostenrijk).

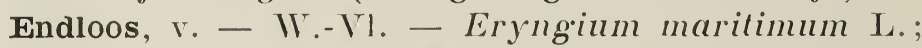
fr. Panicant maritime; vl. Meerdistel. - Verb. van Eindeloos, d. i. zonder einde. De gansche plant is taai en duurzaam als leder; de uitdroging verandert ze niet; men maakt er droge tuilen van, die eindeloos kunnen dienen.

Engelsch-Gers, o. - Uitspr. - Ges. - Oost-Roosebeke en omstr. - Id. als Exglasich-Gris ( $\mathrm{V}$. Mk.). 
Engelwortel, m. - IV.-Vl. - Angelica sylvestris L.; fr. Angélique sauvage; vl. Wilde Eng’elwortel. - De vl. naam is de letterlijke overzetting van den lat. of den fr. naam; men maakt in 't bijzonder gewag van den wortel (in den vl. naam), omdat dit deel der plant het meest gebruikt wordt.

Eppekruid. - W.VI. - Id. als LAvas(sE) (Bijv.). - De bladeren der plant gelijken grootelijks op die der Eppe: Apium graveolens I.; fr. Ache odorante; vl. Sterkriekende Eppe. - De Selderij, in onze moeshoven gekweekt, is slechts eene var. van de Eppe.

Erdgalle, v. - Nederland. - Taraxacum officinale Web.; fr. Pissenlit; vl. Pararde - of Pissebloem. - De plant, veel gebruikt als salade, in de lente, is zeer bitter van smaak, bitter als g*al (fr. bile), en daar ze als tegen den grond geplakt groeit, heeft men ze aardgal (erdgalle) genoemd (fig. 24).

Erdschelle, v. Nederland. - Verb. van 't voorg. w. en dezelfde bet.

Erf, v. - Nederland. - Id. als MuUR (Vl. Wk.). - Z. ook HERF (Bijv.).

Ernterhout. - IV.V1. - Id. als HerexTExHout ( $\mathrm{ll}$. Wk),

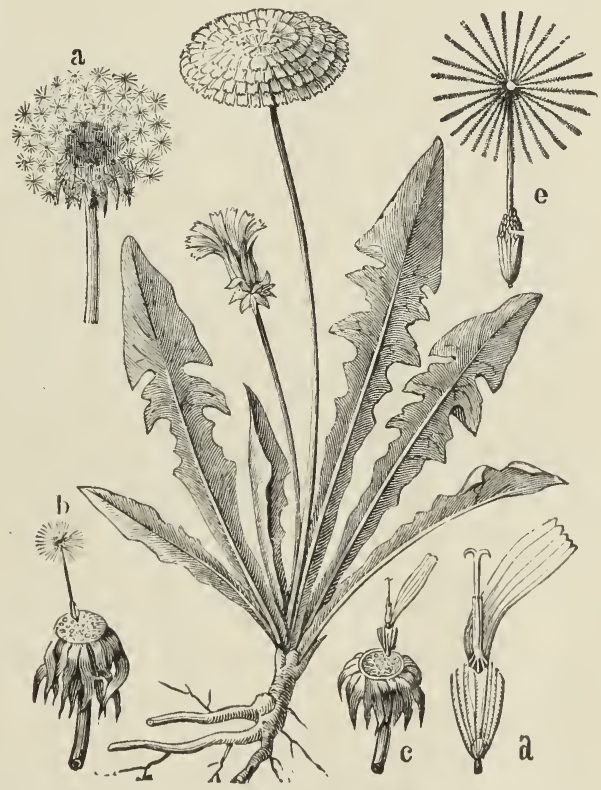

F'ig. 24. - Taraxacum officinale. $a, b, c$, enz. Verschillige deelen van bloem en v'ucht waarvan deze naam maar eene samentrekking is.

Espe, m.; Espenboom, m.- IV.-VTl. en Nederland.-Popılus Tremula, L.; fr. Peuplier Tremble: vl. Ratelpopuplier; 
Esp. - Espe is eigenlijk de duitsche naam van dien boom.

Eukelaar, m. - W.-V1. - Juglans regia L.; fr. Noyer royal; vulg. Nojer; vl. Noteboom; Notelaar. - Eukelaar is eene verb. van okkerlaar (de uitgang laar $=$ boom), d. i. de boom die de okkernoten of gewone noten voortbrengt.

Eukelbraam, v.; Heukelbraam, v. - V.-Vl. - Id. als Hoppelaremex ( $\mathrm{Vl}$. Wk.).

Even, Evene, v. - Nederland en WV.-VI. - Id. als Eve (Vl. Wk.). - Onder dezen naam begrijpt men ook soms de Avena fatua L.; fr. Avoine folle: vulg. Folle-Avoine; vl. Dolle Haver; Oot.

Ezelsooren, o. mv. - $\mathrm{I}^{\mathrm{o}}$ Te Zwijnaarde en omstr., id. als Ezelsblokir ( $\mathrm{T} 1 . \mathrm{W}^{\mathrm{k}} \mathrm{k}$.).; $2^{\circ}$ in $\mathrm{W} .-\mathrm{T} 1$, id. Ezelsoor, EzelsOORE(N) (Vl. Wk.). - Het volk heeft eenige gelijkenis gevonden tusschen de bladeren dezer planten en een ezelsoor.

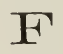

Faldrian, v. - Nederland. - Algem. naam om het geslacht Valeriana L.; fr. Valériane; vl. Valeriaan te beduiden. - Faldrian is eene grove verb. van Valeriaan.

Feem, v. - WV.-V1. - Z 't volg. w.

Feme, v.; ook Fimme, v. - IV.-V1. - Het lang en smal blad van Lisch, Porei, Maïs, Koorn, Haver, Riet, enz. (Kruidw.).

Fenkel, v. - Nederland. - Id. als Vrenkel ( $T$ l. Wk.). - Verb. van den lat. naam Foniculum.

Fennebloem. - Nederland. - Id. als Madeliefue (Vl. IVk.).

Fiefer, m. - W. - V1. - Eene var. van Olmboom, Ulmus L.; fr. Orme, die veel gezocht wordt voou zijne goede kwaliteit van hout. De Fiefer wordt meer geacht dan het Smalblad (Kruidw.).

Fierlaflonke, v. - Brugge en W.-V1. - Duivelsdrek (ook Stercus diaboli geheeten): zoo genoemd om zijnen stinkenden reuk. Dit product is het verdikt sap van Ferula 
Asa-foetida L. (uitheemsche plant), dat soms als geneesmiddel (stuipwerende pillen) gebruikt wordt. - Fierla $=$ verb. van Ferula, naam die 't volk bij den apotheker' gehoord heeft; flonk, flonke, v. = in 't algem., een slecht voorwerp, zonder waarde, b. v. een vuil, versleten kleed, enz. Hier, in dit samengesteld w., drukt het de minrchting van 't volk uit.

Fierlefijn, o. - IV.-V1. - Egopodium Podagraria L.; fr. Égopode herbe-aux-goutteux; vl. Geitepoot. - De plant werd gebruikt om liet flerecijn (fr. goutte) te genezen. Fierlefijn is maar eene grove verminking van flerecijn.

Fijgeboom. - IV.-VI. - Id. als Vi.geвоом (Vl.-Wk.).

Fikowijten, v. mv. - W.-V1. - Sedum maximum Sut.; fr. Orpin de grande taille; vl. Groot Vetgroen.

Filetten, v. mv. - Nederland. - Id. als Stenffier (Vl. Wk.).

Fimme, v. - Nederland. - Z. Feue (Bijv.).

Finkoorde, v. - W.-Vl. - V'inca I., in 't algem.; fr. Pervenche; vl. Maagdepalm. - In W.-VI. zegt men ook Vinkoorde. - Deze volksn. komen van den lat. naam Vinca en koorde : de plant geeft lange wortelspruiten (fr. stolons), die boven den grond loopen en door vorm en taaiheid aan koorden gelijken.

Fistelkruid. - Nederland. - Pedicularis palustris I..; fr. Pédiculaire des marais; vl. Moerasliartelblad. - IVerd eertijds in de heelkunde gebruikt (om de fistels (fr. fistules) te genezen; vandaar Fistelkruid.

Flaweeltjes, o. mv. - Seeverghem en omstr. - Id. als

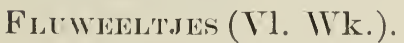

Fledderteer, m. - Heyst-op-den-Berg en omstr. - Id. als Fladdereer (Vl. Wk.). - Voor den uitgang teer, Z. Hekelteer ( $\mathrm{T}$ l. Wk.). - Teer is synoniem van boom : appelteer $=$ appelboom, enz. Het eng. tree $=$ boom, is lietzelfde w. met omzetting van de letter $r$.

Fleuruskruid. - Oultre (bij Ninove), Denderleeuw en omstr. - Id. als IJzerkiuid, I $^{\circ}$ ) (Vl. Wk.). - Wordt soms gebruikt (onder vorm van thee) als middel tegen de pleuris (fleurus, bij 't volk), fr. pleurésie. 
Flierbloem. - Alken en omstr. - Id.als Thier (VI. IVk.).

Flok, v. - Nederland. - Eriophorum vaginatım L.; fr. Linaigrette engainée; vl. Scheededragend Wollegras. - Na den bloeitijd is de plant als met witte vlokken wol bekroond; vandaar ook een andere volksn., Heipluiskens, die elders gebr. wordt. - Z. VI. Wk.

Flokges, o. - Verb. van Vlorgras. - Zwijnaarde, De Pinte, Seeverghem. - Is in gebruik, bij de maaiers, om bijzonderlijk Festuca ovina L. en F. heterophylla Lmk., Nardus stricta L. en Deschampsia flexuosa Nees aan te duiden. Al deze grassoorten groeien in dichte, korte bossen en zijn daarom moeilijk om af te maaien. - Vlok = fr. flocon en ook touffe.

Floor, Floorzaad, o. - Brabant, Limburg. - Id. als Sloor en Sloer (Vl. IVk.). - De bladeren zijn zacht als floer, floor $=$ fluweel (fr. velours).

Flucia, v. - IV.-Vl. - Verb. van Fuchsia. - Z. Fuuc(н)sia (Vl. IVk.).

Fluitekruid - Beeringen en omstr. - Id. als WATERvlier (VI. Wk.). - De kinderen maken fluiten van den hollen stengel.

Fluitstek, m. - Beeringen en omstr. - Id.als 't voorg. w. - Stek = stok, fr. bâton.

Fransche-Klaver, v. - Nederland. - Id. als EeuwigeKlaver (Bijv.).

Franschmannen. - Nederland. - Fagopyrum tataricum Gärtn.; fr. Sarrasin de Tartarie; vl. Tartaarsche Boekweit, ook Fransche B. genaamd. - Het volk meent dat de plant uit Frankrijk uitkomstig is ; vandaar Franschmannen.

Freinzekruid. - W.-T1. - Potentilla sterilis Gke; fr. Potentille stérile; vl. Onvruchtbare Ganzerik. - Een kruid dat zeer op Freinze (fr. fraisier) gelijkt, voor bladeren, bloemen, enz., maar geene vruchten draagt.

Frotter, m. - IV.-VI. - Soort van langachtigen Aardappel, anders ook Tistje geheeten.

Fruitenier, m. - W.-Vl. - Eene soort van Appel.

Frulletabak, m. - W.-Vl. - Uitspl. - toebak en ook 
tubak, volgens de plaatsen. - Soort van lichte Tabak met gefrulde bladeren, anders ook Leiletabak geheoten. (Kruidw.).

\section{G}

Galgejong, o. - W.-V1. en bij L. Fuchs. - Atropa Mandragora L. : fr. Mandragore; vl. Alruin, Tooverwortel.- Men gaf den naam van Galgejong aan deze plant, zegt M. Samyn, wanneer deze onder eene galg groeide, quia credebatur crescere ex patibulati semine. Haar wortel, ook Galgejong genaamd, was vermaard bij de tooveressen. Ja, heden nog, zijn er lieden die zoo een Galgejong voor een behoedmiddel (fr. amulette), zorgvuldig bewaren en alom mededragen, fr. main de gloire, mandegloire (verb. van mandragore). - "Pythagoras heeft dit cruyt Anthropomorphos geheeten, om des wille dat de wortel van desen cruyde eenen mensche eens deels gelijck is. Maer de quacksalvers en de landtvaerders die hebben wortelen te koope, die en sijn also van selfs niet ghewassen, maer sij sijn van rietwortelen ghesneden na de figure van eenen mensche, ende dan setten sij de wortelen wederom in deerde; so comen daer alsulcke wortelen wt, die van hayre, baert, ende ander dinghen eenen mensche ghelijck sijn. Ende daer lieghen sij veel lueghenen toe, datmen dese wortel onder de galghe inoet graven met seker ceremoniën, enz., dat enckel lueghen ende bedroch is. ) (L. Fuchs, I50I-I566).-Men kan, zeggen zij, dezen Alruinwortel niet uitrukken zonder plotselings dood te vallen; daarom neemt men eenen zwarten hond dien men met den steert aan die plant vastbindt, en, met het slag van middernacht, huischt men dien hond op met een groot geschreeuw. De hond springt rooruit, maar valt, met den uitgerukten wortel, dood ten gronde. Dan neemt men onbevreesd den wortel op en gaat er mêe henen (Kruidw.).

Het Galgejong wordt ook Duiveljong genoemd. 
Galle-boven-de-aarde, v. - Uitspr. - d'irde. - Zwijnaarde, Seeverghem, Eecke, Sint-Denijs-Westrem. - Id. als Santoriebloemkes ( $\mathrm{T}$ l. W'k.). - De smaak der plant is bitter als gal. - Daarenboven, zegt J. Paelinck, wordt de plant veel gebruikt tegen de gal (fr. bile). Men zet ze te trekken op jenever, waarvan de gallijder nu en dan een glasje neemt. $Z$. de andere toepassingen dezer nuttige plant, in 't lat. Wk., bl. 504 : ERYTHRAEA (fig. 25).

Galle-der-aarde, v. Oost-Roosebeke en omstr. - Id. als 't voorg. W.

Galvejong, o. - V'erb. van Galgejong. - Z. dit w. (Bijr.).

Gamanderlijn, o.-W. $-\mathrm{T}^{\top} \mathrm{l}$.

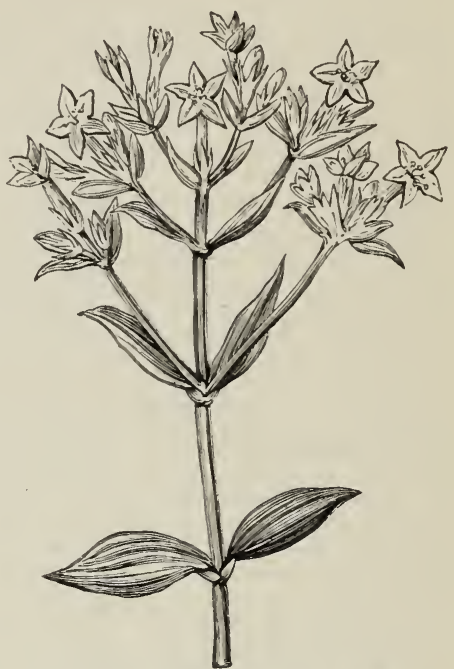

Fig. 25. - Erythraea Centaurium.

-Veronica Chamaedrys L.;

fr. Véronique Petit-Chêne; vl. Gamander Eereprijs. Gamander = Teucrium Chamaedrys L. ; fr. Germandrée Petit-Chêne; de Veronica Ch. gelijkt er zeer op, maar is kleiner van gestalte; vandaar het vklw. Gamanderlijn. Gamander zelf is waarschijnlijk eene verb. van 't fr. Germandrée.

Ganzemoes, o. - IT.-Vl. - Z. GAnzemoere (Vl. Wk.).

Ganzepoothout. - W.- Vl, - Id. als BeEnhouWErshout (Bijv.). - De takken zijn rood van kleur gelijk de pooten der ganzen.

Garzerij, Gerzerij, v. - IT.-Vl. (Uitspr. gezzerie). Eene weide, een grasveld, fr. pré, bijzonderlijk bij of rond eene woning (Kruidw.).

Gaschoenje. - Z. Aschonnje (Bijv.).

Gaskoenje, v. - IV.-VI. - Id. als 't voorg. W.

Gebloemte-Iefte, v. - Z. IEfTE (Bijv.). 
Geblutst. - Z. 't volg. w.

Gebuild. - Zwijnaarde, Eecke, Seeverghem, Sint-DenijsWestrem. - Eene vrucht die op een hard voorwerp valt en gekneusd is, noemt men gebuild. - In Zuid. Belg.Limb., zegt men geblutst (nitspr. gebleuts). - In Brabant: gebutst; fr. bosselé, meurtri, - Buil, v. = fr. bosse.

Gebutst. - Z. 't voorg. w.

Geel-Klaverrankskens, o. mv. - Denderwindeke en omstr. - Trifolium procumbens L. en T. minus Relhan; fr. Trèfle couché en T. nain; vl. Liggende Klaver en Diverg-K. - De bloemen dezer klaversoorten zijn geel en de fijne stengels gelijken op kleine ranken (fr. sarments).

Geel-Rankskens, o. mv. - Denderwindeke en omstr. Id. als Eendenderm (Vl. Wk.). - De bloemen zijn geel en de fijne buigbare stengels gelijken op kleine ranken (fr. sarments).

Geer. - Z. WILDE- (Bijv.).

Geinst, v. - Denderwindeke en omstr. - Id. als Ginst (Vl. Wk.).

Geinstdoorn, m. - Denderwindeke. - Id. als HeksexunUt ( $\mathrm{Vl}$. Wk.).

Geitepoot, v. - Nederland. - Id. als DriJbLa D (V1. Wk.). - Geitepoot is de letterlijke overzetting, van den lat. naam der plant $E$ gopodium; deze komt, op zijne beurt, van 't $\mathrm{gr}$. en bet. Pied de chève, in 't $\mathrm{fr}$ '.

Gèjen, werkw. - Z. WiË̈n (Bijv.).

Gele-Boterstampers, m. mv. - Heyst-op-den-Berg en omstr. - Id. als Boterstampers (Vl. IVk.). - De bloemen zijn geel van kleur.

Gele-Gaperkens, o. mv. - Denderwindeke en omstr. Id. als Gaperke(s)s, $2^{\circ}$ ) (Vl. Wk.).

Gele-Kiek, m. - Nederland. - Id. als HARING (V1. Wk.).

Gele-Klie. - Nederland. - Medicago Lupulina L.; fr. Luzerne Lupuline; Lupuline; vl. Hoppe-Rupsklaver. - Klie = Klee (z. Vl. Wk.) = Klaver. - De plant gelijkt op klaver met gele bloemen.

Gele-Netel, v. - Denderwindeke en omstr. -- Galeobdolon luteum Huds.; fr. Galéobdolon jaune; vulg. Ortie 
jaune; vl. Gele Goudnetel. - De bloemen zijn geel en de bladeren gelijken op die der Netel.

Gele-Waterroos, v. -- Heyst-op-den-Berg. - Id. als GELE-W ATERLELIE (Vl. Wk.).

Gelen-Hanenkam, m. - Denderwindeke en omstr. Iris Pseudo-Acorus L.; fr. Iris Faux-Acore; vulg. Glaïenl des marais; vl. Gele Lischbloem of G. Bloemlisch. - De wortels, zegt Mi. H. Van Wilder, knauwt men (gelijk de Rhabarber), tegen de maagpijn. Men maak t er ook maagbitter mede. - Z. ook Iris PseudoAcorus, in ons lat. Wk. (fig. 26).

Gelikawortel, m. - IT.-Vl. Angelica Archangelica L.; fr. Angélique officinale; vl. Genezende Engelwortel. - Gelika $=$ verb. van Angelica.

Gendarmen, $m$. mr.- Herdersen en omstr. - Id. als Borstel.s (VI. Wk.). - De zwarte bloemhoofdjes (vóór de ontluiking) gelijken niet slecht aan de zwarte gendarmenhoeden.

Gendarmhoed, m. - Z wijnaarde en

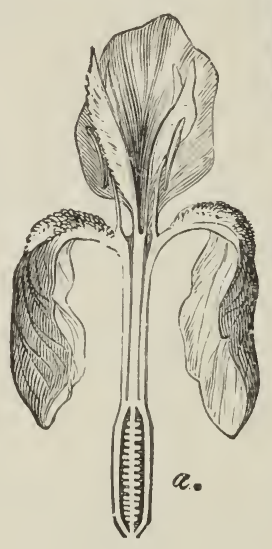

a. Doorgesneden bloem.

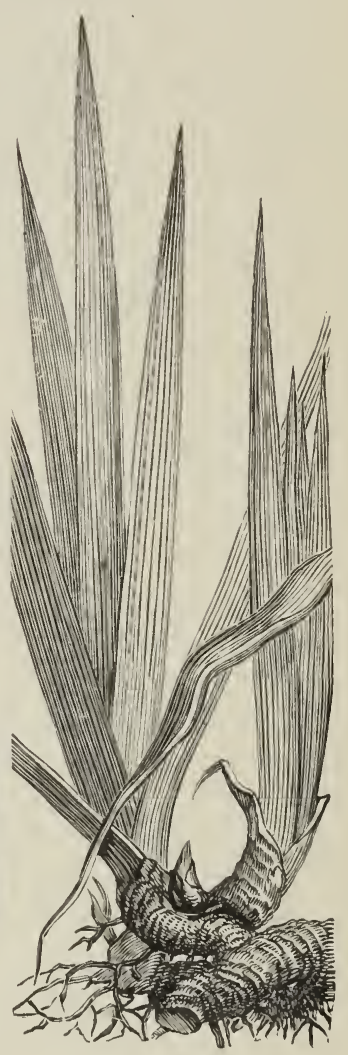

Fig. 26. $-I$ ris. omstr. - Uitspr. Gendurmh. - Id. als WiJWATERSBorseL (Vl. Wk.). - Zoo genoemd naar den vorm der bloeiwijze.

Geraamte, o. - In Holl.-Limb. - Id. als MARENTaK (Vl. Wk.). - De plant ziet er zoo mager, zoo naakt en zoo hoekachtig uit, bijna gelijk een geraamte (fr. squelette). - Elders zegt men ook Raamst. 
Gerspeme, v. - Verb. van Graspeem. - Oost-Roosebeke en omstr. - Id. als Penen (Vl. Wk.).

Gerzerij, v. - W.-V1. - Id. als GARzerIJ (Bijv.).

Geulkenshout. - Recklieim en omstr. - Id. als GAciEL (Vl. IVk.). - Geul, v. = eigenlijk, nauwe invalart; enge haveningang (fr. chenal). Hier is dat w. in eenen uitgebreiden zin genomen, en de naam der plant = hout dat nevens waterplassen, moeraspoelen, enz. groeit.

Geuzenbloem, v. - Diest en omstr. - Id. als BLAUwBloem (Vl. Wk.). De geuzen en liberalen gebruiken deze bloem als kenteeken.

Gierst, v. - Heystop-den-Berg. - Panicum miliaceum L.; fr. Panic Millet; vl Gierst.

Ginnebeer, v. - $\mathrm{II}^{\top}$.V1. - Zingiber officinale Bosc.; fr. Gingembre officinal; vulg. Gingembre; vl. Gember.In $\mathrm{W}$.-Vl. hoort men ook Gienebeer, Ginebère en Gineberg'e. Al deze volksn. zijn verb. van den lat. naam Zingiber (fig. 27).

Gijbe, v. - W.-Vl.

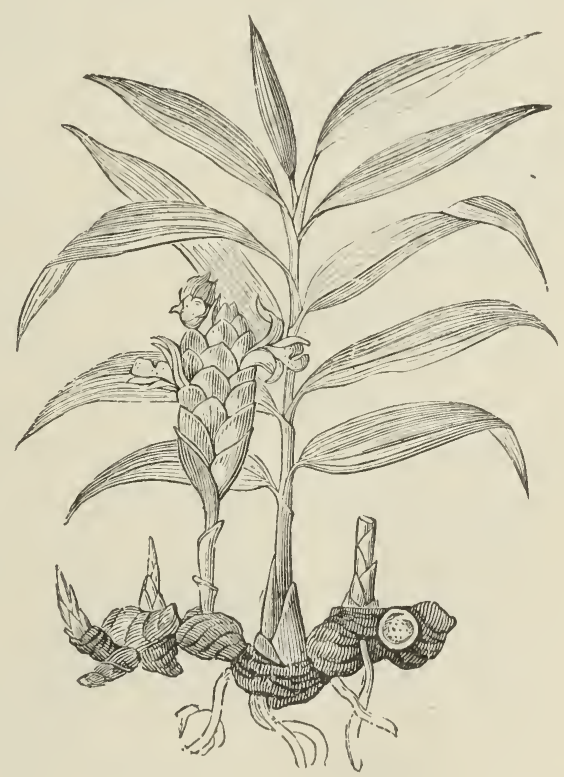

Fig. 27. - Zingiber officinale.

\section{- De vrucht van den}

Crataegus L.; fr. Aubépine; vl. Hag'edoorn. - Men zegt ook Hiepe.

Giroffel, m. - W.-Vl. - Id. als Grroflieks (Vl. Wk.).

Glei, o. - W.-Vl. - Lang, gezuiverd Roggestrooi, waar al de bucht uitgeschud is. Het dient om huizen te dekken, enz.

Glis, v. - Zwijnaarde en omstr. - Id. als Grach'tiscn (Vl. IVk.). 
Godelieve-Lelie, v. - IV.-V1. - Id. als GeEL-Lelie (Vl. Wk.).

Godewaar, Godeware, v. - IV.-VI. - HYPERICUM PLRForatum L.; fr. Millepertuis perforé; vl. Doorboord Herts. hooi; St-Janskruid. - De plant bloeit rond het feest van den H. Godewardus (of Godehardus) dat in 't begin van Mei gevierd wordt (fig. 28).

Godsgenade, v. -W.-Vl. - Gratiola officinalis L.; fr. Gratiole officinale; vl. Genezend Genaclekruid.

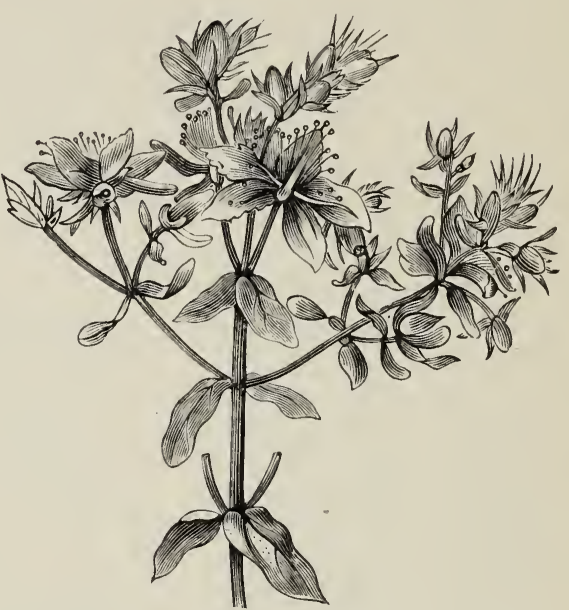

Fig. 28. - Hypericum.

Goezemoeze, v. - W.-Vl. - Id. als MuUR (Vl. Wk.). Verb. van Ganzemoes = Gansemulr.

Gokelbloem, v. - W.-V1. - Papaver Rhoeas L.; fr. Coquelicot; vl. Kolbloem. - Gokel is eene verb. van den fr. naam Coquelicot.

Gorsgras, o. - Nederland. - Glyceria maritima Wahl.; fr. Glycérie maritime; vl. Zee-Zoetgras; Zee-Vlotgras. Gors = aangeslibd land bij de zee, enz.; fr. alluvion. Deze grassoort groeit in de gorzen der zee.

Gortrijst, v. - Nederland. - Ir. als Eмkrkoorn (Bijv.).

Goudhaansvoer, o. - Nederland. -- Lamium album L.; fr. Lamier blanc; vulg. Ortie blanche; vl. Witte DooveNetel. - Dient tot voer (verkorting van voeder, fr. nourriture) voor zekere soorten van goudhaantjes (fr. chrysomèles), behoorende tot de schildvleugelige insecten.

Goudmijne, v. - Poperinghe en omstr. - Id. als GouDEN-MANDEKEN ( $\mathrm{Vl}$. Wk.). - In andere gedeelten van W.-Vl., is deze naam synoniem van GeLE-RiJstpap (Vl. 
Wk.). - De bloemen dezer plantsoorten zijn zeer talrijk en geel als goud.

Greinenhout.-- W.-Vl.-- Bij timmerlieden, zegt M.Samyn, id. als Noordsch dennenhout.

Griete, v. IV.-Vl. - Verminking van Marg'uerite, naam van eene hofbloem : Aster sinensis L.; fr. Reine Marguerite.

Grijm, Grijmsel, Grijmte, v. - W.-Vl. - Eene graanziekte, in 't fr. Cariegenaamd, in 't lat. Tilletia Caries Tul. - De aangetaste graankorrel verandert in een zwart stof, gelijkende op 't rookzwartsel (fr. suie), dat in W.-Vl. den naam van grijm, enz. draagt. - Die ziekte wordt ook Lug.e.e genaamd. Grijze-Olie, v. - Oultre (bij Ninove). - Id. als GRIJZOLEI (VI. IVk.).

Grijzorie, v. -

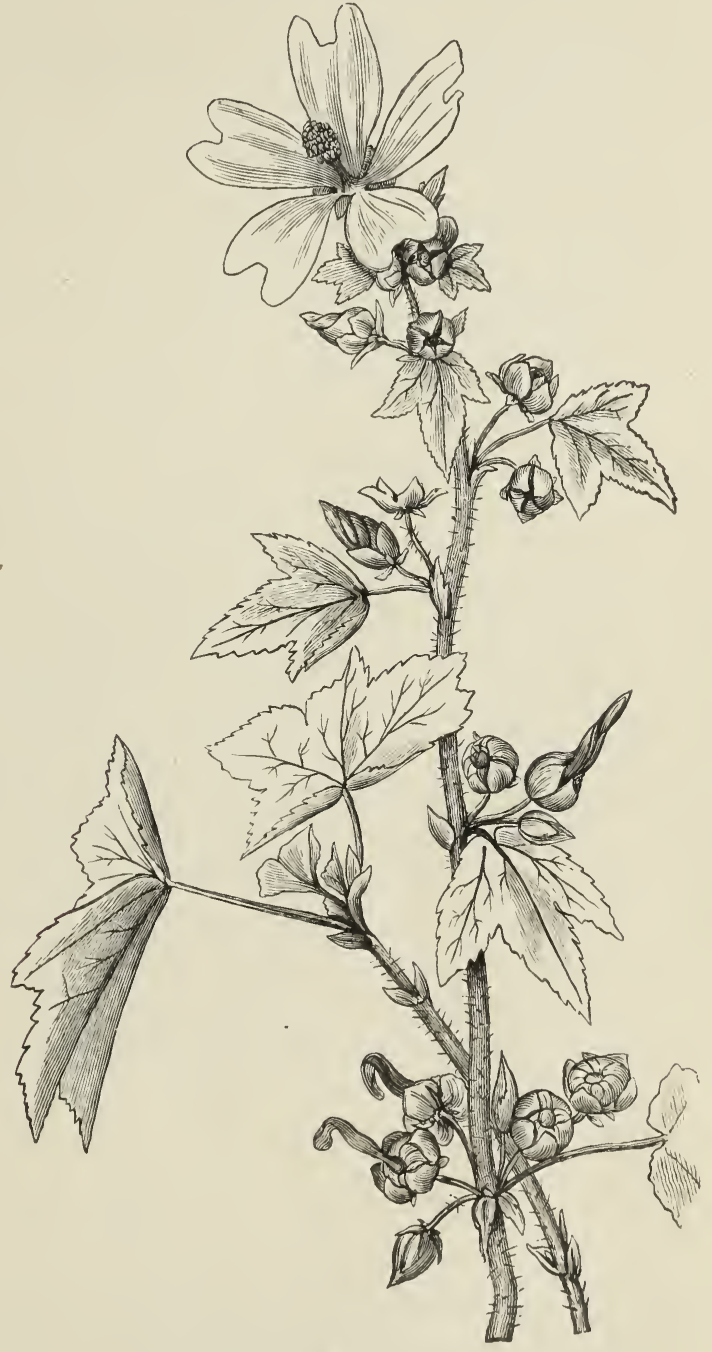

Fig. 29. - Mulva sylvestris.

IV.-VI. - Id. als 't voorg. w. 
Grilkieker, Grilkijker, m. - Nederland. - Viola tricolor L.: fr. Violette tricolore, vulg. Pensée sauvage; vl. Driekleurig Viooltje. - De bloemen (bijzonder bij de gekweekte var.) gelijken dikwijls op een menschenaangezicht, dat daar zoo grillig staat te kijken.

Gringellen, v. mv. - W.-Vl. - Id. als HeILIG-HART (Vl. Wk.).

Groensel, o. - Bijna overal. - Moeskruid tot roedsel der menschen; fr. légumes, herbes potagères. - Porei, kervel, zurkel, enz. zijn groensels.

Groffelier, m. - W.-V1. - Id. al Steenflier (Vl. Wk.).

Grondkruid. - Kerkom en omstr. - Ajuga reptans L.; fr. Bugle rampante; vl. Kruipend Senegroen. - Het grootste gedeelte van de plant is als tegen den grond geplakt: vandaar de naam.

Groot-Paternosterkruid, o. - Denderwindeke en omstr. - Malva sylvestris L.; fr. Manve sanvage; vl. Groote Maluwe (fig. 29). - De kinderen steken de vruchten der plant op eenen draad en vormen zoo eenen krans, den "Paternoster" ) gelijkend. - De Malva rotundifolia L.; $\mathrm{fr}$. Manve à feuilles rondes; vl. Rondbladige Maluwe, wordt aldus ook gebezigd, maar, dewijl de vruchten kleiner ziju, wordt zij Klein-Paternosterkruid genaamd.

Gruitbloempje. - Lillo en omstr. - Hottonia palustris L.; fr. Hottonie des marais; vl. Waterviolier. - Plant die in de gruit, d. i in de modder, het slijk der slooten wast.

Gruunkloten, v. $\mathrm{mr}$. - $\mathrm{O}_{\mathrm{p}}$ vele plaatsen, in Holl.Limburg. - Id. als Regenote(s) (Vl. Wk.). - Vglk. met het fr. Reine-Claude.- Deze pruimen zijn groen (= gruun) van kleur en hebben den vorm van eenen kloot (fr. boule, sphère).

\section{$\mathrm{H}$}

Haagboterbloem - W.-VI. - Id. als SpeEnkRUid (Vl. Wk.). - Groeit gewoonlijk aan den voet der hagen (fr. haies) en draagt gele bloemen gelijk vele boterbloemen (fr. renoncules). 
Haagranken, v. mv. - Herenthals en omstr. - Id. als HaGEWINDE ( $\mathrm{Vl}$. Wk.).

Haamspeen, v. - Maastricht en omstr. - Id. als HaAmspokx (Vl. Wk.).

Haarlem's-Klokkenspel, o. - Nederland. - Eene var. van Saxifraga granulata L.; fr. Saxifrage granulée; vl. Knollige Steenbreek, met gevulde, d. i. dubbele bloemen (fr. vulg. ¿̀ fleurs doubles).

Haarpioene, v. -- W.-Vl. - Paeonia tenuifolia L.; fr. Pivoine à fentilles menues; vl. Fijnbladige Pioen. - De biaderen zijn zoo fijn doorgesneden dat zij op haren (fr. cheveux) rrelijken.

Hagebinde, v. - Poperinghe, Steene (bij Oostende). Id. als HAGEWINDE (Vl. Wk.).

Hagel-en-zijn-Maat, v.-- W.-Vl.-Saxifiaga umbrosa L.; fr. Saxifrage des lieux ombrag'és; vulg. Désespoir du peintre; vl. Lommerlievende Steenbreke.

Hagelte, Agelte, v. - W.-Vl. - Id.als GAgel (Vl. Wk.). - "Het volk drinkt thee van Hagelte, zegt M. Samyn, om den (sic) koorts te genezen. De gedroogde Hagelte riekt eenigszins lijk de wortels van Rhabarber. Men gebruikt de Hagelte om aan het bier zekere bittere en dronkenmakende eigenschappen te geven en de hop te vervangen. De heidebewoners maken er ook bezems van. " - De twee bovenstaande volksn. zijn waarschijnlijk maar eene verb. van den vl. naam Gagel.

Hageriet, 0. - W.-V1. - Calamagrostis epigeios Roth; fr. Calamagrostide terrestre; vl. Aardsch Rietgras; vulg. Duinriet. - Deze grassoort, door hare gestalte, gelijkt op een Riet en rij groeit gewoonlijk tusschen struiken en hagen.

Halm, m. - I ${ }^{0}$ Bijna overal : Stengel (ler grassoorten, fr. chaume, tige des Graminées; $2^{\circ}$ te Beeringen : Holcus lanatus L.; fr. Houlque laineuse; vl. Wollig Zorgrgras; $3^{\circ}$ in W.-V1. Ammophila arenaria Link; fr. Ammophile lles sables; vulg. Oyat; vl. Zandgras. - Deze grassoort groeit in het duinzand, war het ook reel geplant wordt om het zand vastheid te geven. 
Halve-Frankenkruid. - Oultre (bij Ninove). - Lysimachia Nummularia L.; fr. Lysimaque Nummulaire; vl. Jodenkruid. - De bladeren zijn rond gelijk een muntstuk; vandaar ook de lat. naam Nummularia (nummus = muntstuk).

Handjesbloem. - Nederland. - Orchis latifolia L.; fr. Orchis à larges feuilles; vl. Breedbladig Standelkruid; ook IIandekenstiruid. - De onderaardsche knollen zijn handvormig. verdeeld.

Hanekam, m. - ${ }^{\circ}$ Te Lebbeke, Denderleeuw en omstr. : Monarda didyma $\mathrm{I}$.; fr. Monarde didyme. - De roode blociwijze der plant gelijkt aan een hanenkam. $-2^{\circ}$ In W.-Vl. : Cynosurus cristatus I.; fr. Crételle commune; Cynosure à crêtes, enz.; vl. Kamdragende Cynosurus; vulg. Kamgras. - Zooals al de roorgaande namen het genoeg aanduiden, gelijkt de bloeiwijze van deze grassoort op eenen hanekiam (fr. crête de coq). - Z. ook 't volg. w.

Hanekammen, m. mv. - Herenthals en omstr. - Id.als HANEPOOTEN (Vl. Wk.). - De bloemkroon is rood en doorgesneden gelijk een hanekam (fr. crête de coq).

Hanekammetjes. - Nederland. - Onobrychis viciaefolia Scop.; fr. Sainfoin à feuilles de vesce; vulg. Sainfoin, Esparcette; vl. Hanekamklaver. - Voor uitleg, z. de voorg. woorden.

Haneklauw, m. - Diest en omstr., Gheel, Westerloo. - Id. als Hanepooten (Vl. Wk.).

Haneklooten, m. mv. - W.-Vl. - Id. als Herterooze (Bijr.).

Haneklootjes, o. mv. - Nederland. - Id. als SPEeNKruid (V1. Wk.). - Het volk lieeft eenige gelijkenis gevonden tusschen de knotsvormige wortels dezer plant en haneklootjes of teelballen van den haan.

Hanenstat, m. - Conrsel en omstr. - Verb. van - steert of staart. - Natthecium ossifragum Huds.; fr. Narthécie des marais; vl. Moeras.Narthecium; vulg. Sipelgras. Het volk vindt dat de bloeiende plant(bladeren en bloemen te samengenomen) met een hanenstaart overeenkomt. 
Hanespoor, v. - Herenthals en omstr. - Id. als HANEPOOTEN (Vl. IVk.).

Hanetree, m. - Nederland. - Anagallis arvensis L.; fr. Mouron des champs; vl. Akker-Basterdmuur.

Hanevoet, m. - Nederland. - Algem. naam om liet geslacht Ranunculus L.; fr. Renoncule; vl. Ranonkel; Boterbloem te beteekenen.

Hangt-op-d'haag, v. - Lebbeke, Hendersem. - Id. als HofrANK (Vl. IVk.). - De plant heeft een fijnen, zwakken stengel die aan de hagen kileeft om zich recht te houden.

Harde-Koppen, m. mv. - W.-Vl. - Id. als IJZERKKUID (Bijv.). - De bloemhoo/djes (fr. capitules) dezer plant (Centaurea Jacea L.) zijn zeer hard.

Hard-Hoofden, o. mv. - IV.-VI. - Id. als 't voorg. w.

Harik, m. - IV.-V1. - Men zegt ook Harink, Herik, Herrik. - Id. als HARING (Vl. Wk.).

Harrenteer, m. - Prov. Limburg : op eenige plaatsen.

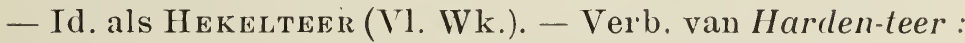
het hout is zeer hard. De uitgang teer is 'tzelfde als laar, leer; men vindt : notelaar en notelteer, mispelaar en mispelteer, enz. Als deze uitgangen ziju synoniem ran boom.

Haverbezie, v. - Bij Kiliaan, vindt men dit woord in den zin van Vaccinum Myrtillus L.; fr. Airelle Myrtille; vulg. Myrtille; vl. Mirlenbeziestruik.

Hazegès, o. - Zwijnaarde, Eeverghem, Eecke, SintDenijs-IVestrem. - Id. als Hazegers $2^{\circ}$ ) (Vl. Wk.).

Hazeklaver, m. - Mall, Sluizen en omstr. - Oxalis stricta L.; fr. Oxalide droite; vl. Rechtstandige Klaverzuring. - Men zegt dat de hazen op deze plant zeer verlekkerd zijn.

Hazemuil, v. - W.-VI. - Id. als HAzEBAKKESSEN (Vl. WTk.).

Hazengerwe, v. - Nederland.=Id. als GERF (Vl. Wk.).

Hazengras, o. $-\mathrm{I}^{0}$ In Nederland : id. als 't roorg. w.; $2^{\circ}$ te Denderwindeke en omstr. : Alopecurus agrestis L.; fr. Vulpin des champs; vl. Veld-Vossestaart; 30 te Tongeren en omstr. : verscheidene soorten van Agrostis I.; 
fr. Agrostide; vl. Struisgras. - Al deze planten, of groeien waar de hazen geerne hun verblijf houden, of zijn hoogstens goed ow door de hazen afgeknabbeld te worden.

Hazenkelver, v. - Nederland. - Id. als HAZENGERWE (Bijv.), waarvan dit w. maar eene rerb. is.

Hazenklaver, v. - Nederland. - Oxalis stricta L. en O. Acetosella L.; fr. Olaxide droite en O. Petite-Oseille; vl. Rechstandige en Gewone Klaverzuring. - Z. ook Hazeklaver (Bijv.).

Hazepootje, o - Nederland. - Trifolium arvense L.; fr. Trèfle des champs; vl. Veld-Klaver.

Hazetjok, m. - Oost-Roosebeke, Wielsbeke en omstr. - Z. Herterooze (Bijv.).

Heed, o. - Zwijnaarde, W.-V1. - Id. als Heide (Vl. Wk.), waarvan dit w. eene verb. is. - Eng. heath.

Heelblaadjes. - Nederland. - Pulicaria dysenterica Gärtn.; fr. Pulicaire dysentérique; vl. Vlooientruid; Heelkruid. - De bladeren werden eertijds in de heelkunde gebezigd tegen den bloedloop, (fr. dysentérie).

Heelblad. - Nederland. - Thalictrum flavum L.; fr. Pigamon jaune; Thalictre - ; vl. Gele Snelgroeier. Bij 't rolk wordt de plant nog gebruikt (bijzonder de wortel) als zuiverend heelmiddel.

Heemst, m, - Oost-Roosebeke en omstr.; Gheel, Westerloo. - Althaea officinalis L.; fr. Guimauve officinale; vl. Genees-Heemst (fig. ro). - Plant, gewoonlijk rond het heim of heem (fr ferme) gekweekt, roor hare genezende eigenschappen : randaar Heemst genoemd. - Z. ook Arteewortel (Vl. Wk.).

Heemstwortel, m. - Z. 't voorg. W. - 't Is de wortel die bijzonder in gebruik is.

Heerd, m. - Land van Aalst. - Vlasstengel; fr. : tige de Lin.

Heers, v. - Nederland. - Id. als DriJbLaD (Tl. Wk.).

Heet, bijv. - In $\mathrm{W} .-\mathrm{Vl}$. = vroeg rijp, vroegtijdig; ir. précoce, hâtif.

Heetegaal, v. - Nederland. - Ononis spinosa L.; fr. Bugrane épineuse; vl. Gedoornd Stalkruid. - Heete 
is waarschijnlijk eene verb. van Heed = Heide (z. hooger); fr. bruyère.

Heggesering, v. - Nederland. - Ligustrum vulgare L. ; fr. Troëne commun; vl. Gewoon Mondhout. - De bloemen lijken op die van de Sering (fr. Lilas) en de struik groeit in de hegegen of hagen.

Heidepluis, v. - Nederland. - Id. als Herplurskexs (Vl. Wk.) en dezelfde uitleg.

Heidensch-Wonderkruid. - Nederland. - Solidago Virgra-aurea L.: fr. Solidage Verge-d'or; vl. Guldenroede. - In den ouden tijd beweerde men dat dit kruid allerlej ziekten genas en het werd roor een waar Wonderkruid gehouden. Heden wordt het nog gebr. als waterafzettend, tegen de waterzucht.

Heinenteer, m. - Antwerpen en omstr.; de Kempen. Id. als Hekelteer ( $\mathrm{V} l$. Wk.). - Dient om te heinen fr. enclore) of heiningen (fr. clôtures, haies) te maken.

Heiningbessen, v. mv. - Nederland. - Id. als Fran$\operatorname{BOzE}(\mathrm{N})$ (Tl. Wk.). - Toor heining, z. 't voorg. W.

Heiratelen, m. mv. - Moll en omstr. - Pedicularis palustris L.; fr. Pédiculaire des marais; vl. MoerasKartelblad. - Groeit op vochtige heiden en lijkt aan Ratelen (Rhinanthus).

Heiroosje. - Nederland. - Antennaria dioica Gärtn ; fl. Antennaire diö̈que; vulg. Pied-de-chat; vl. Tweehuizige Kattepoot of Droogbloem. - De roodachtige bloemhoofdjes lijken op kleine roosjes en de plant groeit op drogen zand-en heigrond.

Helster, in. - IV.-Vl. - Id. als Hekeltekr (V1. Wk.).

Hemdeknopjes, o. $1 \mathrm{~m}$. - W.-Vl. - Id. als WrtteKNop.( $\mathrm{Tl}$. Wk.). -- Uitleg is onnoodig.

Hemdsknopskes, o. mv. - Beeringen en omstr. - Id. als Reinetarex (Vl. Wk.). - De bloemhoofdjes lijken op hemdstinopjes.

Hemelgrond, m. - W.-Vl. - Teelaarde; fr. terreau, terre végétale, humus. - Hemel wijst hier terug op de goede kwaliteit van dien grond. 
Hemst, m. - IT.-Vl. en Prov. Brabant. - Id. als HeEmst (Bijr.).

Hennepik, v. - Nederland. - Poa pratensis L. en P. trivialis I.; fr. Paturin des prés en P. commun; vl. Weide-Beemdgras en Ruwachtig. B. - De hennen piktien geerne de bladeren dezer grassoorten.

Hepelbraam, v.- IV.- Vl.- Id. als HifpeiraAm (Bijr.).

Herdersbeurze, v. - Antwerpen en omstr. - Id. als BeCRzEKENSKRUID, I ${ }^{\mathrm{o}}$ ( ( $\mathrm{T}$. Wk.).

Herel, Heerl, m. - W.-Vl. - Vlasstengel, groen of droog; fr. tige de Lin.

Herf. - Pepinghen (bij Halle). - Id. als Gerf (V1. Wk.). - Met de geperste bladeren strijkt men het hoofd der jonge kinderen om er de pellen (erf of herf geheeten) te doen verdwijnen ( $T$. Cousinne).

Herik, Hering, v. - Nederland. - Id. als Haring (Vl. Wk.).

Herk, v. - Nederland. - Id. als 't voorg. w.

Hernlaar, m. - W.Vl. - Id. als Hekelteer (Vl. Wk.).

Herntril, m. - W.-Vl. - Id. als 't voorg. w.

Hertebaard, Ertebaard, 11. - W.-Vl. - Ornithopus perpusillus L.; fr. Ornithope délicat; vulg. Pied-d'oiseau ; vl. Teeder Vogelpootje.

Herterooze, Hertrooze, v. - IV.-Vl. - Id. als ViJfVingerkruid ( Vl. Wk.). — “ De Hertrooze wordt bij 't volk geprezen als goede medecijne voor de maag ", zegt M. Samyn. - De bloem lijkt op een geel roosje, en daar zij als weldoend gehouden wordt voor de maag of het hert ('tgeen op 'tzelfde uitkomt voor het volk), werd zij herterooze genaamd.

Hertrik, m. - Leuven en omstr. - Id. als HedDERIK (Vl. Wk.).

Heul, m. - Denderwindeke en omstr. Papaver somniferum L.; fr. Pavot somnifère; vl. Slaapwekkende Maankop (fig. 3o).-Heul is 'tzelfde als hol en duidt op de groote, holle Fig. 30-Zuadbol vruchten der plant.

Heulbol, m. - Nederland. - Id. als 't voorg. w' 
Heulenteul, m. - Hier en daar in Prov. Limburg. Verb. van Holenteer (z. Bijv.)

Heulkoppen, m. mr. - Antwerpen en omstr. - Id. als Heulbol (Bijv.).

Heultoppen, in. mv. - Berthem en omstr. - Id. als 't voorg. w'.

Heuning. -- Z. Howing (Bijv.).

Heupelbramen, V. mv. - Zwijnaarde en omstr. - Id. als HuPPELBRAMEx (Vl. Wk.).

Hiefte, v. - W.-Vl. - Z. IEFTE (Bijv.).

Hiep(e), v. - W.-VI. - Id. als GiJBE (Bijv.).

Hiet, v. - Nederland. - Id. als HeEd (Bijv.). - Verb. van Heide; Calluna vulgaris Salisb.; fr. Callune commune; vl. Struikheide.

Hiethekel, m. - Nederland. - Genista anglica L.; fr. Genêt d'Angleterre; vl. Stekelbrem. - Hiet = hier heide, fr. bruyère, $\mathrm{d}$. i. eene uitgestrektheid lands met heideplanten bewassen; hekel, zinspeelt op de punten of doorns der plant.

Himst, m. - W.-Vl. - Id. als Heemst (Bijv.).

Hippebraam, v. - W.-V1. - Rosa canina I.; fr. Rose de chien, vulg. Églantier; vl.Hondsroos, Egelantier, eng. Heptree. - Het eng. hep of hip bet. Egelantierbezie, fr.gratte-cul.-Vglk. Hepelbraam, Huppelbraam, Hoppelbraam, enz., die allen dezelfde bet. hebben (fig. I 7 ).

Hippen(e), Ippen(e), o. - IV-VTl. - De vruchtbol van het vlas; fr. fruit du Lin.

Hirelir, m. - Zwijnaarde en omstr. - Id. als HERrELEER ( $\mathrm{Tl}$. Wk.).

Hirs, v. - Nederland. - Id. als Heers (Bijr.).

Hittel, m. - In 't Brugsche, wordt ditw. gebruikt voor Netel, fr. Ortie. - Dit ware de echte vorm, indien het w. afstamde van heet, hitte, gelijk het lat. Urtica vau 't werkw. urere $=$ branden.

Hivernagie, v. - Bij de landbouwers in $\mathrm{W}^{-} \cdot \mathrm{V} 1 .=$ mengeling van Rogge en Vitsen, dienende tot voeder van het vee; fr. hivernage. 
Hocht, m. - Lubbeek en in 't Hageland. - Een struik, 't zij van houtgewas, 't zij van een kruid (fr. touffe, arbrisseau). b. v. een aardappelstruik, een heesterstruik, is een hocht. - In W.-Vl., zegt men Hut, in denzelfden zin (z. Tl. ITk.).

Hoedje, o. - Denderwindeke en omstr. - Vinca minor L.; fr. Pervenche à petites feuilles; rl. Kleine Maagdepalm. - De bloemkroon heeft den vorm van een ongekeerd hoedje.

Hoenderhaag, v. - Denderwindeke, ()ultre (bij Ninove), Lebbeke, Denderleeuw. - Id. als OnderhaAg (Tl. Wk.), waarvau deze naam eene verb. is.

Hoephout, o. - Nederland. - Salix amygdalina L.; ir. Saule à feuilles d'Amandier; vulg. Osier brun; v1. Amandelbladige Wilg. - Het hout dient om hoepen (fr. cerceaux) te maken.

Hofgars, o. - Z. Hofgras (Bijv.).

Hofgras, o. - W.-Tl. en op vele andere plaatsen. Poa annua L.; fr. Paturin annuel; vl. Klein Beemdgras. - Dit gras komt veel in de hoven en bijzonder in de lanen (fr. allées) die niet wel onderhouden worden.

Hofklaver, v. - Herentlıals en omstr. - Id. als HAzEKLAver ( Vl. Wk.). - De planten ziju drijbladig als Klaver en komen veel in de hoven.

Hofkruid, o. - Meerbeke (bij Ninove). - Id. als Schijtkruid (Tr. ITk.). Kwaud kruid dat zeer overvloedig in de hoven te vinden is.

Hofzweerd. o. - Oostham en omstr. - Verscheidene soorten van Gladiolus L.; fr. Glaïeul; vl. Zwaardlisch, maar bijzonder de Gladiolus gandavensis Tan Houtte, die 't meest in de hoven ge̊kweekt wordt. De bladeren dezer planten lijken op een zweerd.

Hokkeldemokkel, m. - W.-V1. - Zoo noemt men in zekere streken, zegt M. Samyn, den Geranium sanguineum L.; fr. Géranium sanguin; vl. Bloedroode Ooievaarsbek.

Holde, bijv. - W.-Tl. - Waar een hol in is; fr. creux. - De stroohalmen zijn holde (Kruidw.). 
Holderteer, m. - Nederland. - Id. als Holenteer (Bijv.).

Holeerze, Holleerze, v. - W.-Vl. - Terscheidene soorten van Primula L.; fr. Primevère; v1. Sleutelbloem. - De saangegroeide kelkblaadjes (fr. sépales) dezer planten vormen eene buis of laars (ook soms leers genaamd, fr. botte), die'tonderste gedeelte der bloemkroon o m geeft. Deze laarsis bijnaaltijd trechter- of buikvormig (bijzonder na den bloei), zono dat zij er als hol (fr.creıx) uitziet: vandaar Holleerze (fig. 3i).

Holen teer, $m$. - Maastricht en omstr., Nederland. - Id. als Heulenteer ( $\mathrm{V}$. Wk.), en dezelfde uitleg.

Hollandsche Ajuinen, III. inr. -- Denderwindeke en omstr. - Hyacinthus orientalis L.: fr. Jacinthe d'Orient ; vl. Hiacint. - Boldra-

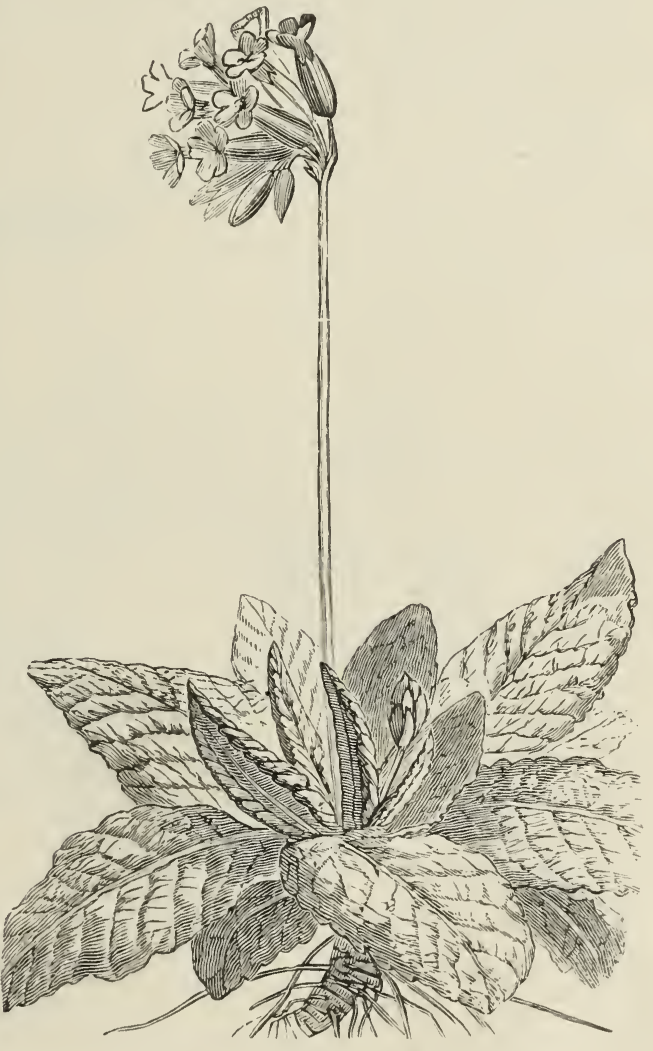

Fig 31. - Primula officinalis. gende planten ( $\mathrm{fr}$. plantes à bulbes), gelijk de Ajuinen, en veel gekweekt in Holland, van war zij naar België overhandigd worden.

Hollebos, m. - Zwijnaarde en omstr. - Papaver somni-

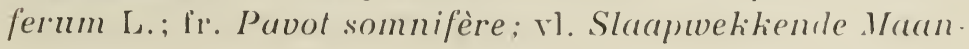


kop. - Bos = bus (fr. boite), zinspelende op den vorm der vrucht. Holle kan aanzien worden of als eene verb. van olie (fr. huile) : de zaden zijn oliegevend, of als een bijv. (fr. creux): de vruchten of bossen zijn zeer buikvormig en grootendeels hol (fig. 3o).

Holk, m. - W.-Vl. - Holcus lanatus L.; fr. Houlque laineuse; vl. Wollig Zorggras en H. mollis L.; fr. H. molle; vl. Zacht Z. - Holk is eene verb. van den lat. of van den fr. naam der plant.

Holleerze, v. - Z. Holeerze (Bijv.).

Hollijs, m. Soort van Appel, in O.-Vl. zeer gemeen (Alg. $\mathrm{Vl}$. Idiot.). - Misschien verb. van hol-huis : deze appel tamelijk hol zijnde. - Vglk. R A M M E L È R ( $\mathrm{V}$ l. Wk.).

Hondebeien, v. mv. - Nederland. - Vruchten (en ook de struik) van Rhamnus Frangula L. ; fr. Nerprun Bourdaine; vl. Pijlspork, Pijlhout, Stinkhout, enz. - De naam

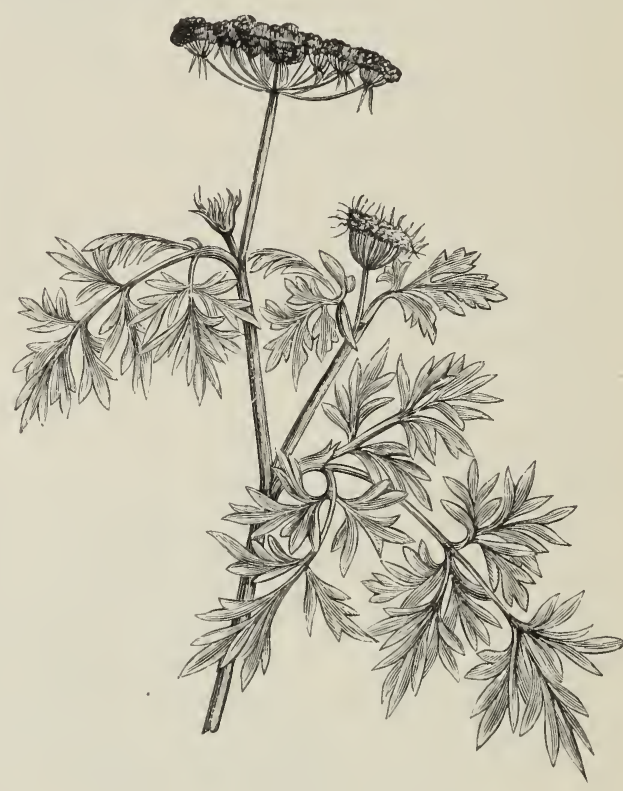

Fig. 32. - Athusa Cynapium.

van Hondebeien (fr. baies de chien) beduidt de weinige waarde dezer vruchten.

Hondebeishout. - Nederland. - Id. als Elfrank(Bijv.). Hondekervel, m. - IV.-Vl. - Ethusa Cynapium L.; fr. Éthuse Petite-Ciguë; vl. Hondspeterselie. - Eene vergiftige plant, die op kervel en op peterselie gelijkt en dikwijls in de moeshoven voorkomt (fig. 32). - Heet ook Dulle Kervel, enz. (z. Vl. Wk.). 
Hondeklaar. - Nederland. - Id. als Hondeherf (VI. Wk.). - Klaar = samentrekking van Klaver.

Hondelierhout. - Zwijnaarde, Eecke, Seererghem en omstr. - Id. als Hondeleere(N) (Vl. Wk.).

Hondenkruid. - Nederland. - Mentha aquatica L.; fr. Menthe aquatique; vl. Watermunt.

Hondsbes, v. - Nederland. - $\mathrm{I}^{0}$ Vaccinium VitisIdaea L.; fr. Lirelle ponctuée ou du Mont-Ida; vl. Roode Kraakbes; $-2^{\circ}$ Solanum nigrum L.; fr. Morelle noire; vl. Zwvarte Nachtschade (fig. 2).

Hondsbloem. - Nederland. - Id. als Pissebloen (Vl. IVk.).

Hondsbossen, m. mr. - Nederland. - Deschampsia caespitosa P. Beauv.; fr. Deschampsie gazonnante: v1. Veen-Boendergras. - Deze grassoort vormt groote bossen (fr. touffes), waartegen de honden geerne blijven staau.

Hondslook, o. - Nederland.- Id. als PisP(w)orr (Tl. WVk.).

Hondsnetel, r.-Nederland. - Lamium album L.; fr. Lamier blanc; vulg. Ortie blanche; vl. Witte Doove-Netel (fig. 33).

Hondspriem, m. -W.-VI. - Orobanche minor Sutt.; fr. Orobanche mineure; vl. Kleine Bremracup. - De zuigtepels (fr. sucoirs) dezer woeker-

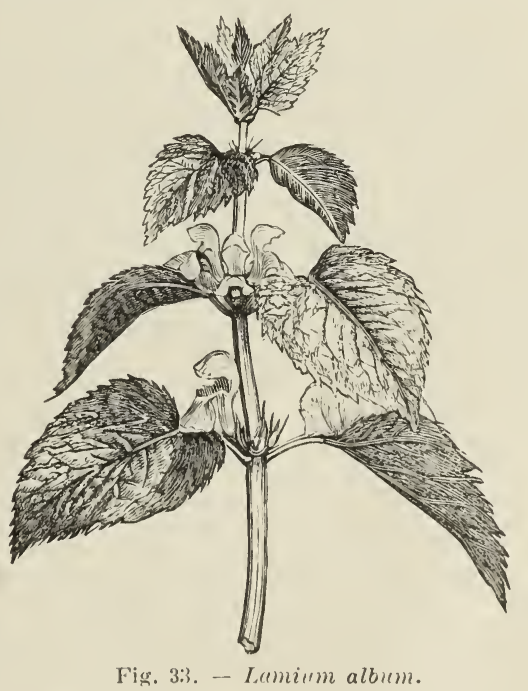

Fig. 33. - Lamium album. plant dringen in de klaverwortels lijk een priem (fr. poincorl).

Hondstootjes, o. mv. - Oost-Roosebeke en omstr. Id. als Kalvertotex (Vl. Wk.). - Tootjes = synoniem van muilljes. 
Hondstoten. - Id. als 't voorg. w.

Hondsvinkel, m. - Wareghem, Cruyshautem en omstr. - Verb. van - venkel. - Id. als Hondsdille (Vl. WVk.).

Honger, m. - Welle, Oultre (bij Ninove), Denderleeuw, Lebbeke, Iddergem. - Id. als Hondspriem (Bijv.). - De Bremrapen zijn woekerplanten : vandaar de naam van Honger : hij wijst op de vernielingen door deze plant in de klavers angericht.

Honger-in-de-Klaver, m. - Denderwindeke en omstr. - Id. als 't voorg. w. - De boer verkeert hier in 't gedacht dat de Honger maar op de klaver valt, wanneer de grond uiterst mager of uitgehongerd is.

Honig, m. - Z. Honing (Bijv.)

Honigbloem. - Nederland. - Knantia arvensis Coult.; fr. Knautie des champs; vulg. Scabieuse des champs ; v1. Akker-Knautia. - De bloem wordt veel door de bieën bezocht, zijnde rijk in honig.

Honing (Honig). - Uitspr. Heuning; soms zegt men ook Neuning. - Poperinghe en omstr. - Deze naam beduidt twee kryptogamische ziekten der Hop (fr. Houblon). Men onderscheidt : $\mathrm{I}^{0}$ den zwarten Honing; eene zwarte Schimmelplant, Cladosporium Fumago Link genaumd, en $2^{\circ}$ den witten Honing; eene witte Schimmelplant die, in de Kruidkunde, den naam van Erysiphe Humuli Dr. draagt.

Honnebloem. - Nederland. - Id. als Pissebloem (VI. Wk.).-Honnebloem = verb. van Hondenbloem, naam die, in Nederland, ook aan dezelfde plant gegeven wordt.

Hooibloem. - IV.-V1. - Lychnis Flos-Cuculi L.; fr. Lychnide Fleur-de-Coucou; vl. Gemeene Koekoeksbloem. - Groeit in beemden en weiden, en is in bloem wanneer het rijpende gras voor hooi afgemaaid wordt.

Hoos, Hoze, v. - W.-Vl. - Fr. Spathe; vl. Bloeischeede.

Hoosblad. - Nederland. - Id. als Hoevenblarex (Vl. Wk.).

Horde, v. - Nederland. - Men zegt ook: Gele Horde. - Rhinanthus minor Ehrh.; fr. Rhinanthe mineur; vl. Kleine Ratelen; K. Ratelaar. 
Huinentuin, m. - Verb. uitspr. van Heulenteer (z. Vl. Wk.).

Huisduif, Huisduive, v. - W.-V1. - Naam eener gekweekte plant: Cineraria L.; fr. Cinéraire; vl. Aschkruid.

Huisloof, o. - Nederland. - Id.als Huislook (Vl. Wk.).

Hul, m. - W.-Vl. - Uitstekende groep van bijeen staande voorwerpen; fr. groupe, touffe. - Er groeit hier en daal een hul gers (Kruidw.).

Hunnebessen, v. mv. - Nederland. - Id. als HinneBEZEN (Vl. Wk.).

Hunter, m. - In 't Hageland. - Waarschijnlijk eene verb. van Heinenteer (Heinteer, Hunter); z. Heinente er (Bijv.) en Hekelteer (Vl. Wk.).

Huppelijn. - Denderwindeke en ornstr. - Id. als UPPeliJn, EbBeliJn, enz. (Vl. Wk.).

Hut, m. - W.-Vl. - Struik; een groep van bladeren, stengels of takken die aan den grond uit denzelfden stronk of wortel spruiten of schijnen te spruiten (Kruidw.). Vandaar Hulteboom, Hutlegars, Huttegras, enz.

Huttel, m. - W.-Vl. - Id. als 't voorg. w. - Een huttel netels; een huttel salade.

Huulsblad. - Nederland. - Id. als Hoosblad (Bijv.).

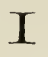

Iefte, v. - Zwijnaarde en omst. - Id. als IJFTE (VT. Wk.) - Eng. Ivy. - De Engelsche onderscheiden den Ground-ivy (fr. Lierre terrestre) en den Tree-ivy; (fr. Lierre grimpant; vl. Boom-Iefte).- In W.-Vl. spreekt men ook van de Gebloemde Iefte : d. i. Pelargonium hederaefolium Hortul.; fr. Pélargone à feuilles de Lierre; vl. Ooievaarsnavel met Klimopbladeren. - Ten onrechte wordt deze plant dikwijls Geranium geheeten. - Zooals de naam het genoeg aanduidt, lijkt deze gekweekte plant op de Iefte (Klimop), bijzonder door deu vorm der bla- 
deren; daarenboven draagt zij veel schoone, rooskleurige bloemen; vandaar : Gebloemde Iefte geheeten. De bloemen der gewone Iefte zijn klein, zonder kleur (groen) en gansch onbeduidend.

Iersgat, o. - Z. IsGAT (Bijv.).

Ifte, v. - Nederland. - Id. als 't volg. w.

IJfte, r. - W.-Vl. - Id. als Iefte (Bijv.).

IJzerkoppen, m. mv. - Poperinghe en omstr. - Id. als Borstels (Vl. Wk.). - Elders, in W.-Vl., zegt men nog : Hard-Hoofden, Harde-Koppen (z.Bijv.), Hondskoppen, enz. - De stengels en de bloemhoofdjes (fr. capitules) dezer plant zijn ijzer-hard; deze laatste hebben daarenboven den vorm van ronde koppen.

IJzerkruid. - W.-Vl. - Id. als 't voorg. w.

IJzerling, m. - W.-Vl. - Winterappel van gemeene grootte, met de eene kaak geel en de andere roodachtig (Kruidw.).

IJzermaal, o. - W.-Vl. - Wordt gezeid van zekere rosse (roestkleurige) vlekken, die somtijds binnen in de aardappels te zien zijn. Zoo zegt men : de aardappels zijn niet goed waar dat er ijzermaal in is. - Vglk. IJzermoL, in ons Vl. Wk. - Wij zullen er bijroegen dat het MoerasSpierkruid (waarvan daar spraak is) bijna altijd rosse of roestkleurige vlekken op zijne bladeren draagt: dit zou dus een andere uitleg van den naam IJzermol kunnen zijn.

Ingroen, o. - W.-Vl. - Id. als Senegroen (Bijv.).

Inker, $m$. - W.-VI. - Het smalle onderdeel van een kroonblad (fr. pétale), in 't fr. onglet, tegenover het breede bovendeel, dat de lepel (fr. limbe), heet.

Ippekruid. - Zwijnaarde en omstr. - Trifolium procumbens L.; fr. Trèfle couché; vl. Liggende Klaver. Ippens en Hippens beduiden, in W.-Vl. en O.-Vl., de vlasbollekens waar het zaad in zit (fr. péricarpes du Lin). De bloeiwijze van de Liggende Kl. heeft den vorm dezer vlasbollekens; vandaar Ippekruid.

Ippellijn. - Denderleeuw, Lebbeke en omstr. - Id. als 
Appelitun, Eppellijn, UppelliJn, enz. (Vl. Wk.). - Voor uitleg, z. vooral EBBELIJN (Vl. Wk.).

Ippens, o. mv. - W.-Vl. - Voor uitleg, z. IPpekruid (Bijv.). - Z. ook Knippers (Bijv.).

Isgat, o. - Zwijnaarde, Eecke, Seeverghem, SintDenijs.Westrem en omstr. - Het onderste gedeelte van een boom waar de wortels aan vast zijn (fr. souche). Trapsgewijze verbasterd, zegt Schuermans (Alg. Vl. Idiot., bl. 206) : irsgat, iers -, eers —, aarsgat. - In Brabant, zegt men eersorat. - In Zuid. Belg.-Limb., zegt men : de kont (van een boom).

Ispel, m. - W.-Vl. - Z. 't volg. w.

Isper, m. - W.-V1. - Wilde Abeel, taai van hout, waar inen meubels van maakt (Kruidw.).

Israëliet, m. - W.-Vl. - Hedysarum coronarium L.; fr. Sainfoin à bouquets; vl. Tuilvormige Klavervits. Het volk heeft, in de bloem, eene gelijkenis gezien met den vorm der wel bekende Israëlieten - of Jodenueuzen.

Ive. - Nederland. - Id. als Ifgroeneboom (Vl. Wk.). $-I v e=$ verb. van den fr. naam : If.

\section{J}

Jaag-den-Duivel, v. - Nederland. - Hypericum perforatum L.; fr. Millepertuis perforé; vl. Doorboord Hertshooi; Sint-Janskruid (fig. 28). - Het volk veronderstelt dat de plant dienen kan om kwade geesten te verjagen.

Jacobsladdertje. - Nederland. - Polygonatum multiflorum All.; fr. Polygonatum officinal; vulg. Sceau-deSalomon; vl. Gewone Salomonszegel. - De stengel der plant, met zijne regelmatige wederzijds gerangschikte bladeren, lijkt niet slecht op een laddertje (fr. petite échelle).

Jansuien (Sint-). - Z. SinT-J ANs U IEN (Bijv.).

Jantje-Korvendraagster, v. - Nederland. - Ipomaea purpurea Link.; fr. Ipomée pourpre; vl. Purperwinde. - 
De plant klimt langs de staken, enz.; de bloemen zijn trechtervormig en lijken niet slecht op rugkorfjes (fr. hottes), welke de plant naar omhoog zoude dragen.

Jedveld, o. - Pepinghen (bij Halle). - Id. als Je Dveri. (Vl. Wk.).

Jeruzalemsche Artisjok, m. - Nederland. - Helianthas tuberosus L.; fr. Topinambour; vl. Aardpeer.-De bloemhoofdjes (fr. capitules) lijken op die van den Artisjok (fr. Artichant).

Jeukkruid, o. - Nederland. - Ranunculus sceleratus L.; fr. Renoncule scélérate; vl. Blaartrekkende Ranonkel. - De blaartrekkende eigenschap der plant is ook oorzaak van hetjeuken (fr. démangeaisons), dat natuurlijk volgt.

Jezusgras, o. - Nederland. - Polygonum lapathifolium L.; fr. Renouée à feuilles de Patience; rl. Zurkelbladige Duizendknoop.

Jichtkruid. - W.-Vl. - Id. als VLINDERKRUid (Bijv.). - Zooals de lat. en de fr. namen het ook aanduiden, is de plant gekend als heelmiddel tegen de jicht ( $\mathrm{r}$. la goutte).

Jodenkers, v. - Lier en omstr. - Id. als KRIEKsKeNin.'THEMD (Vl. Wk.). - De vrucht lijkt op eene kers ( $r$. cerise), maar schijnt geen vertrouwen waardig, zooals de Joden; vandaar Jodenkers.

Jongens-en-Meisjes. - Lebbeke en omstr. - Id. als LoNGERKRUID ( $\mathrm{T}$ l. W'k.). - Zinspeling op de twee kleuren der bloemen : rood en blauwachtig.

Jongens-zonder-liefde, m. mv. - Denderleeuw, Hekelgem. - Id. als Bevende Minne (Vl. W'k.). - Zinspeling op degene die veel uiterlijk beslag maken, marniet rechtzinnig beminnen. Deze grasplant draagt kleine hartrormige aartjes, die bijna altijd in beweging zijn. Haar fr. volksn. = amourette.

Jonkers, m. mv. - Lebbeke en omstr. - Id. als JoNkERKE(N)s (Vl. Wk.).

Jonkertjes, o. mv. - W.-VI. - Id. als 't voorg. w.

Jope, r. - W.-Vl. - Vrucht vall de Hondsroos 
(z. Vl. Wk.), fr. vulg. gratte-cul. - In W.-Vl. zegt men ook Klokike.

Judasbeurze, v. - W.-VI. - Id. als BuzzeKE(N)s (Vl. Wk.), naam die eene verb. van Beurzekens is.

Judasborze, v. - IV.Vl. - Id. als 't voor'g. W.

Jufferschoenen, m. mv. - Nederland. - Algem. naam gegeven aan 't geslacht Lotus L.; fr. Lotier; vl. Rolklaver. - De bloemkroon van al deze soorten heeft den vorm van een fijn Jufferschoentje.

Jukhout, o. - Nederland. - Carpinus Betulus L.; fr. Charme commun; vl. Haagbeuk. - Het hout, zeer hard en taai, past allerbest om jukken (fr. des jougs) te vervaardigen.

\section{K}

Kaaf. - Z. KAF (Bijv.).

Kaakstaal, in. - W.-Vl. - Id. als HARING (VI. Wk.). Kaamst, II. - W. - V1. - Id. als KEMP (Vl. Wk.).

Kaarde, v. - Nederland. - Id. als Aalstekels (Bijv.). - Het w. Kaarde wijst ook terug op de stekels der plant, die op de tauden eener kaarde (fr. carde) lijken.

Kaardekruid. - Nederland. - Dipsacus sylvestris Mill.: fr. Cardère sauvage; vl. Wilde Kaardebol. - Voor uitleg, z. 't voorg. w.

Kaarn, $11 .-$ W.-Vl. - Id. als Hekelteer (Vl. Wk.).

Kaarsjes. - Nederland. - I l. als Pissebloem (V1. WVk.). - De lange, rechte vruchtsteel, boven met witte pluimtjes bekroond, lieeft 't gedacht van kaarsjes doen ontstaan.

Kaasbloem. - W.-V1. - Id. als Plomper (V1. Wk.). Uitspr. - blomme. - Waterplanten met groote bladeren, waarop men voortijds wel boter en kaas leide, voor de frischheid (Kruidw.). Vandaar Kaasbloem.

Kaasjesbloem. - Nederland. - Algem. naam om 't geslacht Malva L.; fr. Mauve; vl. Kaaskeskruid aan te duiden. 
Kabasjeskruid. - Denderwindeke en omstr. - Id. als Heilig Hert (Vl. Wk.). - De bloemen lijken eenigzins op kleine kabassen.

Kaboutje, o. - W.-V1. - Fr. cupule. De vruchten van den eik zitten in een kaboutje.

Kadik, m. - W.-Vl. - Verb. van't lat. Radix = wortel. - Het volk noemt aldus 't geen, bij den apotheker, Radix angelica voor opschrift draagt.

Kaf, o. in V1. - Men zegt dikwijls Kef. - Zwijnaarde, Eecke, Seeverghem en omstr. - In Belg.-Limb. is het w. vrouwelijk en wordt eerder kaaf uitgespr.-De schubbetjes of blaadjes die de graankorrels van Haver, Tarwe, Garst, enz., tot omhulsel dienen alvorens deze graangewassen uitgedorschen worden; fr. glumes en glumelles des Graminées (fig. 34); in de gewone spraak zegt men ook balles.

Kaffieboonekruid. - W.-VI. - Id. als Koffieboontues (Vl. Wk.) en dezelfde uitleg.

Kake, m. - Men gebr. meest het mv. Katien.- W.-Vl.- Id. als KAAKSTAAL (Bijv.).

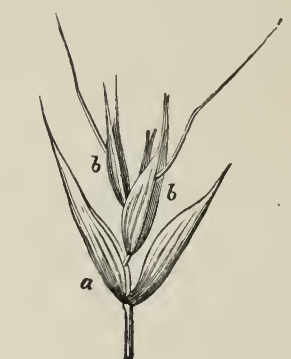

Fig. 34.- Aartje (fr. épillet) van Haver. - $a$. Kafblaadje of kelkkafje (fr. glume); $-b$. Klepblaadjes of kroonkafjes (fr. glumelles).

Kalebas, v. - Nederland. - Cucurbita Pepo L.; fr. Courge Pépon; Citronille iroquoise, Calebasse; vl. Kalebas.

Kalfsnuit, m. - Nederland. - Antirrhinum Orontium L.; fr. Muflier rubicond; vl. Rood Leeuwenmuiltje. - De bloemkroon, door haren vorm, heeft iets weg van een kalfsnuit (fr. museau de veau).

Kalle, v.- W.-Vl.- Eene gekweekte plant, die eertijds Calla aethiopica heette (vandaar Kalle, door verb.) en die nu meer den naam van Richardia draagt.

Kallemoei, v. - W.-Vl. - De bloemen der Plompen (z. Vl. Wk.).

Kalm, m.; Kalmus, m. - W.-V1. - Id. àls Kalmoes (Vl. Wk.). 
Kalmoes, m. - Id. als 't voorg. w.

Kalmus, m. - W.-Vl. - Z. de twee voorg. woorden.

Kalverhanke, v. - W.-Vl. - Soort van grooten zomer.appel, rood en bleek, peervormig gelijk de Renetting, (fr. Reinette) (Kruidw.) - In 't Brugsche, Anke, Hanke = schinkel, schenkel, fr. gigot. - Het peervormige uiterlijke van dien Appel heeft aan eene kalverhanke doen denken.

Kalvertong, v. - Z Wijnaarde en oustr. - Id. als A RIKEL en BAKBLoEM (Vl. Wk.). - De bladeren zijn min of meer tong'vormig.

Kalvertongblaren. - Herdersem, Lebbeke, Denderleeuw en omstr. - Id. als KaLverblaren (Vl. Wk.).

Kamerbloeme. - W.-V1. - Spiraea Ulmaria L.; fr. Spirée Reine-des-prés; vl. Moeras-Spierkruid. - De thee van Kamerbloeme is goed tegen de waterzucht (fr. hydropisie).

Kamerkruid. - W.-Vl. - Id. als't voorg. w.

Kamermille, v. - W.-Vl. - Id. als Hondsdille (V1. Wk.). - Deze naam is eene verb. van 't fr. Camomille. Voor uitleg, z. HondsDille (Vl. Wk.).

Kamille, v. - Bij de landbouwers, in $\mathrm{W}$.- Tl. = Camelina sativa Crantz.; fr. Cameline cultivée; vl. Gekweekt Aardvlas; G. Vlasdotter. - Wordt gekweekt voor het zaad dat olie oplevert.

Kammekensblad. - Lillo en omstr. - Potentilla Anserina L.; fr. Potentille Ansérine; vl. Zilverschoone Ganzerik. - Zoo genaand om den bladvorm : deze is gevind en op een kam gelijkend.

Kammekensgras. - W.-V1. - De aar dezer grassoort gelijkt op eenen lianekam; vandaar ook IIanekam genoemd. - Cynosurus cristatus I.; fr. Cynosure i crêtes; vulg. Crètelle; vl. Kandragende Cýnosurus ; vulg. Kamgras.

Kammeke(n)skruid. - Weert (bij Puers). - Scandix Pecten-Veneris L.; fr. Scandix Peigne.de-Vénus ; vl. Naaldenkervel. - De lange, naaldvormige en kort bij malkaar staande vruchten vormen als een kam (fr. peigne); vandaar ook de fr. en de lat. naam der plant. 
Kamomillebloem. - Denderwindeke en omstr. - Eene var. van Anthemis nobilis $\mathrm{L}$.; fr. Anthémide noble; vulg. Camomille romaine, die in de tuinen gekweekt wordt.

Kampane. - Z. AxE - (Bijv.).

Kanariekruid - Nederland. - Senecio vulgaris L.; fr. Seneçon commun; vl. Gemeen Kruiskruid. - De kanarievogels zijn zeer verlekkerd op het zaad.

Kaneelingen, m. mv. - Thielt en omstr., Oost-Roosebeke. - Id. als Parinnen (Bijv.).

Kanker, m. - IV.VI. - Papaver Rhoeas L.; fr. Coquelicot; rl. Klaproos, Kolbloem. - Eens in de akkers gevestigd, neemt de plant toe, gelijk de kanker, zegt men.

Kankerbloem. - Nederland. - $\mathbf{I}^{\circ}$ Nuphar luteum Sm.; fr. Nuphar jaune; vl. Gele Plomp. - Eens in de vijvers, enz. gevestigd, verspreidt de plant zich gelijk de kanker, bij middel harer talrijke wortelstokken. - $2^{\circ}$ Ranunculus sceleratus L.; fr. Renoncule scélérate; vl. Blaartrekkende Ranonkel of Boterbloem. - De roode blaren die de plant veroorzaakt, lijken niet slecht op kankerwonden, of, volgens de meening van 't rolk, zouden kankerwonden kumnen worden.

Kanneboenders, m. mv. - Nederland. - Typha L.; fr. Massette; vl. Lischdod, in 't algem.; maar wordt bijzonder gezegd van den T. latifolia L.; fr. Massette à larges fenilles; vl. Breedbladige Lischdod. - De stengel, met de rijpe vruchten er aan, gelijkt op eenen kanonborstel; fr. écoluvillon; vandaar ook de naam kanonpoetsers (z. verder). - Boender $=$ fr. frottoir, een werktuig om holle voorwerpen van binnen te kuischen; kan = fr. canette, cruche. - Misschien is de naam maar eene verb. van kanonboenders, synoniem van kanonpoetsers, enz. (z. hierna), namen die in vele plaatsen in zwang zijn.

Kanonborsels, m. mv. - Verb. van - borstels. - Zwijnaarde en omstr. - Z. 't volg. w. (Bijv.).

Kanonkuischers, m. mv. - Zwijnaarde en omstr. Eene gekweekte plant : Metrosideros Banks; vl. Ijzermirt. - De bloeiwijze, met haren langen steel, ziet er uit als een kleine kanonborstel; fr. écouvillon. 
Kanonpoetsers, m. mv. - Beersel, Kinroy en omstr. Typha latifolia L.; fr. Massette à larges feuilles; vl. Breedbladige Lischdod. - De opeenhooping der vruchten, met den langen steel die ze draagt, maakt den indruk van een kleinen kanonborstel; fr. écouvillon.

Kantebeet. - Z. KatTeBEeT (Bijv.).

Kanteernkruid. - Poperinghe en omstr. - Id. als EENDENDERM (Vl. Wk.). - Deze plant heeft den naam van tot geneesmiddel te dienen tegen de kanteers; fr. les catarrhes.

Kanthaver, v. - W.-VI. - Soort van zaaihaver, anders ook Treurhaver genaamd, omdat hare zaadhuisjes op eenen kant overhangen : Avena orientalis Schreb.; fr. Avoine d'Orient ou de Hongrie; vl. Oostersche of Hongaarsche Haver (Kruidw.).

Kapellekens, o. mv. - Denderwindeke en omstr. Veronica Chamaedrys L.; fr. Véronique Petit-Chêne; vl. Gamander Eereprijs. - De schoone blauwe bloempjes gelijken op kapellekens (fr. petits papillons) met nitgestrekte vlerken.

Kaphout. - W.-Vl. - Slaghout; fr. bois taillis.

Kapiltjes, o. mv. -- Lebbeke en omstr. - Dianthus barbatus L.; fr. QEillet barbı; vulg. Willet des poètes, Bouquet parfait, B. tout fait: vl. Baardanjelier. - Kapiltjes $=$ vklw., met verb. van Kapeelijes. Kapeel, in VI., bet. een tuil wier bloemen in een dirhten drom staan, zooals bij besproken plant. Vandaar ook le fr. volksn.: Bouquet...

Kappers, m. mv. - Maastricht en omstr. - Bloemknoppen van Capparis spinosa L. en ork van Tropaeolum majus L., wiens vruchten soms, gelijk de echte kappers, als toekruid gebezigd worden.

Karmeswortel, m. - W.-Vl. - Id. als KaLmoes (Vl. Wk.), waarvan deze naam eene verb. is.

Karmoeswortel, m. - IV - Vl. - Id. als 't voorg. w.

Karn, m. - W.-V1. - $\mathbf{I}^{\circ}$ Kerf, tand; fr. entaille, dent d'une feuille. $-2^{\circ}$ Ook een boom, die anders Hernlaar, enz. heet (z. Bijv.). 
Karnaatscheuten, $\mathrm{v} . \mathrm{mr}$. - IV.-V1. - Lychnis calcedonica L, fr. Lychnide de Calcédoine; vulg. Croix de Malte ou de Jérusalem. - Karnaat $=$ verb. van inkarnaat: de bloemen (de scheuten, voor 't volk) zijn intarnaatrood.

Karnalieboom, m. - Denderwindeke en omstr. - Id. als KornoelJeboom ( $\mathrm{T}$ l. Wk.).

Karnoffel, - nagel, m. - W.-V1. - Kruidnagel ; fr. Clou de girofle.

Kasseike(n), Kassouden, Kassouwen, Kersouw zijn, zoowel als Cassoude, verb. van Consolida, Consoude. In de middeleeuwen werd Bellis perennis L., Consolida minor genoemd. Vandaar de naam van Het Kersouwlien, gegeven aan eene sedert vier eeuwen bestaande rederijkkamer, te Leuven (Ed. Martens). - Voor verderen uitleg, z. KAssEI$\mathrm{KE}(\mathrm{x}) \mathrm{s}$, enz. in ons Tl. Wk., en ook Bellis PERENNis, in ons lat. Wk.

Kasseitjes, o. mv. - Denderwindeke en omstr. - Bellis perennis L.; fr. Pâquerette vivace; v1. Madelieftien."De weiden zijn er in de lente, als 't ware, mede g•elasseid (fr. pavées) ", zeggen de inwoners van Denderwindeke. Z. ook een anderen uitleg, bij 't roorg. w.

Kasteeling, m. - W.-T1. - Soort van grooten Appel, geel van pel, met roode langachtige sproeten bespikkeld. De kasteelingen zijn winterappels die lang bewaren (Kruidw.). - Deze Appel is kostelijk en wordt bijna niet dan in de kasteelhoven gekweekt ; vaudaar Kasteeling.

Kasteleintje, o. - W. V1.-- Soort van allerbeste Peer ; fr. Bergamotte d'Esperen. - Van kastelein; fr. châtelain. Dezelfde uitleg' als voor 't voorg. w.

Kattebeet, v. - W.-Vl. - Klokhuis van eenen Appel of eene Peer; ook Kantebeet genaamd.

En als Jan zijn appel eet,

Pieter crijght de catte-beet.

(Lev, der Stud., in Kruidw.)

Kattedoorn, m. - Z. KraAidoorr (Bijv.).

Kattekees, m. - Uitspr. - kies. - Maastricht en omstr. - Id. als Kiasbroou (Tl. Wk.). - In t duitsch 
vindt men Kattenkeese (Göttingen, Oldenburg, enz.); in 't deensch : Katost, dat dezelfde bet. heeft (ost = kaas).

Kattekruid, o. - Maaseyck, Leuth, Asch, Kessenich. - Id.,als Kattepunt (V1. Wk.). - Ballota fatida Lmk.; fr. Ballote fétide; vl. Zwarte Stinknetel. - Kattepunt is misschien eene verb. van Kattemunt : de plant gelijkt op zekere soorten van Munt (fr. Menthe) en hare geur trekt op dien van kattepis.

Kattenhout, 0. - Noord-Brabant. - Salia fragilis L. ; fr. Saule fragile; vl. Kraakwilg.

Kattepier, m. - W.-V1. - Valeriana officinalis I.; fr. Valériane officinale; vl. Genezende Valeriaun. - De wortel, die onder de aarde leeft als de pieren (fr.vers de terre), is zeer gezocht door de katten : zijne geur veroorzaakt bijzondere uitwerksels op haar zenuwsysteem.

Kattepisse, v. - W.-V1. - Soort van Muskadeldruif, fr. Raisin muscat. - Men zegt ook Kattepieze. - Naam ontleend aan den bijzonderen smak dezer druif.

Kattesluize, v. - W.-V1. - Id. als KATteBeET (Bijv.).

Kattesmeer, o. - W.-Vl. - Sedum maximum Suter; fr. Grand Orpin; vl. Groot Vetgroen. - Smeer = vet, fr. graisse, suif. - Voormelde plant behoort tot de Vetplanten; fr. Plantes grasses.

Kattesteert, m. - Denderleeuw, Lebbeke, Diest, Webbecom, Schaffen en omstr. - Id. als KATTesteert, Io) (V1. Wk.).

Kauwel, Kouwel, m. - W.-Vl. - Kool; fr. chou.

Keelkruid, o. - W.-V1. - Filag'o 'Tournef., in 't algem. ; fr. Cotonnière; vl. Draad-of Schimmelkruid.

Keersebloem, v. - W.-Vl. - Id. als KoffieboontuES (Vl. Wk.). - De lange bloeiwijze der plant richt zich statig omhoog lijk eene keers.

Keesjesbloem, v. - Nederland. - Id. als KAAsJESBLOEM (Bijv.).

Kef. - Z. KAF (Bijv.).

Kegelaar, m. - W.-V1. - Fr. Conifère. - De Sper is een Kegelaar of Kegeldragende. - De vrouwelijke bloeiwijze dezer boomen is kegelvormig; fr. en forme de cône. 
Kegelbotte, Schubbebotte, v. - W.-Vl. - De vrouwelijke bloeiwijze (botte genaamd, in W.-Vl.) der Kegeldragende boomen (z. 't voorg. w.). - Schubbe; fr. écaille: ieder kegel is uit talrijke schubben samengesteld.

Keiken, o. - In Brabant. - Id. als KEIKE(N)s(Vl. Wk.).

Keizerinneke(n)s, o. mv. - Oost-Roosebeke en omstr. - Een vroeg zomerpeertje dat veel gelijkenis heeft met eene andere soort die den naam van Brugsche-Meiskens draagt. Z. dit laatste w. (Bijv.).

Kemp, m. - Nederland. $-\mathbf{I}^{\circ}$ Wordt in den gewonen zin gebruikt, (fr. Chanvre), als in België; $-2^{\circ}$ Beteekent daarenboven ook Trifolium repens L.; fr. 'Trèfle rampant; vl. Kruipende of Witte Klaver.

Kempkruid, o. - W.-Vl. - Id. als WrLde Kemp (Vl. Wk.) en zelfde uitleg.

Kennep, m. - Nederland. - Id. als KeмP, I ${ }^{\circ}$ ) (Bijv.).

Keper, m. - W.-Vl. - Sparreboom; fr. Sapin; lat. Abies Tournef.; Picea Don.

Kerkeroos, v. - W.-Vl. - Id.als Peerdsrozen (Vl. Wk.).

Kerneuteling, m. en o.- W.-Vl. - Verneuteld gewas, vrucht of fruit dat zijnen vollen wasdom en grootte niet bekomen heeft.

Kerstdagkrieken, v. mr. - W - Vl. - Id. als KRIEKAPPELKENs (VI. Wk.). - De vruchten van dit gekweekt boomken gelijken op kersen of krieken; vandaar ook zijn fr. volksn. cerisette. De vruchten zijn .rijp rond Kerstdag.

Kettingbloem, v. - Nederland. - Id. als Pisbrocir ( V1. Wk.). - De kinderen maken kettingen (samengesteld uit ringen) met de bloem - en vruchtsteleu.

Keunaas, o. - W.-V1. - Tragopogon pratensis I..; $\mathrm{fr}$. Salsifis des prés; vl. Beemd-Boksbaard.-A as=voedsel; fr. pâture, nourriture. - Keun $=$ westvl. w. dat konijn bet. - De arme menschen geven deze plant tot voedsel aan hunne konijnen.

Keunemommel, m. - W.-V1. - Id. als KAAsKe(N)sKRUID (Vl.Wk.). - Keune = konijn, z. 't roorg. $\pi$. Mommelen $=\mathrm{fr}$. mâchonner, manger; dus voedsel der konijnen. - Mommel, alleen, = ook Kaaske(n)skruid, in IV.-Vl. 
Keuneratels, m. mv. - W.-Vl. - Ratels die door de keunen (z. 't voorg. w.) gegeten worden. - Melampyrum pratense L.; fr. Mélampyre des prés; vl. Weide-Zwartkoorn.

Keunewafel, v. - W.-Vl. - Id. als KeunemommeL (Bijv.). - Wafel = fr. gaufre; bet. hier voedsel. - De vruchten der plant hebben den vorm eener kleine wafel (fr. gaufre).

Keunewortel, m. - Stavele en omstr. - Heracleum Sphondylium L.; fr. Berce Branc-Ursine; vl. Berenklauw. - Voor uitleg, z. KEUNAAs (Bijv.).

Keunoore, Konijnoore, v. - W.-Vl. - Plantago lanceolata L.; fr. Plantain lancéolé; vl. Lancetbladige Weegbree of Hondsribbe, - rebbe. - De vorm der bladeren lijkt op dien van de ooren der keunen of konijnen.

Keutelkeerze, v. - IV.-Vl. - Uitspr. - kèze. - Id. als Schittkazekes ( $\mathrm{V}$. Wk.).

Keutellakers, v. - O.-V1. - Lees Keutella-kers.- Id. als 't voorg'. w. - In dezelfde streek zegt men Hemellawerken, voor Hemelwerken.- Dus verb. van Keutelkers.

Kiek. - Z. Gele - Witte - (Bijv.).

Kiekenmeur, v. - IV.-V1. - Id. als MuUn (Vl. Wk.).

Kikkerbeet, m. - Nederland. - Hydrocharis Morsusranae $\mathrm{L}_{.}$; fr. Hydrocharis des grenouilles; vulg. PetitNénuphar; vl. Vorschen-Duitblad.-Kikker =kikvorsch ; beet $=$ morsure, coup de dent : letterlijke overzetting van 't lat. Morsus-ranae.-De plant groeit in de waters waar de kikvorschen hun verblijf houden (stille waters), eu deze proeven somtijds van de bladeren en de wortels.

Kikkerbloem, v. - Nederland. Butomus umbellatus L.; fr. Butome en ombelle; vulg. Jonc-fleuri; vl. Schermdragende Zwanebloem (fig. 35). - Groeit aan den boord der waters; voor 't overige, 'z. 't voorg. w.

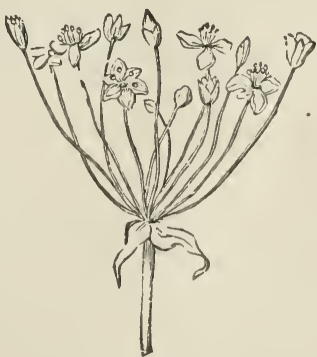

Fig. 35. - Bloeiwijze van Butomus umbellatus.

Kikkerbloempje, o. - Nederland. - Ranunculus scele- 
ratus L.; fr. Renoncule scélérate; vl. Blaartrektiende Ranonkel. - Bloempje dat groeit waar de kiktiers verblijven, d. i. in waterplassen, enz. - Kikker = kikrorsch.

Kikkerkruid, o. - Nederland. - Id. als Kikkerbeet (Bijv.).

Kimp, m. - Zwijnaarde en omstr. - Id. als KEмP (V1. Wk.). - In V1. zegt men nog : Kempst, Kampst, Kaamst, Kompst, enz.

Kippen-en-haantje. - Nederland. - Corydalis cava Schw. en K.; fr. Corydale creuse: vl. Holle Helmbloem.De bloeiwijze lijkt op een hanelam (fr. crête de coq) en de fijn doorgesueden, min of meer op pluimen lijkende bladeren, hebben bij 't rolk 't gedacht van kippen (hennen) doen ontstaan.

Kinderen-zonder-vader, o. mv - Heyst-op-den-Berg' en omst. - Id. als MoEdernaAktex (Tl. Wk.) (fig. II). De bloemen (= kinderen), bij deze plant, komen róór de bladeren (= den rader), tegenover den algem. regel.

Kinsoen, o. - $\mathrm{IT}^{\mathrm{T}}$ - Tl. - Id. als Hoxdspille ( $\mathrm{Tl}$. W k.). - Kinsoen = verb. van Quenneçon, fr. volksn. dezer plant.

Klaaroogen, o. mv. - Heyst-op-den-Berg en omstr. Id. als KLEEROOG ( $\mathrm{T}$ l. W'k. j.

Klakkerkens, o. $\mathrm{mr}^{\mathrm{r}}$ - Denderwindeke en omstr. Stellaria Holostea L.; fr. Stellaire Holostée; vl. Hardstengelig. Sterrekruid. - De vruchten zijn bolvormig en klakken of kletsen (fr. claquer), als men ze tusschen de handen of onder den roet verplettert.

Klakwilg, r. - IV.-T1. -- Io Salix fragilis L.; fr. Saule fragile; vl. Broze Wilg. - De takken breken licht, zooals de naam het zegt, en dan doen zij eenen klak (fr. bruit sec, claquement) hooren. - $2^{\circ}$ Toornoemde soort wordt gewoonlijk als kropwilg gekweekt (fr. saule têtard) en daarom geeft men denzelfden naam (ran klakwilg) ook aan al de kropwilgen zonder onderscheid.

Klakwulge, r. - Id. als 't voorg. W., in W.-VI.

Klapbes, v. - Io Rotterdam en omstr. - Id. als KLAPBessex (Vl. Wk.) en zelfde uitleg. - $2^{\circ} \mathrm{Hier}$ en daar, in 
België. - Id. als BlaAsboom (Vl. Wk.). - De peul van dit struikgewas is blaasvormig en geeft een knal of klap als men er op slaat.

Klarrebos, m. - Nederland. - Beduidt het geslacht Lappa Tournef., in 't algem.; fr. Bardane; vl. Klis. Men zegt ook Kladdebos, - wortel, ibid.

Klaterpeppel, m. - Nederland. - Id. als Krater (V1. Wk.) en zelfde uitleg. - Peppel is een volksn. van Populier (fr. Peuplier).

Klauwiertje, o. - Bij de oude kruidkundigen : Dodoens, enz., synoniem van hechtrankje (fr. vrille). Stamt af van klauw (fr. griffe), d. i. een lidmaat waarmede de plant naburige voorwerpen aangrijpt, om zich te steunen.

Klaveraas, o. - W.-V1. - Medicago maculata Willd.; fr. Luzerne maculée; L. tachetée; vl. Gevlekte Rupsklaver. - Dus genaamd omdat de bladjeś eene zwartachtige vlek dragen, die doet denken aan het klaveren aas van een kaartspel (Kruidw.)

Klaverbalsem, m. - Brugge en omstr. - Melilotus coeruleus Lam. (Trigonella - Ser.); fr. Mélilot bleu; vl. Blauwe Honigklaver. - De bladeren zijn drijbladig lijk bij de Klaver en de bloem (bijzonder gedroogd) verspreidt eenen alleraangenaamsten balsemgeur.

Klaverpriem, m.- Kortrijk en omstr.- Id. als HoxisPRIEur (Bijv.) en zelfde uitleg.

Klaverruie, v. - In 't Brugsche en elder's in $\mathrm{W}^{\prime} . \mathrm{VI}$. Id. als Reuwe (Vl. Wk.). - Deze woekerplant tast verscheidene soorten van planten aan, maar bijzonder de Klaver, waar zij groot nadeel veroorzaakt. - In. IV.-Vi. zegt men ook : Klaverruwe, - ruide.

Klavertap, m. - In 't Brugsche en elder's in W'.Vl. Id. als KLAverPriem (Bijv.). - Deze woekerplant tapt het sap uit de wortels van de Klaver.

Kledderboonen, v. mv.- Diest, Tongeren, Mall, Sluizen en omstr. - Phaseolus vulgaris L.; fr. Haricot commun; vl. Gewone Boon, Krombek. - Kledderen = klauteren (fr. orimper), in die streck : dus boonen die langs de 
staken kledderen of klauteren, tegenover de Steufkesboone (n) (z. Vl. Wk.) of Struikboonen (fr. Haricot nain), die niet kledderen.

Kleef, v. - Nederland. - Id. als Kleften (Vl. Wk.).

Kleefte, v. - Kortrijk en omstr. - Id. als 't voorg. w. - In $\mathrm{W}^{\mathrm{T}}$.-V! zegt men ook Klifte.

Kleine-Molekens, o. mv. - Denderwindeke en omstr. - Id. als Cathrienewiel (V1. Wk.). - De doorgesneden bloemkroon wordt aan een klein molenrad vergeleken. De kinderen ook doorsteken twee bloemen met eene speld, blazen duchtig en doen het kleine toestel draaien als een moleken.

Klein-Paternosterkruid, o. - Denderwindeke en omstr. - Malva rotundifolia L.; fr. Mauve à feuilles rondes; vl. Rondbladige Maluwe.- Voor uitleg, z. Groot-PAterNOSTERKRUID (Bijv.).

Kleine-Haver, v. - Zwijnaarde en omstr. - Id. als Fransch-Gras (Vl. Wk.). - De aartjes dezer grassoort gelijken grootelijks aan die van de gewone Haver, maar zijn veel kleiner: vandaar werd de plant Kleine-Haver genaamd.

Kleine-Knopkiek, v. - Nederland. - Erysimum cheiranthoides L.; fr. Vélar Fausse-Giroflée; vl. Violierachtige Steenraket.

Klematik, v. - Maastricht en omstr. - Verb. van den fr. naam Clématite. - Id. als Dievenkruid (V1. Wk.).

Kles. - Oostham en omstr. - Uitgeloopen gommig sap aan steenvruchten en aan fruitboomen, zoo genoemd als 't versteven is.

Klet (mv. kletten). - $\mathbf{I}^{\circ}$ Maastricht en omstr. - Id. als Klessen (Vl. Wk.); $2^{\circ}$ Elders in Nederland. - Id. als KLeften (Vl. Wk.).

Klie $_{s}$ m. - Maastricht en omstr. - Id.als KLEE (V1. Wk.). Kliester, m. - W.-V1., Nederland. - Z. KLIJster (Bijv.). Klift, v. - Nederland. -- Id. als KLeften (Vl. Wk.).

Klifte, v. - Z. KLeEfTE (Bijv.).

Klijster, m. - W.-Vl. - Wortelbol van Tulpen, Leliën, enz.; fr. bulbe, oignon. 
Klijsterberenhout, o. - Beeringen en omstr. - Verb. van Lijster -. Id. als HAveresch (V1. Wk.).

Klis, v. - W.-Vl. - Id. als KLESSEN (Vl. Wk.).

Klit, v. - Nederland. - Id. als KLA RREBos (Bijv.).

Klitze, v. - Nederland. - Algem. naam om het geslacht Xanthium Tournef. te beduiden; fr. Lampourde; vl. Stekelnoot. - Waarschijnlijk eene verb. van Klit of Klis (Lappa Tournef., fr. Bardane). - De vruchten dezer plantsoorten gelijken op malkander : zij zijn bolvormig en van stekels voorzien.

Klokjes-wind. - Maastricht en omstr. - Id. als HAAGLELIE (V1. Wk.). - Winde met klokjesvormige bloemen.

Klokke, v., Klok, v. - W.-Vl. - I ${ }^{0}$ De Fuchsia in 't algem. In dien zin, gebr. men bijzonder het verkleinw. : de klokskens bloeien.- $2^{\circ}$ De vrucht van Rosa canina L.; fr. Rose de chien; vl. Hondsroos. De bloem en de vrucht, waarvan spraak is, zijn klokvormig.

Klokkebloamkruid, o. - Maastricht en omstr. - Id.als KLoKJES-wind (Bijv.).

Kloosterling, m. - IV.-V1. - “ Sappige winterappel, van grootte en fatsoen gelijk de Bellefleuring, maar geelgroen van pelle met roode streepjes en spatjes van den steert weg tot ten halve den appel. » (Kruidw.).

Klotsberenhout, o. - Beeringen en omstr. - Id. als KLotskens (Vl. IVk.).

Klotsen. - Alken (bij Hasselt) en omstr. - Id. als Klakboshout (Vl. Wk.).

Knetserke(n)s, o. mv.-Heyst-op-den-Berg en omstr. Id. als KNEKKERS ( 1 1. Wk.). - Men vermaakt zich met de bollen (de vruchten) onder de voeten te treden en te doen knetteren.

Kneuveltarwe, v. - IV.Vl. - Tarwe met getakkelde aren; fr. froment à épis rameux; blé de miracle, enz. Waarschijnlijk verb. van knevel - : de aren zijn van knevels voorzien, tegenover de andere soorten, wier aren niet getakkeld zijn.

Knippens, o. mv. - Z. 't volgende w.

Knippers, o. mv. - Zwijnaarde, Eecke, Seeverghem en 
omstr. - Elders, in Vl., zegt men ook Knippens, Knuppens, Nippens, Nuppens, Ippens, Oppens, enz. - De rruchten of beter de vruchtomhulsels ran het Vlas; fr. péricarpe dı Lin. De knippers bevatten het lijnzaad.

Knobbelgerste, r. -- W.-V1. - Hordeum distichon L.; fr. Orge à deux rang's; vl. Tweerijige Gerst. - De aren dezer soort schijnen knobbelachtig; fr. bosselé, inégal.

Knooppeem, r. - II.-Tl. - Id. als Fransch-Gras (Vl. Wk.). - Een peem is eene grassoort met langen onderaardschen wortelstok (fr. rhizome). Nu, de hier besproken peem is, onder de aarde, van dikke knoopen of bollen voorzien : vandaar Knooppeem; randaar ook de fr. volksn. : Aroine à chapelet; Chiendent à chapelet.

Knopkiek. - Z. KLEINE - (Bijv.).

Knuppens, o. $\mathrm{mr}$. Z. Knippers (Bijv.).

Kobben, r. mv.- $\mathrm{II} .-\mathrm{Tl}$. - Nigella damascena L.; fr. Nigelle de Damas; vulg. Pattes-d'araignées; Herbe à l'araignée; vl. Nigella van Damas. Kobbe, in W.-V1., = kuif; $\mathrm{fr}$. aigrette. - $\mathrm{Nu}$, de bloemen en vooral de vruchten dezer plant zijn omringd ran fijn doorsneden blaadjes, die eene soort van kuif of liobbe uitmaken.

Koeibies, v. Men zegt ook : bieze; - biezem.

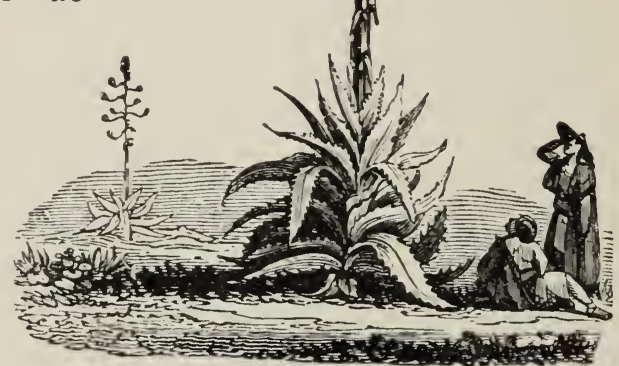

Fig. 36. - Agave americana.

- W.-Tl. - Id. als Biezex ( Tl. Wk.).

Koeienbloem, r. - Nederland. - Id. als MadeliefJE 
(Vl. Wk.). - Groeit in de weiden, waar de koeien er geerne van proeven.

Koeitongen, r. mv. - Poperinghe en omstr. - Agave americana L., var. variegata; fr. Agave d'Amérique, var. à feuilles panachées (dikwijls, maar verkeerd, Aloès geheeten); vl. Amerikaansche Agave, ook Boomaloë genaamd (fig. 36). - Koeitongen, zinspeelt op den vorm der bladeren.

Koeiwafel, v. - W.-Vl.-Heracleum Sphondylium L.; fr. Berce Branc-Ursine; vl. Berenklanw. - De plant groeit in de weiden en beemden, waar de koeien grazen, en hare vrucht heeft den rorm van eene kleine wafel (fr. gaufre).

Koeiwortel, m. - W.-Vl. - Anders ook Peerdewortel genaamd. - "Varieteit van pee of carote die grooter en minder goed is dan de roode Hovenierswortel. Zij zijn bleek en het bovenste deel, dat uit den grond kijkt, is groenachtig : zij worden gekweekt voor de stalbeesten. " (Kruidw.).

Koekoeken, m. mv. - Herenthals, Moll en omstr. $i^{\circ} \mathrm{Id}$. als Koекоек(e)вloem (Vl. Wk.). $-2^{\circ}$ In deze plaatsen, wordt dezelfde naam ook gegeven aan Brunella vulgaris L.; fr. Brunelle commune; vl. Gemeene Bruinelle.

Koekoeksbrood, o. - Nederland. - Id. als HazenKLAVER (Bijv.). - Volgens de meening van 't volk, zouden deze plantsoorten tot voedsel (brood) dienen voor den koekoek.

Koemommel, m. - In 't Veurne-Ambacht. - Spiraea Ulmaria L.; fr. Spirée Ulmaire; vulg. Reine-des-prés; vl. Moeras-Spierkruid. - Mommelen $=$ fr. mâchonner, manger. Dus Koemommel = voedsel, eten der koeien.

Koetjes, o. mv. - Denderwindeke en omstr. - Id. als Aaronsoore(x) (VI. Wk.).- Het volk heeft eene gelijkenis gezien tusschen de knotsvormige bloemkolf dezer plant (fig. r2) en den tepel eener koe; vandaar : koetjes.

Koffieboonen, v. mv. - Nederland. - Id. als KrkkerBLoex (Bijv.). - De vorm der bloemknoppen en der vrucht heeft iets weg van eene inoffieboon. 
Kokeloere, v. - W.-Vl. - Lychnis coronaria L.; fr. Lychnide couronnée; vulg. Coquelourde. - Kokeloere is eene verb. van dezen laatsten fr. volksnaam.

Kokertjeskruid, o. - W.-Vl. - Id. als Peerdesteert (Vl. Wk.). - De stengels dezer planten zijn samengesteld uit een groot getal kokertjes (fr. tubes, étuis), die in malkander steken.

Kokte, v. - W.-V1. - Eene Kolte is synoniem van eene Schermdragende plant (fr. une Ombellifère). - In Kruidw., bl. 63, kan men eene lange redekaveling vinden, welke voor doel heeft te bewijzen dat het w. Kolite oorspronkelijk hetzelfde is als 't lat. Cicuta, enz.

Kolijkekriek, v. - W.-Vl. - Id. als KrIeKsKen-IN(DEN)-ZaK (Vl. Wk.). - De vrucht (kriek) is vergiftig en zou kolijkien ( $\mathrm{fr}$. coliques) veroorzaken, indien men er van at.

Kokskenskruid, o. - Lebbeke, Herdersem en omstr.Gebrekkige uitspr. van Koekske(n)skruid en zelfde bet.Z. Koekske(N)skruid, Io) (Vl. Wk.).

Kolkbiezen, v. mv. - Beeringen en omstr. -- Scirpus lacustris L.; fr Scirpe des lacs; vl. Meer-Bladbies. - De plant gelijkt op de Biezen (fr. Joncs) en groeit gewoonlijk in diepe waters (kolken).

Kollebloem, v. - Denderwindeke en omstr. - Id. als $\left.\mathrm{KoL}, \mathrm{I}^{\circ}\right)(\mathrm{V}$. Wk.).

Kollepiet, m.- Oultre (bij Ninove).-Id. als. PietekoL (V1. Wk.).

Komeine, v. - W.-Vl. - Id. als Kamille (Bijv.). Men zegt ook Komelmeine, Kamelmeine, enz.

Konijnenblad, o. - Nederland. - Plantago major L.; fr. Plantain majeur; vl. Groote Weegbree. - De bladeren der plant zijn welkom bij de konijnen.

Konijnen-Eten, o. - Denderleeuw en omstr. - Id. als ZeEnkruid (Bijv.). - Wordt aan de konijnen gegeven.

Konkernelle(n)boom, m. - Maaseyck en omst. - Id. als Kornellexboom en Kornoeljeboom (Vl. Wk.). - De duitsche naam is Kornel-Baum; de eng. Cornell-tree. 
Konkernolle(n), v. mv. - Maastricht et omstr. - De vruchten van den Kornoeljeboom. - Voor uitleg, z. 't voorg. w.

Kont, v. - In Zuid. Belg.-Limb. - Id. als IsGAT (Bijv.).

Koolbloem, v. - Denderwindeke en omstr. - Id. als Hoevenblaren (Vl. Wk.). - Het volk beweert dat, waar deze plant groeit, steenkoolen liggen.

Koornroos, v. - Nederland. - Id. als KoL $\mathrm{I}^{\circ}$ ) en IEGEL (Vl. Wk.). - Deze twee onkruiden groeien in de koornvelden en hunne kleur (rood en purperachtis), als ook hun vorm, hebben eenige gelijkenis met de rozen.

Koortsbloem, v. - Denderwindeke en omstr.-Id. als Santoriebloem (Vl. Wk.). - Wordt, in deze streek, veel gebr. als thee, tegen de koorts en de maagontsteltenissen (fig. 25).

Kopboomen, m. mv. - Z. Strinkbol (Bijv.).

Koraalhout, o. - Nederland. - Id. als Kornoe L.JE Boon (Vl. Wk.). - De rijpe vruchten zijn rood als koraal.

Koraalkruid, o. - Nederland. - Id. als Aspersie (V1. Wk.). - De rijpe vruchten zjin rood als koraal.

Korenwortels, v. mv. -- Uitspr. Korewurtels. - Zwijnaarde, Eecke, Seeverghem, Sint-Denijs-IVestrem.-Wortels (fr. carottes) die men in de rogge (het koren) zaait, in Maart-April.

Korinteboom, m. - In Fransch-V1. - Ribes alpinum L.; fr. Groseillier des Alpes; vl. Alpen-Aalbessestruik.De kleine vruchten gelijken op korinten of krenten (fr. raisins de Corinthe).

Kornel, m. - Nederland. - Algem. naam van het geslacht Cornus Tournef.; fr. Cornouiller; vl. Kornoeljeboom, zonder onderscheid van soorten.

Kortse(n)bloem, v.- W.-Vl.- Uitspr.- blomme. - Id. als Koortsblokm (Bijv.).

Kouwel, m. - Z. KaUWEL (Bijv.).

Kraaibessen, v. mv. - Nederland. - Id. als HondeBEIEN (Bijv.).

Kraaiebloem, v. - Nederland. - Id. als KLEINE-MoLEKENS (Bijv.). 
Kraaidoorn, m.- W.-Vl. en elders. - Id. als HEIDoorN $\mathrm{I}^{\mathrm{o}}, 2^{\mathrm{o}}$ en $\left.3^{\circ}\right)(\mathrm{V} 1$. Wk.).

Kraaienpoot, v. - Nederland. - Senebiera Coronopus Poir.; fr. Senebière Corne-de-Cerf; vl. Hertshoornig. Senebier's kruid. - Het volk heeft eene gelijkenis met eene kraaienpoot gevonden in den neerliggenden, vertakten stengel van dit kruid.

Kraaiepooten, v. mv. - Nederland. - Ranunculus repens L.; fr. Renoncule rampante; vl. Kruipende Ranonkel. - Zelfde uitleg als bij 't voorg. w.

Kraailook, o. - Nederland. - Id. als Pisp(w)orr (Vl. Wk.). - Look dat, ten hoogste, goed is voor de kraaien.

Kraaksalade, v. - W.-Vl. - Id. als TeldsalaAd (Vl. Wk.). - De harde en stijve bladeren van deze salade kraken tusschen de tanden.

Kraalboom, m. - Nederland. - Id. als Haveresch (Vl. Wk.). - Voor Koraal - . De rijpe vruchten zijn rood als koraal.

Koraaltjesbloem, v. - Nederland. - Id. als PereLKENS (Vl. Wk.). - Ieder bloempje is als een rond koraalperelken.

Krabbeklootjes, o. mv. - Nederland. - Id. als WrLDEAlsem (Vl. Wk.). - Krabbe, v., is, in vele plaatsen, synoniem van rist, tros (fr. grappe) : eene krabbe druiven. De bloemhoofdjes van besproken plant hebben den vorm van bollekens of klootjes, die in lange krabben gerangschikt staan.

Krabbekwaad, o. - Nederland. - Salicornia herbacea I.; fr. Salicornie herbacée; vl. Kruidachtige Zeekraal. - Plant die in zeeklei groeit, waar de krabben (fr. crabes) ook gevonden worden.

Krabbestruik, m. - Nederland. - Id. als 't voorg. w.

Krakke, v. - Io Oost-Roosebeke en omstr. - Id. als Krakebeze(N) (Vl. Wk.); $2^{\circ}$ elders, in W.-Vl., id. als Bessemhei (Vl. Wk.).

Kransje, o. - Nederland. - Id. als MadeliefJE (Vl. Wk.). - De witte bloempjes van ieder bloemhoofdje vormen als een kransje rondom de gele bloempjes. - Daar- 
enboven, de kinderen maken kransjes met de bloemen dezer plant.

Krek(ke). - Z. KRIKKELARE (Bijr.).

Kreupelgras, o. - Nederland. - Id. als VErkensgers (Vl. Wk.). - De plant lijkt op gras dat kreupel is, d. i. dat tegen den grond neerligt.

Kreuze. - Nederland. - Id. als Eendengroen (Vl. Wk.).

Kreuzen. - Nederland. - $\mathrm{I}^{\circ}$ Vaccinium Vitis-Idaea L.; fr. Airelle ponctuée ou A. du Mont-Ida; vl. Roode Kraakbes ; 2"Vaccinium Oxycoccos L.; fr. Airelle Canneberge; vl. Veenbes. - In plaats van Kreuzen, zegt men ook Kroozen. - Kroos = Lemna, in 't algem.; fr. Lenticule d'eau. - Misschien is Kreuzen maar eene verb. van Kroos, Kroozen : al de planten, waar hier spraak van is, hebben klcine, rondachtige bladeren, die veel op Kroozen (fr. Lenticules d'eau) gelijken. - Z. ook Kroos (Bijv.).

Krikkelare, m. - Oost-Roosebeke en omstr., Wareghem, Tieghem. - Een boom die kleine, wilde pruimen draagt (fr. Créquier). - De vrucht heet krik(ke), krek(ke); fr. crèque.

Krissen, v. inv. - Nederland. - Id. als StekelbeziëN (Vl. Wk.). - Krissen = fr. égratignures; zinspeling op de stekels waarvan dit struikgewas voorzien is.

Krissiehout, o. - Maastricht en omstr. - Verb. van Kalissichout. - Z. dit w. in 't V1. Wk.

Krodde. - Nederland. - Id. als HARING (Vl. Wk.). Z. ook WitTe - (Bijv.).

Kroenepialen, v. mv. - Beeringen en omstr. - Id. als Keizerkroon (Vl. Wk.). - Kroenepialen is eene grove verb., met samentrekking, van den fr. volksn: : Couronne impériale. - Z. verder ook: Kroon-imperiaal, Kroonpreaal, enz. (Bijv.).

Kroezelkens, o. mv. - Denderwindeke en omstr. Knautia arvensis Coult.; fr. Knautie des champs; vulg. Scabieuse des champs; vl. Akker-Knautia. - De bloeiwijze is als uit gekroezelde (fr. frisé) bloemkroontjes samengesteld. 
Krombekken, m. mv. - Maastricht en omstr. - Eene hoog geschatte soort van Aardappelen, die, in Zuid. Belg.-Limb., Geitenhoorns genoemd wordt.-Voor uitleg, z. Geite(x)hoorss (Vl. Wk.).

Krompiere(n). - Z. Crompiere(s) (Bijv.).

Krompreaal, v. - W.-VI. - Id. als Kroenepialen (Bijv.) en zelfde uitleg.

Kroon, v. - Nederland. - Id. als Pretekol (Vl. Wk.). - De vruchtbladen (fr. carpelles), met groote stekels voorzien, verwijderen zich van malkander na den bloei en vormen eene schoone kroon.

Kroon imperiaal, $\mathbf{~} .-\mathrm{W} .-\mathrm{V} l$. en Nederland. - Id. als Kroenepialex (Bijr.) en zelfde uitleg.

Kroon-preaal, v. - IV.-Vl. - Id. als 't roorg. W.

Kroontjeskruid, o. - W.-Vl. - Id. als KrooxkexsKRUID ( Vl. Wk.).

Kroos, o. - W.Vl., Nederland. - Men noemt alzoo verscheidene soorten van Lemna L.; bijzonder de L. minor L., L. trieulca L. en L. polyrrhiza L.; fr. Lenticule mineure; vulg. Lentille d'eau; L. à trois lobes en L. à plusieurs racines; vl. Klein Eendentroos. Drielobbig E. en Veelwortelig: E. - De èenden zijn zeer verlekkerd op deze waterplantjes; vandaar Eendenkroos of Kroos alleen, kortheidshalre. - Kroos $=$ hier voedsel.

Kroozen. - Nederland. - Z. Kreuzex (Bijr.).

Kruideken-tik-mij-niet, o. - W.-Vl. - Id. als KRUIDEKEN-ROER-MIJ.NIET (Vl. Wk.). - Tiktien = zachtjes aauraken; fr. toucher légèrement.

Kruidnagels, m. mr. - Nederland. - Id. als HyAcint ( Vl. Wk ). - De rorm der bloem trekt op eenen Kruidnagel; fr. Clou de girofle.

Kruien, werkw. - (Verb. van kruiden, werkw.). Reckheim en omstr. - Kruien, is groot onkruid in de bezaaide akkers (haver, rogge, tarwe, enz) uittrekken, om het veld te zuiveren en tevens het vee te roederen (Th. Coenegracht). - Z. ook WIEËN (Bijr.).

Kruilook, o. - W. -Vl. - Id. als KRAalLOoK (Bijr.). 
Kruip-door-den-tuin, o. - Nederland. - Id. als KruiptDOOR-D(E)-HAGE (V1. Wk.).

Kruipende-Wurf, m. - Beeringen en omstr. - Id. als Kruipweurft (Vl. Wk.).

Kruipertje, o. - Nederland. - Id. als HANs-KRUIF-IN (Vl. Wk.), en zelfde uitleg.

Kruipmel, v. - Nederland. - Chenopodium polyspermum L.; fr. Ansérine polysperme; vl. Veelzadige Ganzevoet. - Mel of Melde is synoniem van Ganzevoet; de takken van besproken soort kruipen langs den grond.

Kruipnetel, v. - Denderwindeke en omstr. - Ajuga reptans L.; fr. Bugle rampante; vl. Kruipend Senegroen. - De plant gelijkt, in 't gedacht van 't volk, aan de Purpere Doove-Netel en hare zijstengels kruipen langs den grond.

Kruipvitse, v. - W.-V1. - Ornithopus perpusillus L. ; fr. Ornithope délicat; vulg. Pied-d'oiseau; vl. Teeder Vogelpootje; vulg. Vogelpootje. - Het plantje heeft iets weg van de Vitse (fr. Vesce) en kruipt langs den grond.

Kruisdistel, v. - Nederland - Algem. naam, die het geslacht Eryngium Tournef. beduidt; fr. Panicaut; vl. Kruisdistel. - De plant heeft stekels gelijk de Distel.

Kruisdoorn, m. - Nederland. - Id. als Stekelbezil̈N (Vl.Wk.).

Kruiskruid, o. - Nederland. - Id. als KaArskensKRUID (VI. WVk.).

Krukken-over-zee, v. mv. - Gheel, Westerloo en omstr. - Verb. van Krieken-. - Id. als KrIeksken-vaNoVER-zeE (Vl. Wk.). - Over-zee = eene ingevoerde, niet binnenlandsche plant.

Kuipersboom, m. - W.-Vl. - Eik of Esch van widdelbare grootte, waar de kuipers (fr. tonneliers) duigen van uaken.

Kulletjeskruid, o. - Nederland, Nieuwerkerke. Orchis Morio L. : fr. Orchis boulfon; vl. Harlekijns-Standelkruid. - Voor uitleg, z. Kullekexskruid (Vl. Wk.).

Kunne, v. - Nederland. - Id. als Koendel (Vl. Wk.).

Kurpraap, v. - Beeringen en omstr. - Id. als KeURFRAAP (Vl. Wk.), en zelfde uitleg. 
Kurtsebeier, m. - W.-V1. - Hagedoornbezie; fr. baie d'Aubépine. - Kurts ook kuts) = koorts; fr. fièvre.

Kurtskruid, Kortskruid, Koortskruid, o. - W.-Vl. I Id. als SAxtoriebloeM (T1. Wk.) (fig. 25). - 20 Lotus corniculatus L.: fr. Lotier corniculé: rl. Gehoornde Rolklaver. - Deze planten worden, bij 't rolk, als thee gebr. tegen de koorts.

Kuulrabe(n), r. $m r$. - Maastricht en omstr. - Id. als KoolraAp (Tl. Wk.).

Kwâ-Oogenbloem, r. - Lebbeke en omstr. - Id. als WExDROZE (Vl. Wk.).

Kwabbel. - Z. KWEвBEL (Bijr.).

Kwachtbeziën, r. mr. - Herenthals, Oolen en omstr. - Id. als Goorbes (V1. Wk.). - Kwacht = een moeras. eene soort ran reen.

Kwebbel, m. - Verb. $\operatorname{ran} K w a b, K w a b b e l .-Z w i j-$ naarde, Eecke, Seererghem, Sint-Denijs-Westrem. - De knolziekte der Kruistbloemigen (frr. Crucifères) : Plasmo. diophora Brassicae. Men rindt ze bijzonder bij Rapen. Koolzaad. enz.

Kweek. r. - Mechelen-a Maas. - Id. als Hoxdsgras (Vl. Wh.). - In 't duitsch Queche en in 't zweedsch Quichert geheeten. De naam liweeh is rerwant aan het rerouderde kwik= lerendig, rlug. Tandaar kwikzilver, (een metaal dat rloeibar is en zich snel, rlug be reegt) en vertwititien = verlevendigen. - De kweek wordt zoo geheeten omdat zij zich, door hare lange onderaardsche stengels (fr. rhizomes) snel voortzet (J.-U. Vits.)

Kwei, Kweipeer, r. - Maastricht en omstr. - Id. als KWEEPEER ( $\mathrm{Tl}$ l. Wh.).

Kweldergras, o. - Nederland. - Glyceria distans Wahlenberg: fr. Glycérie distante; rl. Verwijd Zoetgras. - Kwelder, $\Gamma_{.}=$grond, gelegen aan den buitenkant eener dijk en wair dit gras goed gedijt. - Dezelfde naam beduidt ook Glyceria maritima M. en $\mathrm{K}$.

Kwets, r. - Nederland. - Trucht ran Prunus domestica L.; fr. Prunier domestique; rl. Tamme Pruimboom. - Hetzelfde $\pi$. Wordt bij de Franschen (fr. Quetsche) en bij de Duitschers geronden. 
Kwetsenbeienboom, m. - Nederland. - Id. als HAver$\operatorname{EscH}(\mathrm{Vl}$. ITk.).

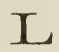

Laaielier, m. - Zwijnaarde, Eecke, Seeverghem en omstr. - Id. als LAvelier (= Laurierboom) (Vl. Wk.).

Laan, Lane, v. -- W.-V1. - $\mathrm{I}^{\circ}$ Phragmites communis Trin.; fr. Phragmites commun; vulg. Roseau; vl. Gemeen Dekriet. - $2^{\circ}$ De dunne deelen vau de Saladebladeren, zonder den steel of de ribben(fr. le parenchyme)(Kruidw.).

Laar, Lare (uitgang van zekere boomnamen).-Z. TEER (Bijv.).

Lampenpoetser, m. - Nederland. - Id. als KANoNpoetsers (Bijr.). - Voor uitleg, z. ook Kanneboenders (Bijv.). - Hier is er spraak van de rolvormige glazen der lampen te poetsen.

Lampionplant, v. - Nederland. - Id. als KRIEkskeNIN-(DEx)-ZAK (Vl. Wk.), en zelfde uitleg. - De rijpe vrucht, omringd van haren rooden, blaasvormigen kelk, lijkt op de gekleurde, bolvormige lampen (fr. lampes vénitiennes), die tot de verlichtingen dienen.

Lamsooren, o. mv. - Nederland. - Blitum BonusHenricus Rchb.; fr. Blite Bon-Henri; vl. Goede-Hendriks Sapkelk; Algoede Ganzevoet. - De bladeren der plant hebben eenige lijkenis met lamsooren ( $\mathrm{fr}$. oreilles d'ag'neau)

Landebloem, v. - Maaseyck en omstr. - Id. als SpaAxche Dorris (Bijv.).

Landjebloem, r. - Nederland. - Id. als MADELLEJE ( Ti. Mik.).

Landsloof, Lansloof, v. - W.-Tl. - Id. als DRIJBLAD ( I' l. I'k.).

Langschieter, m. - W.-Tl. - Id. als KEenspopleiter ( ${ }^{\prime}$ l. W'k. - Deze Populier schiet zeer lang omhoog.

Lansloof, r. - Z. LANisLoof (Bijr.). 
Lanteerning, m. - W.-Vl. - « Soort van langwerpigen, vierkanten Appel, witgeel van pelle, redelijk goed ran smaak en nog al vroeg rijp. Dus genaamd omdat zijn vorm gelijkt aan een kleen vierkante lanteerntje. ")(Kruidw.).

Larius, m. - W.-Vl. - Wordt hier en daar gehoord voor LARIx (z. Vl. Wk.).

Larke, m. - Nederland. - Id. als 't voorg. w. - Verb. van Lork, Lorkenboom.

Lauwerstijn, m. - Poperinghe en omstr. - Id. als LauWers-Tien ( Vl. Wk.).

Lavas, Lavasse, v. - W.-V1. - ro Levisticum officinale Koch; fr. Livèche officinale; vl. Genezend Lavas. $2^{\circ}$ Brandewijn, waarop voornoemde plant getrokken heeft (fr. infusion de Livèche dans le genièvre). - Z. ook EppEKRUID (Bijr.)

Lavermonje, v. - W.-Vl.- Id. als Averuoexie (Bijv.). Lazerre, V. - W. - V l. - Id. als Luzeers ( $\mathrm{Tl}$. Wk.), waarvan dit w. maar eene verb. is.

Leeuwenklauw, v. - Nederland. - Algem. naam van 't geslacht Alchemilla Tournef.; fr. Alchémille; vl. Leeuwentilauw. - Men heeft, in den vorm der bladeren, eene gelijkenis met eene leeuwentilauw gevonden.

Lei(e)wortel, m. - Meenen en omstr. - Id. als KALAMUSWorTEL (Vl. Wk.). - Alzoo genaamd, in deze streek, omdat de plant overvloedig groeit in de Lei (fr. la $L y$ s).

Lemmersteert, m.-Zwijnaarde, De Pinte, Seeverghem. - Verb. van Lammerstaart. - Id. als LAMMERSTLERTEX (Vl. Wk.).

Lentegrensing, v. - W.-Vl. - Potentilla verna L.; fr. Potentille printanière; vl. Lente-Ganzerik.-Grensing, in W.-V1., is synoniem van Ganzerik.

Lepelblad, o. - Io Te Gronsveld, Eysden en andere dorpen, bij Maastricht. - Id. als FLikKerkesboom (Vl. Wk.). - De vruchten gelijken aan twee kleine lepels te samengegroeid (fig. $7,8,9$ ). — 20 In Nederland. - Capsella Bursa-Pastoris Mönch.; fr. Bourse-à-pasteur; rl. Herderstasjes. - 30 In W.-V1. - Cochlearia Armoracia L.; fr. Cochléaire (Cranson) d'Armorique; vulg. Raifort 
sauvage; vl. Mierik-Lepelblad. - De rruchten of de bladeren dezer twee laatste soorten zijn lepelvormig.

Lepels-en-vorken, m. mv.- Nederland.- Id. als I_EPELBLAD, $2^{\circ}$ ) (z. 't voorg. w.). - De lepels = de bladeren der' plant; de vorken = haar lange viuchtentros.

Lepeltjesdief, m. - Nederland. - Id. als 't voorg. w.-Hier zijn de lepeltjes vertegenwoordigd door de vruchten der plant, ieder afzonderlijk beschouwd : zij hebben den vorm van lepeltjes. Dief zinspeelt op het groot getal der vruchten : zij zijn zoo talıijk, dat men zou denken dat de plant er zoo wat moet gestolen hebben.

Levendige-Peer, in. - Diest en omstr. - Id. als LEVENDig-KRuid (Vl. Wk.). - Peer = samentrekking van Peter, Petrus : een toenaain die 't volk in talrijke uitdrukkingen binnenbrengt. Voor verderen uitleg, z. Levendig-Kruid ( $\mathrm{Tl}$. Wk.).

Lidgras, o. - W.-Vl. - Id. als Pemen (Vl. Wk.).- De onderaardsche wortelstok (fr. rhizome) is uit talrijke leden samengesteld, die men licht van elkaar kan scheiden.

Liefdegras, o. - Nederland. - Algem. naam van 't geslacht Eragrostis Host; fr. Éragrostide, eene grassoort, met kleine, fijne aartjes, zeer lief om zien : wordt gebezigd voor de wintertuilen (fr. bouquets secs).

Lief-Vrouwkensvlas, o. - Coursel en omstr. - Id. als Heipluiskens (Vl. Wk.). - De haren der witte pluiskens gelijken op fijne vlasvezels.

Liesgras, o.- Nederland.- Glyceria aquatica Wahlb.; fr. Glycérie aquatique; vl. Water-Zoetgras. - Lies, lis, lesch, enz., bet., onder andere, een zweerdvormig blad (fr. feuille ensiforme). Nu, de beduide plant is eene grassoort, maar lieeft liesachtige bladeren.

Lieve-Vrouwkesvlas, o. - Beeringen en omstr. - Id. als Heipluiskens (Vl. Wk.).

Liever-Bedstroo, o. - Berthem. - Id. als O.-I.-V. Benstroo ( $\mathrm{V}$ l. Wk.).

Liewesse, v. - In 't V'eurne-Ambacht, noent men alzoo den waterhonig, de mede (ir. hydromel).

Lijkblaêr, o. mv. -- Beeringen en omstr. -- Id. als 
Klimop, $2^{\circ}$ ) (Vl. Wk.). - Lijk $=$ fr. corps mort, cadavre. De stam van het Klimop schijnt als dood, als een lijk, op 't grootste gedeelte zijner lengte; 't is op dat lijk dat men de immergroene bladeren ziet te voorschijn komen; vandaar : Lijkblaêr.

Lijsorboom, m. - Uitspr. Lizor. - W.-Vl. - Id. als Koningin-der-Weiden ( Vl. Wk.).

Lijsterbezen, v. mv. - Deze naam beduidt bijna overal de Haveresch (z. dit w., in Vl. Wk.). - Te Zwijnaarde en omstr., noemt men aldus ook de vruchten van den wilden Viburnum Opulus L.; fr. Viorne Obier; vl. Zwelkenhout. Watervlier.- De kleine, ronde vruchten worden rood, ongeveer als bij de Haveresch, en zijn door de lijsters gezocht.

Limoenkruid, o. - Nederland. - Statice Limonium L.; fr. Statice Limonium; vl. Limoenkruid. - De naam is eene verb. van het lat. w. Limonium.

Lisbotte, Lischbot, v. - W.-V1. - Het zaadhoofdje ran Lisch; fr. Glä̈eul; lat. Gladiolus.

Lisdodde, Lischdodde, v. - IV.-V1. - Id. als Don, DoDDE (VI. Wk.).

Lis- of Lischdoddegras, o. - W.- Y'l. - Verscheidene soorten van Phleum L.; fr. Phléole; vl. Phleum. - De bloeiwijze van deze grassoorten, eene lange, dichte, rolvormige aar, gelijkt heel wel (in 't klein), op den vruchtcilinder der Lischdodden.

Lis- of Lischkalm, m. - W.-Vl. - De wortel van KAL$\operatorname{MOES}$ (V1. Wk.).

Lof, o. - Nederland. - Id. als Wi'T-Loof (VI. Wk.). Lof $=$ verb. van Loof.

Logge. - Z. LugGE (Bijv.).

Lok, v. - Nederland. - Id. als Heipluiskens (Vl. Wk.). - Lok $=\mathrm{fr}$. boucle de cheveux. Zinspeling op de witte vlokken die, na den bloeitijd, de stengels dezer moerasplanten bekroonen.

Longerblaren, o. mv. - Oost-Roosebeke, Wielsbeke. Farfugium grande Lindl., eene gekweekte sieraadplant; de bladeren zijn groot, rondachtig en dragen gele, ronde 
vlekken. - De boerenlieden willen in die bladeren eene gelijkenis vinden met de longen eener koei. (A. De Jaegher.)

Looge, $r .-\mathbb{T} .-\mathrm{Vl}$. - Wordt in eenige gewesten gezegd voor Look; fr. Ail; lat. Allium.

Loogkruid, o. - Nederland. - Salsola Kali L.; fr. Sonde Kali; vl. Loogkruid. - Plant (ler zeeduinen, die sodazouten bevat. De soda- en de potaschzouten (ook aschzout) dienen om de loog (fr. eau de lessive) voor te bereiden. Vandaar Loogkruid; ook soms Sodakruid genaamd.

Look-zonder-look, o. - Nederland, W.-V1. - Sisymbrium Alliaria Scop.; fr. Sisymbre Alliaire; vulg. Alliaire; vl. Lookreukige Raket. - Plant van de familie der Kruisbloemigen (fr. Crucifères); dus gansch verschillig van al de soorten van Look, die tot de familie der Lelieachtigen (fr. Liliacées) behooren. Niettegenstaande, ruiken de versche bladeren en zaden der plant geheel en al naar knoflook. De plant is dus look (door den reuk) zonder waarlijk look te zijn. - Bovenstaande namen Alliaria, Alliaire, komende van Allium, fr. Ail, vl. Look wijzen op dezelfde bijzonderheid terug.

Lookbiezen, v. mv. - Beeringen en omstr. - Id. als LEUKBIEZEN (Vl. Wk..

Lookzim. - W.-Vl. - Zim $=\operatorname{sim}$, aap; van 't lat. simius, w. dat aap bet. - Id. als LoOK-ZONDER-LOOK (Bijr.): - Dus, eene plant die geenszins look is, maar het look wil nä̈pen, namelijk voor de geur.

Loovers, m. mv. - Te Zwijnaarde en omstr., bet. dit w. gewoonlijk de afgevallen bladeren van de wondboomen.

Lubbestok, m. - Nederland. - Id. als Lavas (Bijv.).

Lugge, v. of Logge, v. - W.-Vl. - Eene graanziekte; fr. la carie, veroorzaakt door eene Schimmelplant: Tilletia Caries Tul. genaand Deze ziekte randt bijzonder de Tarwe aan. - Z. ook GriJu (Bijv.).

Luisbloem, v. - Denderleeuw, Denderwindeke, Oultre (bij Ninove) en omstr. - Id. als Bosch-Aкwaxı( (Yl. Wk.). 
Luiskruid, o. - Nederland. - I $^{\circ}$ Id. als GAGEL (V1. Wk.). - 20 Pedicularis palustris L.; fr. Pédiculaire lles marais; vl. Moeras-Kartelblad. - Deze planten werden eertijds gebr. om 't ongedierte (fr. la vermine) te doen verdwijnen. - Pedicularis en Pédiculaire komen van 't lat. pediculus = luis (fr. pour).

Luismelde, v. - Nederland. - Id. als MaLeM, Iº) (Tl. Wk.).

Luizekoorn, o. - VV.-Vl. - Melampyrum arvense I.; fr. Mélampyre des champs; vulg. Rougeole; vl. VeldZwartkoorn.

- Luizen. - Z. Toввак - (Bijr.).

Lullemoederken, o. - W.-Vl. - Een van de talrijke namen die 't volk aan de Primula elatior Jacq. geeft; fr. Primevère élevée; vl. Hoogstengelige Sleutelbloem.

Luus. - Nederland. - Id. als Liesciras (Bijr.). - Verb. van Lies.

Luusch. - Nederland. - Carex acuta L.; fr. Carex aigu ou Laiche aig'ü̈; vl. Spitze Zegge. - Misschien verb. van Lies. Toor uitleg z. Liesgras (Bijr.).

\section{M}

Maagmunt, v. - Denderwindeke en omstr. - Mentha piperita Sin.; fr. Menthe poivrée; vl. Pepermunt. - In deze streek, wordt roornoemde Munt, en nog eenige andere soorten, gebr. als geneesmiddel tegen de maagpijn : men droogt gansch de plant, kapt ze in stukjes en maakt er thee van.

Maagdekeerse, r. - Veurne, Ghistel en omstr. - Id. als Pyramidaal (Vl. Wk.). - De bloeiwijze vormt als eene schoone lange keers. - Maagd, bet. hier waarschijnlijk de H. Maagd of O.-L.-Vrouw : deze bloemen dienen veel om, in Mei, de beelden van Maria te versieren.

Ma(a)lme, v. - Zwijnaarde en omstr. - Verb. vau MALUWE: z. dit W. (in Tl. Wk.). 
Maartenlook, o.- Nederland.-Gagea arvensis Schult.; fr. Gag’ée des champs; vl. Akker-Goudster. - De plant heeft eenen knolwortel (fr. bulbe) als look en bloeit rond Maart.

Madekeerse, v. - Verb. van Maagdekeers. - IV.-V1. Id. als. LEMTEKENSBLAREN ( $/$ I. Wk.).

Magerman, m.- W.-Vl.-Id. als KoNINGIN-DER-WEIDEN VI. Wk.). - Goed geneesmiddel tegen de waterzucht (fr. hydropisie) : wie, van te voren, door het water opgezwollen was, wordt, na gebruik, een mager man.

Majoraan, v. - Nederland. - Origanum Majorana L.: fr. Origan Marjolaine; rulg. Marjolaine; vl. Marjolein.Eene verb. van den lat. naam Majorana.

Makeblijde, v. - W.-V1. - Euphrasia officinalis I.; fr. Euphraise officinale; vl. Gewone Oogentroost.- Makeblijde is de vertaling van Euphrasia, w. dat van't gr. komt en blijdschap bet.

Maldegeer, v. - Nederland. - Gentiana cruciata L ; fr. Gentiane Croisette; vl. Maldegeer. - Het volk bezigt dus den waren nederl naam.

Malotte, v. - W.-V1. - Melilotus officinalis I.; fr. Mélilot officinal; vl. Genezende Honighlaver. - Grove verb. van Mélilot.

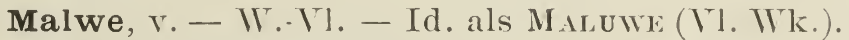

Mannetjes-en-Wijvetjes, o. mv. - W.-Vl. - Id. als Bolikens-Ex-Boerinnetjes (Bijv.). - Buiten den uitleg die wij hooger voor Boerkens... gegeven hebben, zou men ook kunnen aanmerken dat de bloemen dikwijls verschillig" zjin van kleur: de eene ziju rood, de andere wit; het volk zal er een verschil van geslarht in gezien hebben.

Malwillempjeskruid, o. - Nederland. - Hyoscyamus niger L.; fr. Jusquiame noire; vl. Bilzentruid; ook Dolkruid genaamd. - Mal, m. = model, in 't klein, waarnaar' iets gemaakt moet worden (fr. modèle, putron, à échelle réduite). - Een tvillempje = gouden nederlandsch geldstuk (waarle : ro gulden). - Nu, de bloemkroon der plant is geel van kleur (goudkleur); haar opperste deel is rond en zreëffend als cen geldstuk en men ziet er zekere teeke- 
ningen : zij is violet geaderd (fr. gaarnie de veines violettes). Vandaar Malwillempjestiruid.

Mare, v. - Dit w. bet. eigenlijk in 't fr. cauchemar, fiève. - In W.-Vl., gebr. men de uitdrukking' van de mare bereèn (roor bereden), om te bet. dat een tak plat gegroeid is, in plaats ran rolvormig te zijn, rolgens den algem. regel (fr. fascie: fasciation).

Marentak, m. - Z. Vl. Wk. - Wij zullen er bijvoegen dat, rolgens sommige schrijvers, de plant dezen naam kreeg omdat hare takitien zoo taai zijn dat men er de maren melle kan binden (fr. cauchemars, fièvres). - Z ook 't roorg. $w$.

Masschel, Masscher, Masser, m. - Z. MAssel... (Vl. Wk.). - Te Zwijnaarde, Eecke, Seererghem, Sint-DenijsWestrem en omstr., gebr. men Masser in den zin ran Tilletia Caries Tul.; fr. Carie des blés; rl. Vermolming.

Masscher. - Z. Masschel (Bijv.).

Masser. - Z. Masschel (Bijr.).

Masteluin, 0.- Antwerpen en omstr. - Id. als MAsLuix (Vl. Wk.).

Matboom. - Z. Мatтевоoм (Bijv.).

Matelieve, r.- W.-Tl.- Id. als MadeliefJe (Vl. Wk.). Mater, r. - Oost-Roosebeke en omstr. - Id. als MATER. 3o) (Vl. Wk.).

Matroosjes, o. $\mathrm{mr}$. - Nederland. - Dielytra spectabilis DC.; fr. Diélıtre remarquable. - De bloeiwijze, met hare talrijke, schoone, platte en neerhangende bloemen, doet natuurlijk denken aan een schip dat net wimpels en vlaggen rersierd is. Vandaar is 't rolk tot 't gedacht ran matroosjes overgegaan.

Matteboom, Matboom, m. - W.-Vrl. - "Zonder wr., zijude een collectief. Varieteit van den Buxus sempervirens L.; fr. Buis; vl. Buksboom, die maar een roet hoog groeit, en veeltijds de bloemperken in de hoven omringt en zoomt, fr. buis à parterre, buis nain. " (Kruidw.).

Mee. r. - Nederland. - Rubia tinctorum L.; fr. Garance des teinturiers; vl. Meekrap.- Mee is de verminking van dezen latsten naam. 
Meekop, m. - W.-VTl. - Id. als Meikoppen (Vl. Wk.). Meekrap, r. - Nederland. - Z. MeE (Bijv.).

Meelraai, r. - Nederland. - Holcus lanatus L.; fr. Houlque laineuse; vl. Wollig Zorggras. - Raai is de naam eener andere grassoort, niet zonder lijkenis net de deze; maar aangezien deze laatste met een witachtig. harendons overdekt is werd zij Meelraai genaamd (meel, fr. farine).

Meelw, Meelwig, Meluw, bijv. - W.-Vl. - “ Wordt gezegd van rijp fruit, dat met te liggen zacht en teeder geworden is. Meelwe appels." " (Kruidw.).

Meelwig. - Z. 't voorg. w.

Meerdistel, v. - Nederland. - Eryngium maritimum L.; fr. Panicaut maritime; vl. Meerdistel; Zeedistel. - De plant is stekelig als eene distel en groeit alleen in de zeeduinen.

Meereke(n)spalm, v. - Herenthals en omstr. - Id. als $\operatorname{ME}(\mathrm{E})$ REKESPALM (Vl. Wk.).- In zekere plaatsen, ver vormt de $d$ zich nog al gemakkelijk tot $r$ : alzoo gat me(e)deken tot me(e)reken over. - Bij plechtige inhalingen en in de processiën, worden kleine meisjes in 't wit gekleed en bekranst met takjes ran deze plant: deze kinderen noemt men meerekens (in Zuid. Belg.-Limb. : bruidjes). - De bladeren der plant gelijken aan die van de Palm (fr.buis). - Voor verderen uitleg, z. ook ME(E)REKESPALM (Tl. WVk.).

Meerschenplaag, v. - Denderwindeke en omstr. - Id. als Borstels (Vl. Wk.). - Dit kruid is roor sommige weiden, beemden, enz. eene ware plaag.

Meerschratelaars, m. mv. - Poperinghe en omstr. Id. als Meerschratel ( Vl. Wk.).

Mei. - Z. Strinkende - (Bijv.).

Meibottelen, v. mv. - Reckheim en omstr. - Id. als

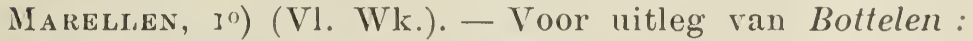
Z. Bottelbremen (Bijv.). De Marellen komen in 't begin van Mei.

Meibotten, v. mv. - Reckheim en omstr. - Id. als het voorg. w.

Meien, v. - Nederland. - Id, als Menzoom ( V I. Wk.). 
Meienhout, o. - Oost-Roosebeke.-Id. als Berkenhout (fr. bois de Bouleau).

Meikeest, m. - Oost-Roosebeke en omstr. - Eene varieteit van witten Aardappel, die slechts in de Meimaand keest of kiemt.

Meikruid, o. - Nederland. - Id. als Meidraxk (V'l. Wk.) en zelfde uitleg.

Meiroos, r. - W.-Vl. - Men gebr. bijua altijd het verklw. Meiroosje. - Kerria japonica L. (CorchorusThumbg.); fr. Kerria ou Corète du Japon. - Een sierstruik uit Japan, veel in de tuinen gekweekt, schoone gele roosjes dragende die in Mei blocien.

Meirooskes, o. $\mathrm{mr}$. - Zwijnaarde. De Pinte, Seeverghem. - Id. als Oranjebloem (Vl. Wk.).

Melekaton, v. - W.-V1. - Id. als Merkaton (Bijr.).

Meliefke, o. - Nelerland. - Id. als MadeliefJE (V1. Wk.i, waarvan het W. maar eene verb. is.

Melkbloem, v. - Nederland. - Id. als Mílktinger, (V'. Wk.). - De kinderen zuigen den honig uit de witte bloemen : vandaar' 't gedacht aan melk, bij 't rolk (fig. 33).

Melkjeskruid, o. - W.-T'. - Id. als Kroonkenskruid ( Vl. Wk.). - De plant bevat een sap (fr. latex), wit als melk, maar zeer brandend.

Melknetel, v. - W.-Vl. - Id. als MeLkbioem (Bijv.).In IV.-Vl., zegt men ook - nittel, - hittel.

Melkplaat, - plate v. - W.-VI. - Tragopogon pratensis I.; fr. Salsifis des prés; vl. Beemd-Boksbaard: Het sap (fr. latex) is wit als melk. - Plaat (verb. van planl?), alleen gebr., lueeft denzelfden zin als Melkplaat, in deze streek.

Melkwied, o. - $\mathrm{I}^{\circ}$ Poperinghe en omstr. - Id. als HAZEKOOLEN (Vl. Wk.). - $2^{\circ}$ Elders, in W.-Vl., id. als Pisblonu (fig. 24) ( $\mathrm{fl}$. Wk.). - Wied = onkruid. - Het sap) (fr. latex) dezer twee plantsoorten is wit als melk.

Mellewijt, o. - Nederland. - Id. als Hazekoolex (Vl. Wk.). - Mellewijt is Waar'schijnlijk maar eene verb. van Melkwied : z. 't voorg. w.

Melote, v. - Nederland. - Id. als MaLot're (Bijr.). 
Mengelsoen, Mingelsoen, 0.- $\mathrm{W} .-\mathrm{V}^{\top} 1 .-\mathrm{Id}$. als M AsLuiN (Vl. Wk.).

Mennekersstaar, v. - Nederland. - Phalangium Liliago Schreb; fr. Phalangie à fleurs de Lis; vl. Leliebloemige Phalangium. - De bloemen ziju gelijk kleine witte sterren. Het volk heeft zich de Kerstster (fr. éloile de Noël, étoile des Mages) herinnert, die de drij Koningen naar de kribbe mende (d. i. geleidde).

Mennistezusjes. o. inv. - Nederland. - Id. als HoELANGER-HOE-LIEVER, $2^{\circ}$ ) ( $\mathrm{Vl}$. Wk.): - Zulsjes=zusterkens. Mennisten = zekere secte vin doopsgezinden (te lang om hier uit een te doen; z. de Woordenboeken). - De lieve bloempjes dezer plant staan dicht bij elkander en schijnen kortelings gedoopt te zijn : hunne bloemblaadjes zij nals met schoone roode druppeltjes overdekt; vandaar : Mennistezusjes.

Merdellewortel, m. - IV.-Vl. - Id. als BorDELLEWORTEL ( $\mathrm{Vl}$. Wk.).

Merkaton, v. - Antwerpen en omstr.; Zuid. Belg.Limb. - Eene groote gele perzik, die eerst in den herfst rijp is; fr. mirlicoton; sp. melecoton - Merkaton $=$ verb. van deze laatste namen.- In W.-Vl., zegt men Mellekiton en Melehaton.

Meruwe, Meerwe, Merwe, v. - IV.-VI.- Eene Schimmelplant, die bijzonder de bladeren der graan-en grassoorten aantast en daar verschijnt onder den vornu van geel bruin - of zwartaclitig stof. \%. Braxd (Vl. Wk.).-Heden worden bijna al die vormen tot ééne soort van Schimmelplant teruggebracht, Puccinia Graminis Pers. genaand; fr. Puccinie des Graminées. - Voor verderen nitleg, \%. onzen Cours de Botanique, 3ne uitgave, bl. 45.2.

Messeljoen, Misseljoen. Misteljoen, enz, (). - IV... V'l. - Id. als MAsuuin ( $\mathrm{Tl}$. Wk.).

Metel, Medel, r. - Nederland. - Id. als Plumuras, $\mathbf{I}^{\circ}$ ) ( $\mathrm{Tl}$. Wk.).

Meulenaarstenkte, $、-\mathbb{W}^{*}-\mathrm{V}^{\top} \mathrm{I}-\mathrm{-Potentilla}$. Inserina I.; rr. Potentille Ansérine; vl. Zilverschoone Ganzerik.Tenkle, in W.-Vl., is synoniem van Rennvaris (VI. Wk.). 
De bladeren dezer soort en die der Potentilla Anserina gelijken grootelijks op malkander, voor 't geen den vorm aangaat; maar de bladeren der Potentilla zijn wit, alsof er meel overgestrooid was; vandaar : Meulenaarstenkte.

Mezerieboompje, o. - W.-Vl. - Id. als M I Z E R I E B O O II K E ( N ) (Vl. Wk.). - Verb. van den lat. naam Mezereum (fig. 37).

Meziebeen, 0 . W.-T'. - Z. MUGGeBEEN (Bijv.). - Z. ook 't volgende $w$.

Mezierook, Muggerook, m. - IV.-Tl. Wierook, fr.encens. -

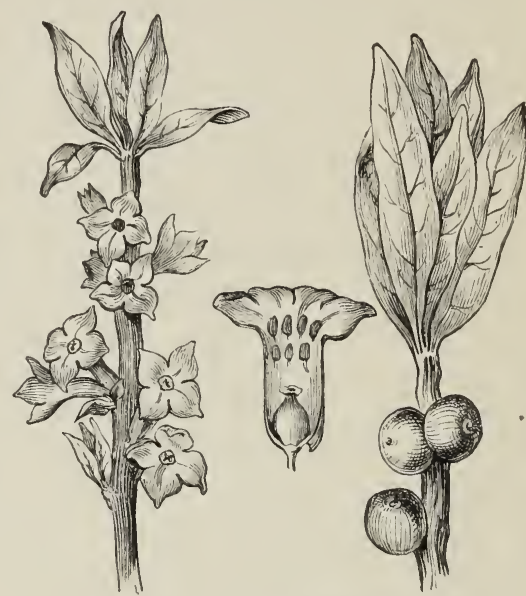

Fig. 37. - Daphne Mezereum.

Zie hier den uitleg van deze zonderlingheid. Mezie, in 't westvlaamsch. = mugge. $\mathrm{Nu}$, in $\mathrm{W} .-\mathrm{Vl}$., bestaat het gebruik van gomhars van sparhout (fr. résine) op kolen te branden, om de muggen, anders meziën, uit eene kamer te verjagen. - De wierook is ook eene gomhars (eene buitenlandsche) en dewijl hij, al brandende, ook veel rook verspreidt, heeft 't volk er geen. verschil in gezien en heeft alles met denzelfden naam bestempeld.

Miemeren. - Z. ROODE - ZWARTE - (Vl. Wk.).

Mierbloem, v. - W.-V1. - Draba verna L.; fr. Drave printanière; vl. Lente-Vroeg'eling.

Mierebellen, v. mv. - Zwijnaarde eu omstr. - Vruchten van Prunus Myrobalana Desf.; fr. Mirabelles; vl. Mirabellen.

Mieregras, o.- In 't westvl. - gars; - gers. - W.-Vl. - Festuca duriuscula L.; fr. Fétuque duriuscule: vl. Hard Zwenkgras.

Mijten. - Z. StruIKen (Bijr.).

Mingelsoen. - Z. MeNGELsonen (Bijv.). 
Miltezaad, o. - W.-Vl. - Id. als VogelzaAD (Vl. Wk.).

Mistletoe. - Nederland.- Id. als Marentak (Vl. Wk.). - Mistletoe is de eng. nam der plant, naam die in Nederl. verhuisd is.

Moeder-met-hare-Kinderen, v. - Denderwindeke en omstr. - Id. als Moederkex-VAN-duizend-Kinderex ( $\mathrm{T}$ ]. IVk.).

Moeder-van-alle-Bloemen, v. - Oost-Roosebeke, IVielsbeke. - Eene Begonia soort (?), met kleine bloempjes en kleine bladeren, zegt A. De Jaegher.

Moeder-van-duist-Kinders, v. - Poperinghe en omstr. - Id. als Moederkex-van-duizend-Kinderen (Vl. Wk.).

Moenebezen, v. $\mathrm{mv}$. - Men zegt ook : Moerbezen en Mottebeiers, in denzelfden zin. - W.-V1. - Id. als MoErBEZEx (Vl. Wk.). - Morre (moer) is 'tzelfde als Motte, dat, bij Kiliaan, scrofa, sus, porca bediedt (Kruidw.); fr. sanglier; vl. everzwijn, wild zwijn. - Moene = verb. van moere. - Dus bezen die groeien daar war de everzwijnen zich ophouden, d. i. in de bosschen.- Elders, heet de plant ook Boschbezen, (z. V1. Wk.).

Moerbeiers, Moerebezen.- IV.-V1. - Id. als 't voorg. W.

Moerbloem, v. - Maastricht en omstr. - Id. als MuURBLOEM (Bijv.).

Moffepijp, v.-Nederland.-A ristolochia Sipho L'Hérit.; fr. Aristoloche Siphon; vl. Hevel-Barrkruid. - De bloem der plant is pijprormig en gelijkt bijzonder op eene duitsche pijp of moftepijp. - Mof = duitscher.

Moliezen, v. mr. - Zwijnaarde en omstr. - Azalea mollis Blume en 1. pontica L.; fr. Azalée molle en'A. du Pont; vl. Malsche en Pontische Azalea.-Moliezen= verb. van het lat. bijv. mollis.

Molleboonen, v. mr. - Zwijnaarde en omstr. - Phaseolus multiflorus Lamk.; fr. IIaricot multiflore; vl. V'eelbloemige Klimboonen; ook Pronkboonen, d i. die alleen voor' 't siercad gekweekt worden.

Mollebout, Mollesteert, in. - IV.-VT. - Alopecurus geniculatus L.; fr. Vulpin genouillé; vl. Geknikte Vossestaart. - Bout en sleert wijzen terug op den rorm der bloeiwijze. 
Mollekrieken, v. mv. - IV.-Vl. - I Id. als KALFsPoO'T (Vl. Wk.). - Wordt bijzonder gezegd van de vruchten, die eenen tros van roode krieken (roode bessen) vormen, als zij rijp zijn. - $2^{\circ} \mathrm{W} .-\mathrm{Vl}$. - Id. als KrIEKAPPELKENs (Vl. Wk.).

Mollesteert. - Z. Mollebout (Bijr.).

Mommel, m. - W.-VT. - Id. als KaAsbrood (Vl. Wk.).

Mommeren, v. mv. - Millen en omstr. - Id. als MARELLEN, I ${ }^{\circ}$ ) (Vl. W'k.) (lig. 38).

Monnebeier, Mounebeier, m. W.-VI. - De vruchten van den Braam : z. dit w. (Vl. Wk.).

Monst, o.- W.-Vl.- Id. als Mos' (Vl. Wk.).

Mooren, v. inv. - Nederland. Id. als Heipluiskens (V1. Wk.). Mooren is waarschijulijk een verb. van Moeren. - Moer (onzijdig) = een moeras. De Ileipluiskens zijn uitsluitelijk moerasplanten.

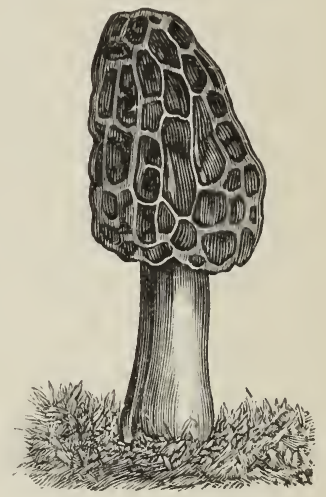

Fig. 3s. - Morchella esculenta.

Moos, o. - Maastricht en omstr. - Id. als moes; $\mathrm{fr}$. légumes. - Men zegt ook zoermoos = fr. choucrô̂te.

Morelle, v. - Denderwindeke en omstr. - Id. als Nachtschade, $\left.\mathrm{I}^{\circ}\right)$ ( $\mathrm{Tl}$. Wk.). - Morelle is de fr. maam der plant (lig. 2).

Morgenster, v. - Nederland. - Id. als ELF-URE-BLoen (Vl. Wk.). - De bloem is stervormig en opent zich 's morgends (omtrent elf uren).

Mottebeier, m. - W.-Vl. - Id. als Moenebezen (Bijv.). Motdissel, v. - Nederland. - Id. als HAzekoolex (V'l. IV.). - Mot, r. = zeug, varken. - De plant heeft stekels gelijk eene distel, en de zeugen of varkens (motten) zijn er op) zeer rerlekkerd.

Motijzel, v. - Id. als 't vool'g. w. - IJ zel=doorzichtig ijskleed dat soms den grond bedekt (fr. verglas). De bijzondere (grijsachtige) kleur der plant ziet er uit alsof deze met ijzel bedekt was. - Voor mot, z. uitleg bij 't voorg. w. 
Mottekruid, o. - $\mathrm{I}^{\circ}$ Beeringen en omstr. - Id. als GAGEL (Yl. Wk.). - De sterke geur dezer plant verdrijft de molten (fr. teignes), zoo men beweert. - 20 Exaarde, Saffelare en omstr. - Id. als Meidrank (Vl. Wk.).

Mounebeier. - Z. MonnebeIER (Bijv.).

Mouzekeutelkes, o. mv.-Zoo noemt men, te Mastricht en omstr., naar den vorm, het in suiker ingewikkelde A nijszaad dat men bij de suikerbakkers vindt.

Muggebeen, o.- $\mathrm{W}^{\top}$.-Vl. en Nederland.- Id. als PiuimGRAS, $1^{\circ}$ ) (Vl. Wk.).

Muggerook. - Z. Mezierook (Bijv.).

Muide, v. - W.-Vl. - Id. als Hondsdille (Vl. W'k.).

Muisoogskens, o. mv. - W.-Vl. - Veronica Chamaedrys L.; fr. Véronique Petit-Chêne; vl. Gamander-Eereprijs.-De schoone blauwe bloempjes gelijken niet slecht op muisoogskens.

Muisoor. - Uitspr. Muuzoore. - Poperinghe, Kortrijk en omstr. - Id. als Vergeet-MrJ-NieTJes (VI. Wk.). - Naar. den vorm van het blad, dat op een muisoor gelijkt. - De lat. naam Myosotis (die van 't gr. komt) heeft dezelfde bet (fig. 39).

Muizekoorn, o. - W.-VI. - Lolium perenne $\mathrm{L}_{\text {.; }}$ fr. Ivraie vivace; vl. Gemeene Dolik; vulg. RayGrass.

Muizenoorekens, o. mv. - Denderwindeke en omstr. - Id. als IEGEL (Vl. W'k.).

Muizesteert, m. - Kerkom en in 't Hageland. - Alopecurus pratensis L.; fr. Vulpin des prés; vl.

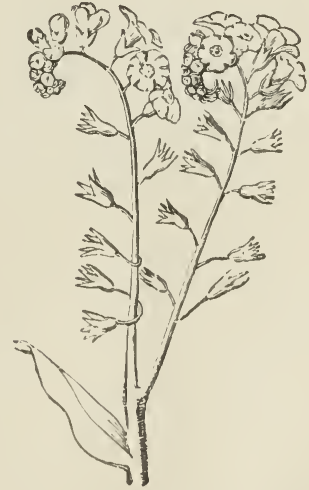

Fig. 39. - Myosolis palus/r)is. IVeide.T'ossesteert.

Muntpeeën, m. mv. - Denderwindeke en omstr. - Id. als Verdmunt ( $\mathrm{T}$ l. Wk.). - Deze Munt heeft lange onderaardsche stengels, die peeёn genoemd worden. - Z. ook Penc, Penës, in 't Vl. Wk.

Murik. - Nederland. - Id. als Muuk (I']. IVk.). 
Murke, v. - W.-Tl. - Id. als MuUR (Tl. Wk.).

Murre, v. - W.-Tl. - Id. als Mucr (Vl. Wk.).

Muskadeldruif, v. - W.-V1. - Fr. Raisin muscat. Z. ook Kattepisse (Bijr.).

Muspel, m. - W. Vl. - Id. als MispeL (Vl. Wk.).

Muurbloem, r. - Maastricht en omstr. - Id. als Flierex, I ${ }^{\circ}$ ) ( $\mathrm{T} 1$. Wk.).

Muzelaan. - Kerkom. - Id. als Postelein ( $\mathrm{V}^{\mathrm{l}} \mathrm{l}$. Wk.).

\section{N}

Naakte-Mannetjes, o. mr. - Tederland. - Id. als SxEectrklokJes ( Vl. Wh.).

Naakte-Naarsjes, o. m. - Nederland. - Id. als 't roorg. $\pi$.

Naakte-Wijfjes., o. mr. - Yederland. - Id. als 't roorg. W.

Naalde(n)kruid, o. - Berthem en omstr.- Id. als KAMMEKE(x)SKRUID (Bijr.).

Nachtkerse, r. - Verb. van - keers. - Gerstingen en omstr. - Enothera biennis L.; fr. Onagre bisannuelle; vl. Tweejarige Nachtheers. - De bloemen staan 's nachts alleen open en de rorm der bloeiwijze gelijkt aan eene keers.

Nachtschel, v. - Maaseyck en omstr. - Id. als NAchtscHADE (V1. Wk.). - Verb. van Nachtschade, W. dat, in eenige plaatsen, ook Nachtschaal, - schaai, enz. uitgespr. wordt. De bolrormige rruchten der plant gelijken op schelletjes (fr. grelots) (fig. 2).

Nachtschui, r. - Berthem. Id. als 't roorg. $W$. - Verb. van Nachtschaai, enz.

Neuning. - Z. Hexisg, Hохпя

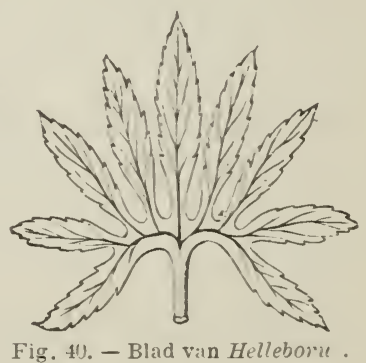
(Bijv.).

Nieskruid, o.- Nederland.-Helleborus L., in 't algem., fr. Hellébore; vl. Niestruid (fig. 4n). 
Nieswortel, m. - W.-Vl., Nederland. - Id. als 't voorg. w.

Nimfkruid, o. - Nederland. - Najas L., in 't algem.; fr. Nä̈ade; vl. Waternimf. - Leeft in 't water, gelijk de Nä̈aden of Waternimfen.

Nimmerstil, v. of o. - Asch, Opoeteren, Kessenich en omstr. - Briza media L.; fr. Brize intermédiaire; vulg. Amourette; vl. Siddergras, Irilgras. - De halmpjes dezer. grasplant zijn bijna altijd in beweging, zijn nimmer stil.

Nippens. - Z. KNippers (Bijv.).

Noenbloem, v. - W.-V1. - Crocus luteus L.; fr. Safran jaune; vl. Gele Saffraan.-- De bloem opent zich bij den noen, d. i. omtrent's middags. - Men gebr. ook soms den volgenden naam.

Noenluiker, m. - IV.-V1. - Id. als HoLeErze (Bijv.).

Notemeschaten, v. mv. - Zwijuaarde, Eecke, Seeverghem en omstr. - Id. als Muskoot (Vl. Wk.).

N'oubliekens, o. mv. - Denderwindeke en omstr. - Id. als Vergeet-mij-Nietjes (Vl. Wk ). - Verb. van den fr. volksn. "Ne m'oubliez pas » (fig. 39). - Overigens, in deze streek, noemt 't volk vele planten bij hare fr. namen : Muguct, Estragon, Pomme d'amour, enz.

Nunnekouse, v. - Veurne, Loo en bijna geheel VeurncAmbacht door.- Id. als KatTEKousen (Vl. Wk.).—Z. ook Holeerze (Bijv.).

Kuppens. - Z. KNiplirs (Bijv.).

\section{O}

Olde-Witte, m. - Nederland. - Nardus stricta L.; fr. Narl roide; vl. Stijue Nardus, vulg. Borstelgras. - Verb. van Oudle-Witte. Deze grassoort vormt ronde grijsachtige bossen, die niet slecht aan 't hoofd van een ouden witten man gelijken. - Old, in 't engl. = oud.

Onderate, v. - $\mathrm{I}^{\circ}$ Oost-Roosebeke en omstr. - Bromus sterilis I.; fr. Brome stérile; vl. Schrale Inravit.-Elders, 
in $\mathrm{W}$.- T1., zegt men soms ook Verbasterde Ate. - Ate = Wilde Haver. - $2^{\circ}$ In 't V'eurne-Ambacht, zegt men Ounderate; misschien roor Hoender-ate.

Onderhave, v. - Nederland; IV.-Vl. - Id. als OxderHAAF (VI. W'k.).

Onderwas, m. of o.- Te Oostham en omstr. - Boompjes en struiken die door de hooge boomen, waar ze onder staan, rerstikt worden.

Onschuld, v. - Nederland. - Arabis alpina L.; fr. Arabette des Alpes; vl. Alpische Scheefkelk; vulg. Randjesbloem. - Teel gekweekt als sierplant, bijzonder om de bloemperken te omzoomen. - De bloeiende planten zien er waarlijk zoo argeloos en onschuldig nit.

Ons-Heeren-Handjes, o. mr. - Maaseyck en omstr. Cardamine pratensis L.; fr. Cardamine des prés; vl. IVeide-Kers.

Ons-Heeren-Traantjes, $0 . \mathrm{mr}^{-}-\mathrm{I}^{\mathrm{o}}$ Poperinghe en. omstr. - Id. als Hoe-LaNGer-Hoe-Liever (Tl. Wk.). $2^{\circ}$ Flders, in W.-Vl. : Polygonum orientale L.; fr. Renonée du Levant; vl. Oostersche Duizendknoop. - De eerste plantsoort draagt kleine roode puntjes op de bloemkroon; de tweede, roodachtige vlekken op de bladeren : 't rolk heeft er bloedtraantjes van den Zaligmaker' gezien.

Ons-Lieven-Heeren-Nageltjes, o. mv. - W.-Vl. - Id. als Beurzekenskruid, $\mathbf{I}^{\circ}$ ) (Vl. Wk.): - De vruchten, die drijhoekig zijn en op een fijn, lang steeltje staan, gelijken waarlijk aan nagelljes.

Ontzwelkruid, o. - W.-Tl. - Id. als Eexdexderm (Vl. Wk.). - " Deze plant heeft den naam van alle vurige gezwellen spoedig te troosten en te doen slinken ". (Kruidu.).

Onze-L.-V.-Hemdekens, o. mr. - Maastricht en omstr. - Id. als HaAglelie (Vl. IVk.). - Zoo genoemd om de schitterende witte kleur der bloemkroon.

Oogenbloemen, v. mv. - Denderwindeke en omstr. Euphrasia officinalis L.; fr. Euphraise officinale; vulg. Casse-lunette; vl. Genezende Oogentroost. - Eertijds reel gebr. tegen de oogziekten. 
Oogenklaar, r. - Nederland. - Id. als StrixkendeG.ıUWE (Vl. Wk.).- Werd eertijds gebr. tegen de oogrlek en andere oogziekten; vandaar ook de fr. rolksn. Éclaire $=$ die de oogen klaar maakt.

Oorling, m.; Oorlingkruid, 0. - W.-V'1. - Arum maculatum L.; fr. Gouet tacheté; vulg. Pied-de-veau; rl. Gevlekte Kalfsvoet; vulg. Aronskelk. - Oorling $=\mathrm{id}$. als oorring; fr. boucle d'oreille. - De plant is dus genaamd omdat het bloemkolfken (fr. spadice) de gedaante heeft van eene oorbel (fr. boucle d'oreille) (fig. I2).

Oosterlucie, v. - IV.-VI. - Aristolochia Tournef; fr. Aristoloche; vl. Baarwortel, Holwortel, Pijplinid; in 't algem. - Oosterlucie is eene grove verb. van den lat. naam Aristolochia. - Vglk. Dulle kamare, komende van dulcamara, enz.

Opeelbloem, v. - Poperinghe en omstr. - Id. als TroßBrLs (Vl. Wk.). - In 't Poperingsche, opeel en kapeel = ruiker, bloemtuil.

Oploop, m. - Kerkom, Sint-Joris-Winghe. - Id. als OMLOOP $\mathrm{I}^{\circ}$ ) en $2^{\circ}$ ) ( $\mathrm{Vl}$. Wk.).

Oppens. - Z. Kxippers (Bijv.).

Osse(n)tong, v. - Nederland. - . Inchusa officinalis L..; fr. Buglosse officinale; vl. Gewone Ossetong.-Deze naam is de letterlijke overzetting van Buglosse, w. dat uit twee gr. woorden is samengesteld, die dezelfde bet. hebben. De bladeren hebben min of meer den rorm eener ossetong.

Ounderate. - Z. ONderate (Bijv.).

Overesschen, v. - Zwijnaarde en omstr. - Id. als Haveresch (Vl. Wk.).

\section{$\mathrm{P}$}

Paardebloem, v. - Oultre (bij Ninove). - Id. als GriTENBAARD (Vl. Wk.). - Te Oultre, wordt de plant ook Thee genamd, omdat ze veel gebr. worlt om thee te bereiden. 
Paardeknap, m. - Berthem. - Id. als PAARDEBEET ( $\mathrm{V}^{\mathrm{T}}$. I I k.).

Paaschsleuterkens, o. mv. - Winkel-Sint-Elooi. - Id. als PaAschlelie ( $\mathrm{Tl}$. Wk ). - De bloem heeft min of meer den rorm van eenen horlogiesleutel en is open, rond Paschen.

Padaan, Padane, v. - W.-Vl. - Id. als HoEVENBLARLiN (Vl. Wk.). - Padach,... is eene verb. van den fr. rolksnaam Pas-d'âne.

Paddegès, o., - gras, - gars, - gers, o. - Io Stavele, Oost-Roosebeke. - Juncus bufonius L.; fr. Jonc des crapauds; vl. Padde-Bloembies. - De plant trekt op gras en groeit in rochtige gronden, waar de padden liefst hun verblijf houden. - $2^{\circ} \mathrm{Zwijnaarde.} \mathrm{-} \mathrm{Wordt} \mathrm{hier,} \mathrm{maar}$ zelden, gebruikt roor Festuca ovina L.; fr. Fétuque ovine; vl. Schapen-Zwenkgras.

Paddevlas, o. - Oost-Roosebeke, omstr. van Roeselare en Thielt. - Io Linaria vulgaris Mill.; fr. Linaire commune; vl. Gemeen of Groot Vlastruid. - $2^{\circ} \mathrm{Bij}$ de landbouwers, (ibidem) : "Variëteit van Vlas, dat met dikke en korte kerels (stengels) opgroeit en weinig hippens (zaadbollen) opbrengt. Het paddevlas is ran geringe weerde ». (Kruidw.). - $3^{\circ}$ Te Denderwindeke en omstr. Id. als Spurrie (Vl. Wk.).

Paling(s)kruid, o. - I $^{\circ}$ Gheel, Westerloo en omstr. Salvia officinalis I.; fr. Sauge officinale; vl. Genezende Salie. - Wordt gebr. in de bereiding van mosselen, visch (paling, enz.). - $2^{\circ}$ W.-VI. - Id. als MAJoraAx (Bijr.). 3o In eenige plaatsen van $\mathrm{W}^{*}$.V1. : Ranunculus aquatilis L.; fr. Renoncule aquatique; vl. Water-Ranonkel. - De uitleg voor $2^{\circ}=\mathrm{id}$. als voor den $\mathbf{1}^{\circ}$. - Voor den $3^{\circ}$ : Plant die groeit, daar waar de palingen zich ophouden.

Pameele, v. - IV.-T'i. - Id. als Krobbelgerste (Bij v.).

Pannekoekjes, o. - Nederland. - Id. als BAKKRUID (Vl. IVk.) en zelfde uitleg.

Papbies, v. - W.-V1. - Id. als Biezen (Vl. Wk.), uitgenomen de Steenbies (z. dit w., in Bijr.). 
Papeneuzen, v. mv.-W.V1.-Id.als RATELKi (V1. Wk.). -De bloemkroon gelijkt, van voren, op eene neus : vandaar ook de lat. naam Rhinanthas, die Neusbloem beteekent

Papenstoelen, m. mv. - Nederland - Id. als Pisiroey (VI. Wk.).

Papoen, m. - W.-V1.-Id. als Pompoen; fr. Citrouille; lat. Cucurbita Pepo I. - Papoen is verb. van 't lat. Pepo. Eenige oude schrijvers hebben : Pepoen. - Zooals men, van papier, pampier heeft gemaakt, zoo ook hebben wij, met die ingeschovene $m$ : Pampoen, Pompoen, enz.

Pappeblaars, o. mv. - Oost-Roosebeke. - Id. als KaAsBrood (Vl. Wk.). - De bladeren dienen om pappen (fr. cataplasmes) te maken. - Men zegt ook Pappels, in denzelfden zin (fig. 29).

Paradijshout, o. - W.-Vl. - Bij hoveniers. Hout nit zaad voortgesproten en niet geënt; fr. sauvageon. - Op paradijshout enten; fr. greffer sur sauvageon (Kruidw.).

Paraplwiekens, o. mr. - Lebbeke. - Id. als KRooNKkskRUID (Vl. Wk.). - Zinspeling. op de rangschikking der bladeren die aan een regenscherm gelijkt.

Parinnen, m. mv.- Men zegt ook Parins.- Poperinghe en omstr. - Bruinachtige Appels die aan de Peerappels gelijken (z. Vl. WVk.).

Parins. - Z. 't voorg. w.

Pasnakel, v. - Zwijuaarde en omstr. - Id. als PAsteNAKEN ( Vl. Wk.).

Passijntje, Pasijntje, o. - V.-Vl. - Viola tricolor L.; var. hortensis; fr. Violette tricolore, vulg. Grande Pensée; vl. Groote driekleurige Viool; Groote Pensée. - Passịjntje $=$ verb. van Penseetje.

Pastoorkinderkens, o. mv. - Denderwindeke en omstr. - Id. als Koet.Jes (Bijv.). - Deze naam wordt bijzonder toegepast op de rijpe vruchten der plant.

Pastoorshoedje, o. - Eelen, Heppeneert en omstr. Id. als Papenumseniout (Vl. Wk.). - De vrucht gelijkt op eene priestersbaret.

Patermoedernaakten, v. mv. - Denderwindeke en oinstr. - Id. als Padiemoedernaakten (Vl. IVk.). 
Patersbladeren, o. mv. - Heyst-op-den-Berg en omstr. - Id. als Paterstok (Vl. Wk.).

Paterskap, r. - Denderwindeke en omstr. - Id. als Paterskappex ( V l. Wk.) (fig. 3. 4 en 5. - " In alle tuinen aantezig. hoewel men zeer goed met hare vergiftige eigenschappen bekend is :

Van bloemen blauw

Lw handen hoû !

zegt moeder, wanneer zij, met hare kleinen, eene eerste wandeling in den hof doet. ") (H. Tan Wilder).

Pauzegeld, 0. - Oost-Roosebeke en omstr. - Id. als J UDASGELD (T1. Wk.).

Pe-Cheval, m. - Dendermindeke en omstr. - Id. als Hoevesblad (Tl. Wk.). - Pe wordt zeer zacht uitgespr.; het moet eene rerkorting zijn ran Pied-cheval (rl. Hoevenblad; fr. rulg. Pas-d'âne; Pas-de-cheval). — Men schenkt er thee van op, tot borstversterking.

Peem. - Z. Pee: Peenriër: Peenex (T1. Wk.).

Peerdetand, m. - W.-Vl. - Mä̈-dent-de-Cheval; lat. Zea Mays L., rar. alba. - Eene var. ran Mais, met rierkantig graan, gelijk een peerdetand.-Deze var. is kleiner en dunner dan de gewone Mä̈s en wordt maar gezaaid om in zijnen bloeitijd afgemaaid te rorden tot roedsel ran het ree (Kruidw.).

Peerdewortel, m. - W.-Vl. - Tar. ran pee of carote die grooter en minder goed is dan de Horenierswortel. De Peerdewortels zijn bleek en het bovenste deel, dat uit den grond kijkt, is groenachtig : zij worden gekweekt roor de stalbeesten (Kruidw.).

Peerka. Perka. Perko, Perico, Perikamp. - W.-V1. Hypericum L.: fr. Millepertuis; rl. Doorboord Hertshooi: rulg. Sint-Janskruid (fig. 28), - Perico, Perko, enz. zijn verkortingen en verb. van den lat. naam Hypericum.

Peerdswortel, m. - Drongen en omstr. - Id. als PeerDESULKER ( TI. Wk.).

Pees, Peezeboum. - Maastricht en omstr. - Id. als PERzIK, - Boom (Vl. Wk.).

Pelaan. - Z. Pladx. $\mathrm{I}^{\circ}$ ( (Tl. Wk.). 
Pemie, v.-Het mv. = Pemiën.-Poperinghe en omstr. - Id. als Penen (Vl. Wk.).

Pensenkruid, o.- Beeringen en omstr.-Pens $=$ bloedworst. - Don Pensenkruid verstaat men, in deze streek, de drie planten die tot 't voorbereiden der pensen gebezigd worden : Soive (Salvia, Sauge), Orego (Origanum, Origan) en Temst (Thymus, Thym).

Peperwortel. m. - Maastricht en omstr. - Id. als Capuciene( N)mostaard ( $\mathrm{Vl}$. Wk.).

Perelkensrank, v. - Herdersen en omstr. - Id. als Hofrank ( $\mathrm{T}$ l. Wk.). - De kleine ronde vruchten, die op deze ranken komen, gelijken aan perelkens.

Perepote, v. - Synoniem ran Pereboom. - Avelghem en omstr. - Pote, in W.-Vl., = stek, tak van Wilg, Els, Populier, enz. die men afsnijdt om in de aarde te poten, te planten: fr. plançon; vl. plansoen. - Naar den Scheldenkant, bet. Pote een boom, vooral een fruitboom, b. v. Appelpote, Perepote (Kruidw.)

Perico, m. - Z. Peerka (Bijv.).

Perikamp, m. - Z. PeErka (Bijv.).

Pessche. - Ir.-Vl. - Z. Perzikioom (Tl. Wk.).

Peterselje, m. - Maastricht en omstr.- Id. als PETEkSILIE (Vl. ITK.).

Petersilie-van-Malsendoren, m. - Verb. van - Macedoniën. - Te Leuren gebr. voor Levisticum officinale Koch ; fr. Livèche officinale; vl. Genezend Lavas. Vroeger werd die naam gegeven aan Seseli macedonicum, eene uitheemsche geneesplant uit den ouden tijd : later, bij vergissing, op Levisticum overgebracht. - Te Leuven, zegt men ook: Processieplant, - kruid.

Piepers, Pieperkes. - Poperinghe en omstr. - Id. als Netendokskris (Vl. Wk.). - Pieperken = chalumeau.De rorm der bloemen is niet zonder eenige gelijkenis met een pieperlien.

Pieramidors, v. mr.-Zwijnaarle, Eecke, Seeverghem. Sint-Denijs-Westrem. - Id. als PyramidaA (Vl. Wk.), met rerminking ran den naam.

Pierenkol, m. - Leuven, Mechelen en omstr. - Id. als

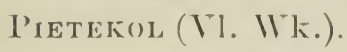


Pijkaards, m. mv. - W.-Vl. - Eene var. van Aardappel, komende uit Pikardië (vandaar Pijkaards).

Pijpdoorstekers, m. - Nederland. - Id. als PiJPeNHENGST (Vl. IVk.).

Pijpekop, m. -- Nederland. - Id. als Duitsche-PiJP (Vl. Wk.).

Pijpestier, m. - Poperinghe en ounstr. - Id. als Pijpenheygat (V1. Wk.).

Pijpestrootjes, o. mv. - Nederland. - Id. als PiJPExhengst (V1. Wk.). - Strootjes (verklw. van stroo, fr. fétu de paille), om de pijpen te kuischen.

Pijpkruid, o. - Nederland. - Anthriscus sy-lvestris Hoffm.; fr. Anthrisque sauvage; vl. Wilde Kervel. - De kinderen maken pijpen (fr. flittes, fifres) met de dikke, holle stengels der plant.

Pijpsteelkruid, 0.- W.-V1. - Cornus sanguinea L.; fr. Cornouiller sanguin; vl. Roode Kornoelie. - De schoone, rechte takken worden gebezigd om pijpsteelen (fr. tuyaux de pipe) te vervaardigen.

Pijpstier, m. - Z. Pijpestier (Bijv.).

Pikane, v. - Hier en daar, in W.-Vl. gebr. voor ANEKAMPANE (Bijv.).

Pimpandoer, m. - W.-Vl. - Verb. van Pépin d'or. Var. van Appel, met goudkleurige kernen.

Pimpoele, Pinpoele, v. - W.-Vl. - Id. als Pietekol (Vl. Wk.).

Pinksterbloemen, v. mv. - Reckheim en omstr. - Pyrethrum Leucanthemum Coss. et Germ.; fr. Pyrèthre Leucanthème; vulg. Grande-Marguerite; vl. Wilde Ganzebloem. - De plant bloeit volop, rond Pinksteren.- Z. ook Pinksterbloemen, in Vl. Wk.

Pinksternak(el), v. - Roeselare. - Id. als PastinaAk ( Vl. Wk.), waarvan deze naam alleen eene verb. is.

Pinkstersblom, v. - Maastricht en omstr. - Id. als Sint-Jansbloemen, $2^{\circ}$ ) (Vl. Wk.).

Pinpoele. - Z. Pimpoele (Bijv.).

Pirlamotten, v. mv. - Zwijnaarde en omstr. - Verb. van Bergamotten: naam van cene platvormige Peersoort. 
Pirkelir, m. - Zwijnaarde en omstr. - Id. als PERKeLвоOм ( $\mathrm{Tl}$. Wk $)$.

Plakkers, m. mv. - Oost-Roosebeke en omstr. - Id. als Plakkruid ( $\mathrm{T}^{\top} \mathrm{l}$. W k.).

Plamen, v. mv. - $\mathrm{I}^{\circ}$ Uitkerke. - Vruchten van Ribes nigrum L.; fr. Groseillier noir; vulg. Cassis; vl. Zwarte Aalbeziestruik. - $2^{\circ}$ Elders, in $\mathbf{W} . \mathrm{Vl}$. - Jeneverbes; fr. baie de Genévrier.

Planekruid, o. - IT.-V1. -- Id. als MelkplaAt (Bijv.).

Platgras, - gars, - gers, o. - IV.-V1. - Id. als V'ogeLVOET, $\left.\mathrm{I}^{\circ}\right)(\mathrm{Vl}$. Wk.).

Platte-Kul. - Berthem en omstr. - Id. als PAPE(N)KULLEKENS ( Vl. Wk.), waarvan dit w. eene verb. is.

Plat-Zaad, o. - $\mathrm{W} .-\mathrm{V} 1 .-\mathrm{I}^{0}$ Phalaris canariensis L.; fr. Alpiste des canaris; vl. Gewoon Kanariegras. $2^{\circ}$ Lijnzaad; fr. graine de Lin.-Plat-zaad : zoo genoemd, omdat 't zaad platachtig is.

Plekkruid, o. - Beeringen en omstr. - Id. als PLAKKRUID (Vl. Wk.).

Pleuriskruid, o. - Denderwindeke en omstr. - Verbena officinalis L.; fr. Verveine officinale; vl. Gewoon IJzerkruid (fig. 4I). - "Bij ribbenvliesontsteking". (fr. pleurésie), zegt M. H. Van Wilder, “ kapt men de plant fijn; met roggemeel, maakt men er een pleurishoek van en deze legt men zoo war'm mogelijk op het zieke deel : de zweeting volgt en de pijn verzacht. »

Plompebot(te), v.- W. V1. - De zaallbol van Waterlelie (Vl. Wk.). Z. ook SLAaPBoTtex (Bijv.).

Pluimgras, $0 .-\mathrm{I}^{\circ}$ Denderwindeke en omstr. - IIolcus mollis I. en II. Lanatus L.; fr. Iloulque molle en II. laineuse; vl.

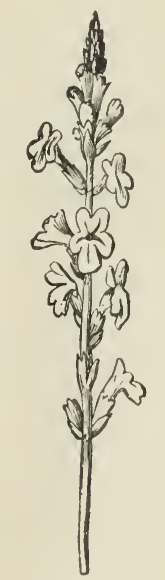

rig. 11. Bloemen van
Terbena oflicinalis. Verbena oflicinalis. zacht en Wollig \%orgrgas. $-2^{\circ} \mathrm{Z}$. ook Plimgras, in Vl. Wk.

Pluiskruid, o. - Nederland. - [d. als KANARIEkUt) (Bijr.). 
Pluk. - Zwijuaarde, Eecke, Seeverghem, Sint-DenijsWestrem. - De afgerallen bloembladeren ran rozen, pioenen, enz. die men bij de processie langs de straten strooit.

Poeierburstel, m. - W.-Vl. - Papaver somniferum L.; var. met dubbele bloemen; fr. Pavot somnifère, var.; vl. Slaapwekkende Maankop, var. - Die dubbele bloemen gelijken aan een burstel = borstel (fr. brosse), en 't fijn zaad, dat in den rruchtbol zit, gelijkt aan poeier of poeder (fig. 3o).

Poeierduts, m. - W.-V1. - Id. als 't voorg. W. - Duts, in 't westrl., = fr. une touffe; een bos, een bundel. - De talrijke bloemblaadjes vormen een waren bos of $d u t s$; voor poeier, z. 't voorg. $w$.

Poepstaal, m. - Z. Popstaal (Bijv.).

Pofferkeshout, o. - Beeringen en omstr. - Id. als KNEKKERS (Vl. Wk.).

Pollekoeken, m. mv. - Beeriugen. - Id. als Polkoogex en Polík koorex ( $\mathrm{T}$ l. Wk.).

Polpiet, m. - Lebbeke, Denderleeuw, Melle en omstr. - Verb. van Kolpiet, Kolpier, namen die elders gebr. worden. - Id. als Pietekol (T1. Wk.).

Pommel. - Z. Bullepees (Bijv.).

Pompbloem, r. - Herenthals en omstr. - Id. als Plompe, $2^{\circ}$ ) (Vl. Wk.). - In Vlaanderen, zegt men Pompelbloem.

Pompe, Waterpompe, v. ; Pompekruid, o.: Pompestaal, m. - W. - Vl. - Id. als Poup (V1. Wk.).

Pompekruid. - Z. 't voorg. W.

Pompelbloem. - Z. Pomprloen (Bijv.).

Pomperluite, r. - W.-Vl. - Id. als PompE (Bijv.). De kinderen gebr. den dikken, hollen stengel dezer plant, om er op te toeten : zij maken er luite of leute mede. Leute, enz., in W.-T1., = vermaak. blijdschap.

Pompernoelden, m. mv. - Verb. van Pompernoeljen, Kampernoeljen. - Cruyshautem, Nokere en omstr. - De ectbare Paddestoelen alleen worden, in deze plaatsen, alzoo genoemd. - Z. ook Kampersotele (Tl. WK.). 
Pootjeskruid, o. - Oostham en omstr. - De Wortelen (fr. Carottes; z. Wortelen, in Tr. Wk.) die in 't wild groeien. - De kinderen zoeken die plant langs de wegen en kanten, om de witte pootjes te eten.

Popelierwiedauw, m. - W.-V1. - Witte wiedauw (of wissen; fr. osier) dienende om manden te vlechten.

Popeloentje, o. - Lebbeke en omstr. - Id. als PAPE(N)kULEN (V1. Wk.). - In 't Walenland, wordt de naam Papalolo gebezigd. Popelont.Je schijnt eene grove verb. van dien naam te zijn.

Poper, m: - Poperinghe, Reninghelst, Woesten, Westvleteren en omstr. - R. Dodonaeus zegt : "Waterbiezen oft vijverbiezen... heeten ook merchbiezen, bobbel, bobbert ende oock poper; ende daerom noemt men de plaetsen daerse reel wassen, in Nederlant, insonderheydt op 't vlaamsch, Poperingen » (Kruidw., bl. 98.) - Vandaar ook de naam der stad Popering he. - Dus, Poper =id.als Stoelbiezen ( $\mathrm{T}$. Wk.).

Popstaal, m. - W.-V1. - Senecio Jacobaea L.; fr. Sene‘'on Jacobée; vl. Jatrob's-Kruistruid. - Staal= stengel, in 't westvl.; $p o p=\mathrm{fr}$. poupée : de bloeiende plant gelijkt niet slecht, alles te zamen genomen, aan eene pop. - $\mathrm{O}_{\mathrm{p}}$ eenige plaatsen, zegt men : Poepstaal of Propstaal.

Poretfeem, - feme; - fimme, - veme, r. - W.-V1. Id. als Poretblad; fr. feuille de Poireau.

Porseleinekruid, o. - W.-V1. - Montia fontana L.; fr. Montie des fontaines; vl. Fontein-Monti'skruid. - Men zou zeggen dat de bladeren en de bloempjes van porselein gemaakt zijn.

Porsellekruid, o. - W.-Vl. - Id, als Dolle-KerVEL (Vl. Wk.). - Porselle, in 't westrl. = perselle, persijn, peterselie; fr. persil. - Het Porsellekruid gelijkt veel op Petersclie; het is vergiftig, groeit soms onk in de moeshoven en, door vergissing, veroorzaakt soms den dood.

Posselaan. - Sint-Joris-IVinghe en omstr. - Id. als Posteleix (Vl. Wk.).

Possem, r. - Nederland. - Id. als G.AGri. (Tl. Tk.).

Post, r. - Id. als 't roorg. W. 
Pote. - \%. Pere - (Bijv.).

Potstok, m. - Zwijnaarde, Eecke, Seeverghem, SintDenijs-Westrem. - Elders zegt men, beter : Pootstok. Id. als Poot, $2^{\circ}$ ) (Vl. Wk.).

Prangwortel, m. -- W.-Vl. - Id. als Heidoors, i $\left.{ }^{\circ}\right), 2^{\circ}$ ) en $3^{\circ}$ ) ( $\mathrm{Vl}$. W Wk.).

Preutefem, m.; het $1 \mathrm{mv}$. is - fems. - W.-Vl. - Eene var. van Appel; fr. prude femme. - Dus, verb. van den fr. naam.

Prieul, Priheul, Prieur, m.- W.-V1. - Thymus vulgaris L.; fr. Thym commun; vl. Gewone Tijm. - Eene welriekende hofplant, dikwijls als toekruid gebezigd.

Prieur. - Z. 't voorg'w.

Priheul. - Z. Prieul (Bijv.).

Prónkers, m. mv. - Nederland. - Phaseolus multiflorus Lamk.; fr. Haricot multiflore; vl. Veelbloemige Staakboon. - Wordt gekweekt voor 't sieraad; 't zijn alleenlijk prónkers.

Puingras, o. - Nederland. - Id. als PeË̈n (Tl. Wk.). - Z. ook Pü̈̈́ (Vl. Wk.).

Puipkoterirs, m. mv. - Verb. van Pijpkoteraars. Zwijnaarde en omstr. - Id. als PidPenkeuters (Vl. Wk.).

Puitboterbloem, v. - Oultre (bij Ninove). - Id. als WATERBoterbloem ( $\mathrm{V}$. Wk.). - Groeit in natte gronden of in 't water, waar de puiten of kikvorschen hun verblijf houden.

Puite-moedernaakte, v.; ook Puitje - . W.-V'l. - Id. als NaAkte-BegiJnen ( Vl. Wk.).

Puitenbloem, v. - Denderwindeke en omstr. - Id. als DoвbeL-Boterbionu ( $\mathrm{V}$ l. Wk.). - Bij gebrek aan wortels (fr. carottes), zegt M. H. Van Wilder, gebruikt men de bloemblaadjes dezer boterbloem (gelijk men ze soms ook noemtj tot het geel verven der boter. - De plant groeit in zeer vochtige en natte gronden, waar de puiten of kikvorschen hun verblijf houden.

Puitereit, o. - Poperinghe en omstr. - Id. als PUREK (Vl. Wk.). - Puil = kikvorsch. "Reit = alle slag van 
kruid dat onder water goeit of er boven drijft. De grachten zuiveren van het reit » (Kruidw. bl. Io3).

Puitooge, v. - W.-Vl. - Putje op den knol van aardappels; fr. les yeux de la pomme de terre.

Pulm(e), m.; het mv. is pulmen en pulms. - Men zegt ook Puwel. - Deze naam bet. de peul of hulze van Koolzaad of Raapzaad; fr. les carpelles de la silique. - Een beddezak met koolzaadpulm gevuld (Kruidw.).

Purpere-Netel, v. - Denderwindeke en omstr. Lamium purpureum L. en L. amplexicaule L.; fr. Lamier pourpre en L. amplexicaule; vl. Purpere en Stengelomvattende Doove-Netel. - De bloemen zijn purperkleurig.

Putterdistel, v. - Nederland. - Cirsium lanceolatum Scop.; fr. Cirse lancéolé; vl. Speer-Vederdistel. - De putters (fr. chardonnerets) zijn zeer verlekkerd op het zaad dezer distel.

Puwel. - Z. Pulm(E) (Bijv.).

\section{$\mathrm{R}$}

Raai, m. - $\mathrm{I}^{\circ}$ W.-V1. - Id. als Dod, Dodpe (V1. Wk.). - $2^{\circ}$ Nederland. - Raai, v. = Galeopsis Ladanum L.; fr. Galéopsis Ladanum; vl. Raai Hennepnetel.

Raamsch. - Maastricht en omstr. - Id. als Marentak (Vl. Wk.). - Deze naam is waarschijnlijk in betrekking met Granamte, die elders gebr. wordt; z. Bijv.

Radijsboompje, o. - Nederland. - Id. als KNEkKERs (V1. Wk.).- Men heeft eene gelijkenis gevonden tusschen de witte bolvormige vruchten van dit struikgewas en de radijzen.

Rammelaar, m. - Oultre (bij Ninove). - Id. als RATELEN (VI. IVk.). - Rammelaar $=$ fr. hochet : de zaden rammelen in de zaạdbollen, als men deze aanraakt.

Rammelkul, m. - W.-Vl. - 'Truffel; fr. Truffe; lat. Tuber.

Rankers, m. 1nv. - '/wijnaarde en omstr. - Pelargoonium hederaefolium Hortul.; fr. I'. à fcuilles de Lierre; 
vl. Veilbladige Ooievaarsbek. - De plant schiet lange, neerhangende takken die op ranken (fr. sarments) gelijken.

Rapier, m. - In Fransch-V1. - Fr. Navets (de gansche plant : knol en bladeren). - De knollen, alleen genomen, heeten Rapen.

Rapunsel, o. - Nederland. - Phytenma spicatum L.; fr. Raiponce en épi; vl. Aardragend Raponsje.-Rapunsel $=$ verb. van 't fr. Raiponce of van 't vl. Raponsje.

Rarels, m. mv. - Zwijnaarde, Seeverghem en omstr.Id. als Ratelen, Ratels (Vl. Wk.).

Rasphout, o.- In Oost-Vl.- Id. als Risshout (Vl. Wk.).

Ratten-en-Muizen. - Lebbeke en omstr. - Id. als Jongens-Ex-MeisJes (Bijv.).

Rattesteert, m. - Merckem en omstr. - Phleum pratense L.; fr. Phléole des prés; vl. Weide-Phleum; vulg. Timothygras. - De lange en rolronde aar dezer grassoort gelijkt niet slecht aan een rattesteert.

Reek, v. - Nederland-Polygonum lapathifolium I. ; fr. Renouée à feuilles de Patience; vl. Zurkelbladige Veenwortel. - De vorm der bladeren gelijkt min of meer op eene kleine reek of eggetje (fr. petite herse).

Reinegalde, Reinegolde, Reinevlode, v. - W.-Vl. Eene var. van beste Pruim: fr. Reine-Claude. - Deze namen zijn verb. van den fr. naam : in Reinculode is de verminking onbeduidend; bij de andere, is de letter $l$ van plaats verschoven.

Reinegelaude, v.-Thielt en omstr.-Id. als 't voorg. w. Reinevane, v.- W.-Vl.-Id. als Reinevaren (Vl. Wk.), waarvan dit w. maar eene verb. is.

Reinevlode, v. - Z. Reinegalde (Bijv.).

Rekop of Rek-op, o. - Nederland. - Een der talrijke volksn. van het Bitterzoet.-Z. Zoet-en-Bitter (Vl. W'k.).

Renetting, m. - W.-V1. - Var. van Appel; ook Renet, m. en Renette, v. geheeten ; fr. Rainette. - Dus, verb. van den fr. naam.

Retsel, o. - Alken (bij Hasselt) en omstr. - Id. als Rondsel (Vl. Wk.). - In W.-Tl., zegt men ook Retse, Rotse en Rootse. 
Reukela, v. - W.-Vl. - Id. als ArikeL (Vl. Wk.). Reukela $=$ verb. van den lat. naam Auricula. - In 't Veurne-Ambacht, zegt men Ruikeloo.

Reukgras, o. - W.- V1. - Id. als Splijtgras (VI. Wk.). - Grassoort, die een zeer aangenamen renk verspreidt (den hooireuk), als zij afgesneden is en begint te verslensen. Men maakt er uittreksel van, dat, in den handel, den naam van hooigeest (fr. essence de foin) draagt.

Reumelingen, v. mv. - Zwijnaarde, Eecke, Seeverghem en omstr. - Van 't werkw. ruimen (fr. débarrasser). Men noemt alzoo 't geen men wegneemt, bij het opsnoeien van jonge Elzen, Kastanjen, Esschen, enz. (J. Paelinck).

Reutsel, o. - Beeringen en omstr. - Id. als Retsel (Bijv.).

Reuzezagge, v. - W.-V1. - Id. als Witte-Pluim (V1. Wk.). - De plant, eene grassoort, heeft lange, snijdende bladeren, gelijk eene Zag g'e (fr. Carex; Laiche) en wordt zeer hoog (3 tot 4 ineters) : vandaar Reuzezag'e.

Rezimaal, Rezimom, Rezimong, m. - W.-VI. - Id. als Hinnevet (Vl.Wk.). - Deze namen = verb. van den lat. naam Erysimum L.; geslacht van Kruisbloemigen, gelijk de Sisymbrium officinale Scop. 't Is deze laatste plant welke 't volk beduidt, wanneer, bij vergissing, de naam Rezimaal, enz., gebruikt wordt.

Rezimom, m. - Z. 't voorg. w.

Rezimong, m. - Z. RezimaAl (Bijv.).

Ribbekes, o. mr. - Oostham en omstr. - Id. als RuBbeN (VI. Wk.).

Ribes, m. - W.- V1. - Id. als Bloembezeleer (V1. Wk.). - Ribes is de algem. lat. naam van dit geslacht van struikgewassen; ir. Groseillier; vl. Aalbeziestruik.

Riet, o. - Denderwindeke en omstr. - Phragmites communis Trin.; fr. Phragmites commun; vulg. Roseau; vl. Gemeen Dekriet. - De bossen van violetkleurige artjes worden in de windertuilen benuttigd.

Rietlisch, o. - W.-V1. - Id. als 't voorg. w.

Rietspriet, .n. - Zwijnaarde, De Pinte, Seeverghem.Baldingera arundinacea Dmrt.: fr. Baldingère Rosean; 
vl. Rietachtige Eenhalm. - Spriet = jachtspies; fr.épieu. De groote en stijve halm heeft iets van een spriet weg en, door hare groeiwijze en groeiplaats, gelijkt deze grassoort aan liet gewone Riet; lat. Phragmites communis Trin.

Rijgkoorde, Rijkoorde, v. - Wr.-Vl. - Id. als Grasper (Vl. Wk.). - Rijg.koorde = de koord waarmede men iets toerijgt. De onderaardsche stammen (fr. rhizomes) dezer grasplant zijn lang en taai als koorden.

Rijerspeen, m. - Zwijnaarde, De Pinte, Seeverghem. - Terb. van Rijderspeen, 't is te zeggen eene soort Peen die, met zijne onderaardsche wortelscheuten, meer dan eene andere Peensoort, wijd van zich af, in den grond rijdt of boort. Het is de $A_{\mathrm{g}}$ ropyrum repens $\mathrm{I}_{1}$, die meestal te velde groeit (J. Paelinck).

Rijkoorde. - Z. RiJGKoORde (Bijr.).

Rijpeltocht, v. - Nederland. - Id. als Plakkruid (Vl. Wk.).

Rijsbes, v. - Nederland. - Vaccinium uliginosum L.; fr. Airelle des fanges; vl. Rijsbes.

Rijspeerd, Rijspeert, o. - W.-V1. - Baldingera arundinacea Dmrt; fr. Baldingère Roseau; vl. Rietachtige Eenhalm.

Rijspeert. - Z. 't voorg. II.

Rikkerekruid, o. - Verb. van Riekend Kruid. - Beeringen en omstr. - Id. als. Averoon (VT. Wk.). - De bladeren der plant hebben een aangenamen reuk.

Roeds. - Z. Roons (Vl. Wk.).

Roeidsel, o. - Lebbeke, Hendersem en omstr. - Id.als Roodsec (Vl. Wk.), waarvan deze naam eene verb. is. De plant is haren naam verschuldigd aan de roode kleur der bloempjes en des stengels.

Roeltekake, m. - W.-VI. - Var. van groote Appel, bewarende tot ver in den winter. Soms ook Geuzing. geheeten.

Roggebloem, v. - Nederland. - Id. als Blauwbloem (Vl. Wk.) (lig. I4). - Groeit veel in de rogereakkers (fr. champs de seigle).

Rondotte, v. - IV.-Vl. - Id. als LoofbLokm (Vl. Wk.). 
Roobeen, o. - W.-VI. - Geranium Robertianum L.; fr. Géraniun Herbe-à-Robert; vl. Stinkende Ooievaarsbek. - Roobeen $=$ verb. van Robert of eerder verb. van Roodbeen : de stengel dezer plant hebbende eene schoone roode kleur.

Roobeete, v. - W.-Tl. - Id. als BEET (Vl. Wk.).

Roobol, m. - IV.-V1. - Eene var. van Aardappel.

Roobolle, m. - W.-Vl. - Id. als I kges ( Vl. Wk.).

Roobotters, m. mv. - Kwijnaarde, De Pinte, Seeverghem. - Van rood en het werkw. botten. Manuelijke Canada Populier, die roode katjes (fr. chatons) draagt, als bloeiwijze, welke 't rolk voor botten anziet. (J. Paelinck.)

Rood-Been, o.-Nederland.-Id. als RoonskL (Vl. Wk.). - De stam is rood van kleur.

Rood-Doppen, m. mv. - Thienen en omstr. - Id. als Roode-Toppen (Tl. W'k.), waarran deze naam maar eene verb. is.

Roode-Horde, v. -- Nederland. - Id. als Luiskruid, $2^{\circ}$ ) (Bijv.).-De plant gelijkt op Hor'de (volksn. der Ratels), naar heeft roode bloemen, in plaats van de gele, die de Horde draagt.

Rood-Sterreken, o. - Lebbeke en omstr. - Id. als Cathrienewiel ( Vl. Wk.). - - De bloemkroon lijkt op een rood sterreken.

Roode-Blagaaize, v. mv. - Oost-Roosebeke en omstr. - Eene var. van Phlox, met roode bloemen.

Roode-Molekens, o. mr. - Denderwindeke en omstr.Melandrium diurnum Dmrt.; fr. Mélandre diurne; rulg. Compagnon-ronge; vl. Roode Valsche-Koekoeksbloem. De bloemkroon is schoon rood, en rond gelijk een molenrad.

Roode-Murekruid, o. - Denderwindeke en omstr. - Id. als RoOi-Mone (Vl. Wk.).

Roode-Wilde-Winde, r. - Denderwindeke. - Id. als KOORNWINE (VT. Wk.).

Roode-Zeembessenstruik, m. - Denderwindeke en omstr. - Id. als /AEEBZEN (V1. W'k.).

Roodte. - Nederland. - Id. als Mew (Bijv.).

Roorebbe, v. - IV.-VI. - Een van de talrijke volksn. 
die men, in Vlaanderen, geeft aan den Geitenbaarl. - Z. dit $w$. in 't Vl. Wk.

Roosjes-zonder-doornen, o. mv. - IT.-T1. - Id. als Meiroos.jes (Bijv.). - De struik is zonder doornen en de bloemen zijn lijk kleine gele roosjes.

Rootse, v. - Id. als Retsis (Bijv.).

Roovoet, m.- W.-Vl.-Id. als Pluimgras ${ }^{\circ}$ ) (T1. Wk.). - Dus geheeten omdat het onderdeel van den stengel rood is (Kruidw.).

Roowilg, r. - Nederland. - Polygonum amphibium L.; fr. Renonée amphibie; vl. Veenwortel. - De stam is rood en de bladeren hebben iets weg van zekere Wilgbladeren.

Roosewied, o. - W.-Vl. - Id. als Kol, Kolbloem, I ${ }^{\circ}$ ) ( Vl. Wk.). - Wied = onkruid en de bloemblaadjes hebben eene rooze kleur.

Rossement, v. - Nederland. - Mentha aquatica I.: fr. Menthe aquatique; vl. Watermunt.-Voor Rosse-ment: ros = bruinachtig, kleur die de bladeren gewoonlijk hebben; ment $=$ verb. van Munt (fr. Menthe).

Roste-Stinkers, m. mv. - Oost-Roosebeke. - Id. als AfrikaANders (VI. Wk.).- De bloemen zijn rost, d. i. ros, bruinachtig van kleur en verspreiden een zeer sterken en onaangenamen geur.

Rotelaars-in-'t hooi, m. mv.-Denderwindeke en omstr. - Id. als Ratelen (Vl. Wk.).

Rotse, v. - Zwijnaarde, Seeverghem, Oost-Roosebeke en omstr. - Id. als Retsel (Bijv ).

Rozemienen, v. mv. - Oostham en omstr. - Id. als JASMrenex ( $\mathrm{T}$ l. Wk.).

Rugge, r. - W.-V1. - Id. als Rogge; fr. Seigle.

Ruikeloo. - Z. Reukela (Bijv.).

Ruivellingen, m. mv. - Te Zwijnaarde en omstr., noemt men alzoo eenige Appelsoorten met ruw (oneffen) vel, b. v. zekere grijze Renetten (fr. Rainettes).

Rusch, v. - Nederland. - Synoniem van Biezen (fr. Joncs). 
Russische-Distel, v. - Nederland. - Id. als Loogkruin (Bijv.). - De bladeren zijn stekelpuntig gelijk bij de Distels.

Russische-Postelein, v. - Nederland. - Id. als WILDiPorselein (Vl. Wk.).

Ruts. - Z. RuDs (Vl. Wk.).

Saailde, v. - '/wijnarde en omstr. - Id. als SAALDE (Vl. Wk.).

Salbei, v. - Maaseyck en omstr. - Id. als WILDESALIE (Vl. Wk.).

Salewei, v. - Maastricht en omstr. - Id. als IVERF (Vl. Wk.). - In 't hoogduitsch : Sahlweide.

Salsafij, v. - Nederland. - Algem. naam voor 't geslacht Tragopogon Tournef.; fr. Salsifis; vl. Boksbaard. - Sal$z a f i j=$ verb. van't fr. Salsifis.

Savelboom, m. - Nederland. - Id. als Zavelboom (V1. Wk.).

Schaapbinde, v. - Poperinghe en omstr. - Id. als KoORNWINDE (Vl. Wk.). - De schapen eten de plant graag.

Schaapderm, m. - IV.-Vl. - Id. als Vi.jF-Vingerkruid (V1. Wk.). - De loopende stengels zijn lang als darmen en de schapen eten de plant nog al gretig.

Schaaptenkte, v. - Oost-Roosebeke en omstr. - Potentilla Anserina L.; fr. Potentille Ansérıne; vl. Zilverschoone Ganzerik. - De bladeren der plant lijken op die der Tenkte, naam die, in Vlaanderen, Tanacetum ; fr. Tanaisie; vl. Reinvaren beteekent. - De plant groeit veel langs de wegen en wordt door de schapen afgegrazen.

Schalonje, v. - Antwerpen en omstr. - Id. als S.JARI.OTTEN (Vl. Wk.).

Schapersborzekens, - burzetjes, o. mv. - IV.-VI. Id. als BEURZEKENSKRUID, I $\left.{ }^{\circ}\right)(\mathrm{Vl}$. W'k.).

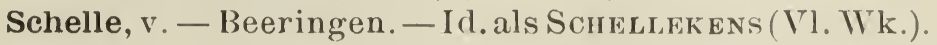


Scheule, Schulle, v. - W.-V1. - Id. als schil, schel; engl. shell; fr. écale, cosse. - De scheule van de okkernoten (le brou des noix); de scheulen van erwten (les cosses des pois) (Kruidw.).

Schijtraap, - rape, v. - W.- T'. - Id. als KeURFRAAP ( Vl. Wk.). - De wortel vormt eene lange en dikke raap die een purgeermiddel is.

Schildersverdriet, o. - W.-Vl. - Id. als HoE-LANGERHOE-LIEVER (Vl. Wk.). - ( )verzetting van den fr. volksn. : Désespoir-du-peintre. De zin is : dat bloempje is zoo schoon, dat geen schilder het zou kunnen namaken.

Schinksenroos, v. - IV.-Vl. - Id. als Pioen (Vl. Wk.). - Schinksen = Sinxen, Pinksterfeest. Deze rorm (Schinksen) is bijzonder gebezigd in 't noorden van Vlaanderen.- - De plant is zoo genaamd omdat men in vroegere tijden, op den Schinksendag, bloembladeren van deze roos door de gaten van de gewelven der kerken liet nedervallen over 't volk, ter gedachtenisse van de vurige tongen die op dien dag over de apostelen daalden. Dit gebruik bestond nog te Nieuwpoort in 1840. ") (Kruidw., bl. III.)

Schoentjes-en-laarsjes, o. mr. - Nederland. - Id. als J UFFERschoenen (Bijv.). - De bloemkroon der plant heeft den vorm van schoentjes, en de bloemkelk, den vorm van laarsjes.

Schokkeljoen, m. - Kortrijk en omstr. - Id. als ScHoKKELOEN ( Tl. Wk.).

Schom, m. - Beeringen, Diest, Caggevinne-Assent, Zeelhem. - Id. als Schoem en Schossem ( Vl. Wk.).

Schoof, v. -- Zwijnaarde en omstr., alsook bijna overal in België. - Een bundel graan van welkdanige soort (fr.gerbe).In Limburg, is dit w. van 't mannelijk geslacht.

Schorfte, v. - IV.-V1. - Id. als REUWE (V1. Wk.).

Schrok. - Herenthals en omstr.-Id.als Krok ( Vl. WVk.).

Schulle. - Z. Scheule (Bijv.).

Schurft-in-de-Klaver, o. - Denderwindeke en omstr. Id. als REUWE (Vl. Wk.). - 't Schurft is meer gevreesd dan de Honger (Orobanche minor). (H. V'an Wilder.) 
Senegroen, o. - W.-T1. - Ajuga reptans I, ; fr. Bugle rampante; vl. Kruipend Senegroen.

Sensejoen, m. - Nederland. - Id. als Sixs.ofr en Silnsonk ( V l. Wk.).

Sentille, Sintille, v. - IV.-V1. - Id. als Pottebloem (Vl. Wk.). - De naam is waarschijnlijk eene verb. van den fr. volksnaam : Eillet gentil.

Sijnnauw. - Nederland. - Alchemilla arvensis Scop.; fr. Alchémille des champs; vl. Veld-Leenwenklauw.

Singsoen, m. en o. - Id. als Siknsonk ( Vl. Wk.).

Sinksoen, m. en o.- Poperinghe, Zwijnarde en omstr.

- Id. als 't voorg. w.

Sinsom, m. - Pepinghen (bij Halle).-- Id. als Siensonk (V1. Wk.).

Sint-Jansranke, v. - IV.-Vl. - Id. als OxderhaAg (V1. Wk.).

Sint-Jansvarnte, v. - W.-V1. - Osmunda regalis L.; fr. Osmonde royale; vl. Konings-Osmunda; vulg. Koning:suaren.

Sint-Jansuien, v. mv. - Nederland. - Id. als S.JARLotTen (Vl. Wk.). - Ui, mv. uien = ajuin, fr. oignon.

Sint-Jeurisbloem, v. - Beeringen en omstr. - Id. als Sint-Jorisiboem ( Vl. IVk.).

Sint-Josephslelie, v. - Oost-Roosebeke en omstr. - Id. als IVITTE-ILELE ( V l. Wk.).

Sint-Pietersknoppen, in. mv. - Eecke, Nazareth en omstr. - Id. als Sint-Pietersblonme (V1. Wk.).

Sint-Pieterstheekruid, o. - Denderwindeke en omstr. - Hypericum perforatum L.; fr. Millepertuis perforé; vulg. Millepertuis; vl. Doorboord Hertshooi (fig. 28). "Op Sint-Pietersdag, hangen de kinderen, over de straten, eene (Sint-Pieters) kroon. De voorbijgangers worden de schoenen gevaagd en geven den kleinen een geldstuk. 's Namiddags, wordt er, onder de kroon, pappenthee, Sint.Pieterstheekruid en melk, - met mastellen gedronken en daarna onder de kroon gedanst. ") (H. Van Wilder.)

Sinter-Nellebladeren, o. mv. - Herdersem en omstr. Scrophularia nodosa L.; fr. Scrophulaire noueuse; vl. 
Knoopig Helmkruid. - Wordt gebr. tot genezing van zweren en etterwonden. - De naam = bladeren van Sinte-Renelle; verb. van Sinte-Reneldis (eene Heilige, die bijzonder geëerd wordt in een dorp, bij Halle gelegen, en den naam van Sinte-Renelde of Sinter-Nelle draagt; in 't fr. Sainte-Renelle of Saintes). De Heilige wordt aangeroepen voor de genezing derzelfde ziekten voor dewelke de Sinter-Nelleblaren gebruikt worden.

Sintille. - Z. Sentille (Bijv.).

Sjonk, m. - In 't Hageland. - Hetgeen in den grond blijft steken, als een boom of heester afgekapt is (fr. souche). - Sjonk of Sjunk is 'tzelfde w. als tronk, stronk, strunk; fr. tronc; lat.truncus, van truncare = afsnijden.

Slaapbollen, m. mv. - Thielt, Ardoye, Berthem. - Id. als SlaApgoed (Vl. Wk.). - De vruchten hebben den vorm van dikke bollen en het zaad heeft slaapwekkende eigenschappen.

Slaapbotten, v. mv. - Oost-Roosebeke en omstr. - Id. als 't voorg. W. - Botte, $\mathrm{I}^{\circ}$ in België, bet. de knop van een gewas, waaruit de bladeren of de bloemen ontluiken, fr. bourgeon, bouton; $-2^{\circ}$ in W.-Vl., bet. ook het zaadhuisje van eene plant, fr. péricarpe. Men bepaalt dikwijls den zin van dit w. met een bijvoegsel : bladbotte, bloembotte, zaadbotte.

Slaapmutsen, v. mv. - Herenthals en omstr. - Id. als Winde (Vl. Wk.).- De kegelvormige bloemkroonen dezer planten gelijken op slaapmutsen.

slangentong, v. - Denderwindeke en omstr. - Id. als Marentak (Vl. Wk.). - Zoo genaamd naar den vorm der. bladeren, waar 't volk eene gelijkenis met eene slangentong' gezien heeft.

Slingerroos, v. - Nederland. - Id. als HAAGLELIE (VI. Wk ).-Er is hier spraak van eene slingerplant, fr. plante voluble of volubile.

Sloer, m. - Beeringen en omstr. - Id. als SLoER (Ti. Wk.). - Sloer wordt ook, in deze streek, als scheldnaam gezegd tegen vrouwen van lichtzinnig gedrag. Op I $^{\text {ste }}$ Meinacht, werpt men sloeren op het dak of hangt ze aan de 
deurklink van de huizen waar jonge dochters wonen die zich slecht gedragen. - Sloeren krijgen, is eene groote oneer. (M. Traneken.)

Slootse. - Z. 't rolg. W.

Slotse, Slutse, Slootse, Slosse, v. - W.-V1. - Hulze, peul van boonen, erwten en andere sehilgewassen; fr. gousse.- Van noten sprekende, zegt men sloester, bolster, dop, groene bast; fr. brou.

Slutse. - Z. 't roorg. w.

Smarte. - Z. SuERTE (Bijv.).

Smeerweuttel, r. - Verb. van - wortel. - Kerkom. Id. als Wille-Beete(n) (Bijv.).

Smerte, v. - Oost-Roosebeke. - Id. als WATERrids (Vl. Wk.).

Smoorpatatten, v. mr. - Berchem (bij Antwerpen). Id. als Boeveest (Vl. Wk.). - Deze Kampernoeliën zijn bolvormig lijk Patatten (d. i. Aardappelen), en de wolk van kiemkorrels die er uit komt, als men er op trapt, heeft de gedaante van smoor, fr. broulllard, fumée épaisse.

Smout-boter-en-kaas. - Denderwindeke en omstr. Id. als KoETJEs (Bijv.). - “ De bloemkolf gelijkt niet slecht ", zegt M. Van Wilder, " aan de kleur dier drie toespijzen. Deze naam is minder gebezigd dan Koetjes. »

Smouter, m. - $\mathrm{r}^{\circ}$ Oost-Roosebeke en omstr. - " Eene grove soort van peer, met bruine pel, die veel op de boomgaarden der landbouwers wast en verkocht wordt als braadpeer ). (A. De Jaegher). - 20 Z. Smouter, in 't Vl. IVk.

Smouters, m. mv. - $\mathbb{W}^{\top}-\mathrm{V}$ l. - V Vr. van Erwten, met groote granen; tot voedsel van het vee dienende. De Smouters hebben lange ranken, maar men laat ze zonder rijzels al dooreen groeien: hunne bloemen zijn wit en de schokken (fr. gousses) groot (Kruidw.).

Snerte. - Z. SuEr'ti (Bijv.).

Snijkoren, o. - Zwijnaarde en oustr. - Koren of rogge die gezaaid wordt, einde September, om na den winter groen afgesnelen te worden, voor het vee.

Snuifneuzen, m. mr. - Zwijnaarde en omstr. - Appels 
en peren, eenen worm bevattende die een bruin poeder naar buiten drijft. Zoo genaamd, naar de kleur dier stof (uitwerpsel van den worm), die op snuif gelijkt.

Soese, v. - Poperinghe en omstr. - Id. als Sousse ( Ir . IVk.).

Soîve, v. - Beeringen en omstr. - Id. als SAUveE, SaveE en Salie (Tl. Wk.).

Soldatentoppen, m. mv. - Denderwindeke en omstr. - Id.als Borstels (Vl. Wk.).

Sophiekruid, o. - Nederland. - Sisymbrium Sophia L. ; ir. Sisymbre Sagesse; vulg. Sagesse des chirurgiens; vl. Sophie-Raket. - Sophie is dus eene verb. of vertaling van den lat. naam Sophia.

Sôr, Sorgras. - Beeringen en omstr. - Carex, in 't algem.; fr. Carex, Laiche; vl. Zegge, Zagge.

Spaansche-Doorns, m. mv. - Maaseyck en omstr. Id. als Stekebrem (Vl. Wk.).

Spaansche-Klaver, v. - Ketzingen (bij Tongeren) en omstr. - Oxalis stricta L.; fr. Oxalide droite; vl. Rechtstandige Klaverzuring. De opgegeven naam is, bijua overal elders, synoniem van Luzerne; vl. Rupsklaver.

Spekwortel, v. - Nederland.-Id.als SMEERWORTEL (Vl. Wk.) (fig. 42). - De wortel der plant is zoo vet als spek; daarom ook dikwijls Vetwortel geheeten.

Spelke, v. - W.-V1. - Id. als Spelt; fr. Épeautre; lat. Triticum Spelta L.

Spelledoorn, m. - W. - V1. - Id. als Hagedoorn; fr. A ubépine; lat. Crataeg'us L.

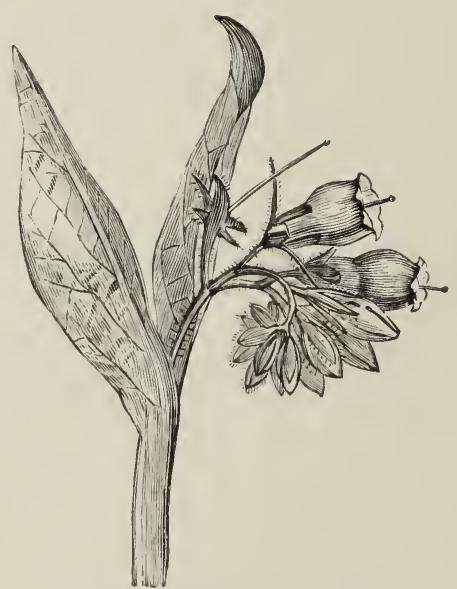

Fig. 42. - Symphylum officinale. - Verb. van Speldendoorn.

De doorns van dit houtgewas gelijken niet slecht op) spelden, fr. épingles. 
Spletgès, o. - Kwijnaarde en omstr. - V'erb. van spletgers, - gras, splijtgras.-Id. als VOGELvoET, Io) (V1. Wk.). - De bloeiwijze dezer grasplant is gespleten in verscheidene uiteenloopende takken, die ze op eenen vogelvoet doen gelijken. Vandaar ook de naam van Vogelvoet, die de plant elders draagt.

Sponnerikskop, m. - Beeringen. - Id.als Dod (Vl. Wk.). Sponnerik $=$ verb. van spinrok of spinrokken (fr. quenouille). De opeengehoopte vruchten der plant vormen een soort van rolvormigen kop, die niet slecht op een spinrok gelijkt.

Sponse-Peupeleer. m. -- Verb, van Spaansche-Populier. - Kerkom en omstr. - Id. als ItaliaAnder (Vl. Wk.).

Spoor, v. - Oultre (bij Ninove). - Id. als Spurrie ( Tl. Wk.).

Spoorkruid, o. - IT.-Vl. - Id. als KAMmEKE(N)SKRUID (Bijv.). - De lange, naaldvormige vruchten hebben iets weg van eene hanenspoor (fr. ergot de coq).

Sporrekruid, o. - W.-Vl. - Id. als 't voorg. W.

Sprinkhaan, m. - Oostmalle, Zoersel en omstr. - Id. als Hanepooten ( $\mathrm{V} 1$. Wk.).

Sproete(n), v. mv. - Maastricht en omstr. - Verb. van Spruiten. - Id. als Spruitkool (Vl. WVk.).

Sprokkel, m: - Nederland. - Id. als Honzenhout (V1. IV k.).

Spruutjes, o. mv. - Maastricht en omstr. - Id. als Sproete(r) (Bijv.).

Stanse, Stonse, v. - W.-V1. - Id. als Capuciene(N) (V1. Wk.).

Steekappel, m. - Berthem. - Id. als Doornapper (Vl. Wk.).

Steeksalaad, v. - Pepinghen (bij Halle). - Id. als. VilinsalaAd (V1. Wk.). - Men gaat die salade in 't veld uil steken.

Steenbies, v.- '/wijnaarde en omstr.-Juncus glaucus Ehrh.: fr. Jonc glanque; vulg. Jonc-des-jardiniers; vl. Zeegroenachtige Bies. - De Steenbiezen zijn harder pn taaier dan de andere biezen, die daarom Papbiezen genoemd worden. 
Steenbrem, m. - Beeringen. - Id. als StekEbrem (V1. Wk.). - De plant is taai en hard als steen.

Steenklavers, v. mv. - Z. Vl. Wk. - Vergelijk : Steinklee (te Darmstadt); Sténklover (in Noord-Denemarken).

Steenkloverkes, o. $\mathrm{mv}$. - Sint-Joris-Winghe en omstr. - Id. als Steenklaver, I ${ }^{\circ}$ ) (Vl. Wk.).

Stek, Stekke, v. - W.-V1. - Eene afgesneden boomscheut die men in de aarde steekt om eenen nieuwen boom te kweeken; fr. plancon.

Stekellisch, o. - V.-VI. - Eene waterplant : Stratiotes aloides L.; fr. Stratiote Faux-Aloès; vl. Valsche Aloës. - De bladeren lijken op die van een Lisch, maar dragen stekels.

Stekels, m. mv. - Ramsel en omstr. - Id. als STEKERs (Vl. Wk.). - De vruchten dragen stekels.

Stekke. - Z. Sтек (Bijv.).

Sterrekens, o. $\mathrm{mv}$. - Denderwindeke en omstr. - Id. als Speenkruid (VI. Wk.). - De bloem heeft den vorm van goudgele sterrekens (fig. 43).

Stesselkenskruid, o.- I ebbeke en omstr. - Verb. van Stijfselkruid. - Draba verna L.; fr. Drave printanière; vl. I.enteVroegeling.

Stiengraas, o. - Verb. van Steengras.-Beeringen en omstr. - Poa annua L.; fr. Paturin annuel; vl. Klein Beemdgras. Groeit veel tusschen de straatsteenen.

Stijlkeers, v. - Herdersem. - Id. als Rietentop (Vl. Wk.).

Stinkblad, o. - Nederland. -

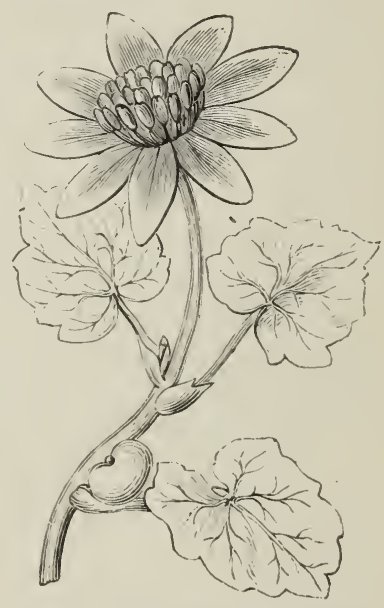

Fig. 43. - Ficaria ranunculnides. (Speenkruid.) Id. als Hoefblad (Vl. Wk.). - Heeft een onaangenamen geur.

Stinkbloem, v. - Nederland. - Id. als Honisdille: (Vl. Wk.). - Eene stinkende bloem. 
Stinkende-Gauw, v. - Z. dit w. in 't Vl. Wk. - Te Antwerpen, bij nitzondering, wordt deze naam aan de Tagetes gegeven. - Z. Strinkers (Vl. Wk.).

Stinkende Govert, v. - Verb. vall - Gauwe. - Beeringen en omstr. - Z. Stinkende-Gauwe (Vl. Wk.).

Stinkende-Mei, m. - W.-V'l. - Id. als Hondsdille (VI. Wk.). - Mei = fr. bouquet; un mai. De algemeene vorm der plant lijkt op eenen mei en hij stinkt geweldig.

Stinkhout, o. - Nederland. - Id. als Hoxzenhout (V1. Wk.). - Het hout riekt onaangenaam.

Stinkpotten, m. mv. - Wordt, te Antwerpen, gezegd van de Tagetes. - Z . ook STInkende-GAuw (Bijv.).

Stinkwied, o. - W.-Vl. - Td. als Hondsdille (VI. Wk.). - Wied = kruid, in W.-Vl.

Stobbels, m. mv. - Zwijnaarde, Eecke, Seeverghem en omstr. - Elders, zegt men stoppels; en, in /uid. Belg.Limb. : stoppelen, v. mv. - De onderste deelen der graangewassen die, na het afmaaien, blijven staan (fr. éteules).

Stoelboon, v. - W.VI. - Id. als HutTeBoon (Vl. Wk.). - Stoelen, o. werkw., beteekent, in W.-Vl., struiken, een struik vormen, gelijk deze kleine boonen doen. Vandaar ook de naam van Struitiboonen, dien zij elders dragen.

Strekbinde, v. - W.-V1. - Polygonum Convolvulus L.; fr. Renouée Liseron; vulg. Faux-Liseron; vl Zwaluwtong. - Binde, in W.-Vl., is synoniem ran Winde. Strek = strik.

Streping, m. - Zwijnaarde en omstr. - Var. van Appel die ronde strepen draagt. Gewoonlijk noemt men aldus den eigenlijken Rambour d'automne. (J. Paelinck.)

Streuvelaar, m. - W.-Vl. - Boom of plant die onderblijft, die niet behoorlijk opgroeit.

Strinkbol, m. - Oostham en omstr.; alsook aan den Maaskant (in Belg.-Limburg). - Arbre tétard. - Strink = verb. van stronk; z. SJonk (Bijv.). - Men zegt ook Kopboomen.

Struif, v. - $\mathbb{I}^{\top} . \mathrm{I}^{\top} 1$ - Eigenlijk, hetzelfde als druif; fr. raisin; maar, in 't gebruik, is de zin ran dit $W$. meer uitgebreid en bet. zooveel als tros, fr. grappe. 
Struikpeem, m. - IV.-V1. - Agropyrum repens P. B.; fr. Agropyre rampant; vulg. Chiendent; vl. Kruipende Agropyrum of Hondsgras. - Een peem die een struit: maakt, die veel scheuten en stengels schiet.

Stuiken, m. mv. - Zwijnaarde en omstr. - Verschillige bundels (schooven, fr. gerbes) graan, te samen gebonden op 't veld en in afzonderlijke rijen geplaatst, om uit te drogen. - In Zuid. Belg.-Limb., zegt men mijten, r. mv. Hetzelfde w. heeft aldaar ook de bet. van 't fr. meule; eene strooimijt $=$ une meule de paille; eene hooimijt $=\mathrm{id}$. de foin, enz.

Suikerbeziën, v. mv. - Herenthals, Oolen en omstr. Id. als Frambozen ( $\mathrm{V}$ l. IVk.).

Sulker, m. - Kerkom en in 't Hageland. - Rumex Acetosella L.; fr. Rumex Petite-Oseille, vl.Schaapszurlel.

Taailing, m. - Denderwindeke en omstr. - Id. als VERKENSGERS ( $\mathrm{Vl}$. Wk.). - De plant is zeer taai.

Tabakpijp. - Z. Товвак - (Bijv.).

Takkebloem, v. - ' C. 't volg. w.

Takkekroed, o. - Terb. van - kruid. - In Geul, aan de Maas(Holl.-Limburg). - Spiraea Ulmaria L.; fr. Spirée Ulmaire; vulg. Reine des prés; v1. Moeras-Spierkruid. Zoo genoemd naar den vorm der bloeiwijze, die, onder de eerste groote bloem, weer nieuwe bloemstengels, eens, twee-zelfs driemaal naar boven schiet, en zoo eene rertakking of vertakten bloesem geeft. (Th. Coenegracht.)

Takroos, v. - W.-V1. - Id. als MAANDrons (T1. Wk.). Talpekruid, 0. - W - V 1. - Id. als Doorna PPEL (T1. Wk.). Tandzaad, o. - Denderwindeke. - Id. als Luizen (Vl. Wk.). - Het zaad der plant is van tanden voorzien; vandaar ook de lat. naam (Bidens), die tweetand beteekent.

Tantemarijne, v. - W.-V1. - De vrucht van een vreemd gewas: Tamarindus indica L.; fr. Tamarinier des Indes. 
- Grove verb van den lat. of den fr. naam. - Men zegt : naar de apotheek gaan om tantemarijne, tegen de tandpijn; fr. tamarin (Kruidw.).

Tater, m. - W.-Vl. - Verkorting van Patater, d. i. Aardappel.

Teer, Tère. - Oud vlaamsch w., synoniem van boom, en niet meer in gebruik dan in samengestelde namen, b. v. mispelteer, holenteer, herenteer, heinenteer, egelenteer, appeltère, notelteer, enz. - De uitgang teer beantwoordt aan den uitgang laar, lare, die ook boom beteekent en vooral bij de namen van fruitboomen in gebruik is: notelaar, mispelaar, appelaar, perelaar, enz. - Het oud vl. w. teer is behouden in 't eng. tree (met rerplaatsing der letter $r$ ), in 't ijslandsch trè, in 't. zweedsch trea, allen woorden die boom beteekenen. Het is onk te vinden (in denzelfden zin) in 't gottisch triu, in 't oud-friesch tere, taere, tree, en bij Kiliaan, die taere schrijft.

Temmerinde, v. - $\mathbb{W}^{-}-\mathrm{V}^{\top}$. - Id. als ReINeVAREN (V1. Wk.).

Temst, m. - Beeringen en omstr. - Id. als 'Trлm (Vl. IVk.).

Tenkte, v. - W.-Vl. - Id. als Reinevaren (V1. Wk.).

Teunisbloem, v. - Nederland. - Algem. naam roor 't geslacht Oenothera L.; fr. Onagre; vl. Nachtkaars. Teunis = Antonius : dus bloem van den H. Antonius. Eene andere plant van dezelfde familie, dicht verwant met de 'Teunisbloem (de Epilobium spicatum Lmk.; fr. Épilobe en épi; vl. Aardragende Basterdwederik), draagt den fr. volksn. : Laurier-de-Saint-Antoine.

Thee, v. - Z. 't volg. w.

Theeboom, m. - W.-Vl. - Id. als GEITENiBAird (Vl. Wk.). - Er wordt veel thee gemaakt met deze plant, bijzonder tegen de waterzucht. '/. SpiraEa Ulmari. L., in 't lat. IV'k

Theeroos, r. - W.-Vl. en bijna overal in Belgï. - Eene var. van gele Rozen die rieken gelijk thee; fr. Rose Montebello.

Tientjes, o. mv. - IV.-VI. - Wordt gezegl van de ver- 
waarloosde appels, peren, noten, enz. die, na de plukking, op den boom blijven staan. - Misschien vindt men hier een gedacht van de tiende, fr. la dime. Het zijn tientjes voor de straatjongens.

Tijdloozen, v. mv. - Denderwindeke en omstr. - Id. als Truloos, $\mathbf{x}^{\circ}$ ) (Vl. Wk.).

Tijlekrijpen, m. mv. - Zwijnaarde en omstr. - Eene vroege var. van Appel : de Roode Zomer-Calviel (fr. Calville roug'e d'été). - De naam is eene samentrekking van tijdelijk-rijpen. Tijdelijk=hier, vroeg.

Tijnde. - Z. Tientues (Bijv.).

Tikbeusten. - Coursel en omstr. - Scirpus caespitosus I.; fr. Scirpe cespiteux; vl. Zodevormende Bladbies.

Tinde. - Z. 'T'rentJes (Bijv.).

Tisanepeem,m.- W.-Vl. - Id.als HondsGras (V1. Wk.). - Tisane, is 't fr. woord, dat opgietsel van kruiden, thee beteekent. Er wordt veel thee gemaakt met de wortelstokken of peemen dezer plant (fr. rhizomes): 't is een pisafdrijvend middel ( $\mathrm{fr}$. diurétique).

Tistje, o. - W.-V1. - Var. van langachtigen Aardappel, anders ook FrotTer genaamd.

Tjokvaroest, m. - Oost-Roosebeke en omstr. - Id. als Boomvaren (Vl. Wk.). - Tjok, in W.-Vl. = tronk, wortelblok van kaphout. - Varoest = verb., van Varen (fr. Fougères). - Deze Varen komen veel op de oude wortelblokken van kreupelhout.

Toebakluizen, v. mv. - Zwijnaarde, Eecke, Seeverghem, Sint-Denijs-Westrem. - Zijvertakkingen aan den gekweekten tabak, nadat hij afgetopt is. Die scheuten worden luizen genaamd, omdat zij ten koste van de bladeren leven. De luizen worden zorgvuldig afgenepen en zonder gebruik gelaten (J. Paelinck en Kruidw.). - Men zegt ook Dief, in denzelfden zin.

Toebakmost, - mos, o. - W.-V1. - Soort van Wieren (fr. Algues), groeiende op de zeerotsen van 't eiland Corsica; fr. vulg. Mousse de Corse; lat. Gigartina Helminthocorton. - In de Pharmacopée belge en bij de apothekers, 
vindt men, onder den ouden naam Helminthocorton, een mengsel van verscheidene Wieren, van de familie der Florideë̈n, dat gebruikt wordt als wormverdrijvend midrlel. Dit mengsel draagt ook den volksn. : Mousse de Corse, en wordt ook, in W.-Vl., Toebakmost geheeten. Het is gekruld gelijk verdroogd mos en heeft eene tabakskleur (geel-bruinachtig) : vandaar de naam van dit geneesmiddel.

Toebakpijp, v. - Oost-Roosebeke en elders in W.-V1. - Id. als Capuciene(n) (Vl. Wk.). - De bloem heeft den rorm eener pijp (fr. pipe).

Toepjeklaver, m. en v. - W.-Vl. - Id. als TopkLAver (Vl. Wk.). - Toepje= verkleinw. en verb. van Top.

Tolrapen, v. mv. - In de Kempen. - Rapen hebbende den vorm van een tol, waarmee de kinderen spelen (fr. toupie).

Tongel, v. - Nederland. - Id. als KLeften (Vl. Wk.).

Tooverboom, m. - W.-V1. - Broussonetia papyrifera Vent,; fr. Broussonetie à papier. - Uitlandsche boom, somtijds gekweekt in hoven en parken en wiens bladeren bijna allen een verschilliger vorm hebben : men zou zeggen dat hij betooverd is.

Topmutsen, v. mv. - Moll, Oolen en omstr. - Id. als Vingerhomdskuid (Vl. Wk.). - De bloemen hebben den vorm van eene topmuts of slaapmuts. - Z. ook SLAAPvits (Bjjv.).

Traat. - Pepinghen (bij IIalle) en omstr. - Id als Verkensiers (Vl. Wk.). - Men vindt het werkw. tratten, voor treden ( $\mathrm{fr}$. fouler aux pieds). Het Verkensgers groeit veel langs en op de wegen; het ligt neer tegen den grond : het wordt dus steeds met de voeten getratten (getreden); vandaar : Traat. - Elders, zegt men Trijt (z. verder, Bijv.).

Trekkebek, r. - Nederland. - Id. als SleEdorin ( $\mathrm{r}$. Wk.). - De sleeën of vruchten van den Sleedoorn zijn zeer samentrekkend (fr. astringent) : zij trekken den mond (dr'n bek) geweldig te samen. 
Tremske, o. - Nederland. - Id. als Blauwbloem ( ${ }^{\top}$ l. IVk.).

Treurappels, m. mv. - Land van Aalst. - Id. als Pronkappess ( $\mathrm{Vl}$. ITk.).

Trijt. - Denderleeuw en omstr., Oultre (bij Ninove). - Id. als Verkensgers (Vl. Wk.).—Z. ook TraAt (Bijr.).

Tripkruid, o. - Mall, Sluizen en omstr. - Uitspr. kraut. - Thymus vulgaris L.; fr. Thym commun; vl. Gemeene Tijm. - Dit welriekend kruid wordt gebezigd om trippen (= worsten) voor te bereiden.

Trommelstokken, $\mathrm{m} . \mathrm{mr}$. - Denderwindeke en omstr. -Id. als Gel.e-Waterlelie (VI. WVk.). - De ronde bloeinknoppen (fr. boutons) der plant, met hunne lange stelen, gelijken zeer wel aan trommelstokken.

Trompettenbloem, v., Trompetten, v. mv. - Soort van Fuchsia, met lange, klaroenvormige bloemen : Fuchsia fulgens DC.; fr. F. éclatant (Kruidw.).

Tronkboom, m. - W.-VI. - Id. als StrinkBoL (Bijv.).

Truisjonker, m. - Oost-Roosebeke en omstr. - Id. als Troвbels (Vl. Wk.). - Truis, in W.-Vl., = bloemtuil; fr. bouquet. - Jonker(kes) = volksn. van dit geslacht van planten. - Nu, bij de vermelde soort, groeien de bluemen dicht bijeen en vormen truizen. Vandaar ook de fransche volksn. : Bouquet tout fait, Bouquet parfait, enz.

Trul, m. - W.-Vl. - 1 $^{\circ}$. Beteekent, in 't algem., een boom, vooral een oude of vernukkelde boom (Kruidw.). $2^{\circ}$ In 't bijzonder', A hornboum: fr. Érable champêtre; lat. Acer campestre $\mathrm{L}$.

Trusblommen, v. mv. - Zwijnaarde en oinstr. - Id. als TruisJoxker (Bijv.). - Trus = verb. van truis.

Tuchtekruid, o. - Thielt, Oost-Roosebeke en omstr. Id als Krooxknskruid (Vl. Wk.). - Z. ook 't volg. w. (Bijv.), voor uitleg.

Tuchtig-Kruid, o. - Id. als 't voorg. w. - Tuchtig. = fr. modeste, retenu. - Het uiterlijke voorkomen dezer plant heeft waarlijk iets zedigs, iets tuchtigs. 
Tuinlepeltje, o. - Nederland. - Id. als LEPELbLaD (Bijv.). - Voor uitleg, z. ook LePeltuesdef en LePelsEx- T'ORKEN (Bijv.).

Tulitanen. - Nederland. - Id. als AfrikaAxder (Vl. Wk.). - Men zegt ook Tunisbloem (bijzonder de oude schrijvers), omdat deze plant van Tunis (in Afrika : vandaar A frikaander) werd ingevoerd.-In Tulitanen, hebben wij waarschijulijk eene verb. van Tunisanen of iets dergelijks.

Tulpane, v. - W.-VI. - Id. als TullepaAx en Tulp (Vl. Wk.). - In 't perzisch, zegt men Thoulyban.

Turksche-Krenten, v. mv. - Nederland.- De vruchten (en ook de struik) van Cerasus Padus DC.; fr. Cerisier à grappes; vulg. Mérisier à grappes; vl. Tropjes-Kerseboom of Hondskers. - De vruchten gelijken aan krenten (fr. raisins de Corinthe). - Turksche $=$ hier, iets dat niet goed is, niet eetbaar.

Tursche-Weit, v. - Nederland. - Id. als Maïs en Turksche-Terwe (T'1. Wk.). - V'Toor uitleg val Weit, z. Bоекшеiт (Bijv.). - In 't fr. zegt men ook, vulg. Bléde-Turquie.

Twaalf-Uren-Bloen, r. - Denderwindeke en omstr. Specularia Speculum Alph. DC.; 1\%. Spéculaire Miroir; vulg. Miroir-de-Vénus; vl. Grootbloemige Vroutvenspiegel. - Het volk meent dat deze bloem maar om 12 ure opengaat: 't geen ointrent waar is.

Tweebok, 11 . - W.-Vl. - Een tros van twee noten, krieken, enz. - Bok, in W.-Vl, is synoniem van tros, in 't algem.

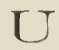

Uilbloem, v. - Verb. van Heulbloem. - Beeringen en omstr. - Papaver somnifermu L.; fr. Pavot soinnifère; v1. Slaapuetitiende Maankop (fig. 3o). 
Uppen(e), o.; 't mv. is Uppens. - $\mathrm{W} .-\mathrm{Vl}$. - Id. als Knippers (Bijv.).

Uppens. - Z. 't roorg. W.

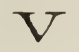

Vaan, o. - Beeringen en omstr. - Id. als VAaxkruid (Vl. Wk.).

Vaanstek. - Id. als 't voorg. w.- Stek, komt van steken (fr.piquer): men steekt een stukje vuurwortel in het oor der zieken dieren. Men heet dat, in Limburg, " het vaan steken ». - Voor verderen uitleg, z. ook VuURWORTEL (Vl. Wk.)

Vanoor, Van-Oore, v. - W.-Vl. - Lig'ustrum vulg*are L.; fr. Troëne commun; vl. Gewoon Mondhout. - Dus genaamd misschien, omdat de mandemakers zich van de takken van dit houtgewas bedienen om de ooren of handvatsels der vannen of wannen (fr. van) te verveerdigen.

Varente, m. - Winckel-Sint-Elooi. - Id. als VAREN (Vl. Wk.).

Varinks, m. - Zwijnaarde, Eecke, Seeverghem, SintDenijs-Westrem. - Id. als VAREN (Vl. Wk.).

Varoest, m. - Oost-Roosebeke en omstr. - Verb. van Varen. Z. dit W. (Vl. Wk.).

Veme, v. - W.-V1. - Blad van Lisch, Porei, Tarwe, enz.; in een woord al de bladeren die min of meer zweerdrormig zijn (fr. feuilles linéaires, fe.ensiformes). - Men zegt ook Feme

Verdjuis, o. - Id. als 't volg. w.

Verdjuus, o.; zonder wv. - Oost-Roosebeke en omstr. - Io Soort van druif die zuur smaakt, zelfs als zij rijp is (fr. verjus). $-2^{\circ}$ Wordt ook gezegd voor druif, in 't algemeen (fr. raisin) : het verdjuus begint te rijpen. Er staat veel verdjuus aan dien wijngaard (Kruidw.).

Verdjuusboom, m. - Oost-Roosebeke en omstr. - Id. als Druivelaar; fr. un cep de vig'ne. - Z. ook 't voorg. w.

Vergauw, v. - Oultre (bij Ninore). - Id. als VERGouw (Vl. Wk.). 
Vergedoor, m. - Uitspr. Verzedoor en Verzadoor (Kruidw.). - Poperinghe en omstr.-Cheiranthus Cheiri L ; fr. Giroflée Violier; vulg. Giroflée-de-muraille, Murailler; vl. Steen-Violier.-Vergedoor is gewis verbasterd. zegt M. Samyn, van 't fr. Verge d'or, hoewel dit eene andere plant zij dan de Violier. - Orerigens, de lange, gele bloemtrossen van deze Violier gelijken ook op eene guldenroede (fr. verg'e d'or). - De plant die, in 't fr., den naam van Verge d'or draagt, is de Solidago Virga-aurea L.; fr. Solidag'e Verge d'or; vulg. Verge-d'or; vl. Gulden Roede.

Vergefbezen, v. mv. - Zwijnaarde en omstr. - Verb. van Vergift - Vruchten van Solanum Dulcamara L. (fig. I). - Z. Stinkend-Hout (Vl. Wk.).

Vernepeling, m. en $0 .-\mathrm{W} .-\mathrm{Vl}$. - Iemand of iets dat zijne behoorlijke grootte niet heeft; fr. rabougri. - Die Appels zij maar vernepelingen.

Vernukkeld, bijv.-deelw. van vernukkelen. - Verneuteld, ingekrompen, fr. rabougri (Kruidw.).

Vernte, m.- IJper en omstr.-Id. als TAREN (V1. WK.)

Veroest, m. - W.-Vl. - Id. als VARoEst (Bijv.).

Verzadoor. - Z. V'TERGEDOOR (Bijv.).

Verzedoor. - Z. VERGEDOOR (Bijv.).

Vesicatorie, v. - Berthem en omstr. - Id. als MeLKkRUID, $2^{\circ}$ ) (Vl. WVk.). - Wordt soms als trekplaaster (fr. vésicatoire) gebruikt, bij de buitenlieden.

Veugelvitse, v. - Verb. van Vogel - Oost-Roosebeke en omstr. - Verscheidene soorten van wilde Vitsen, maar. bijzonder de Vicia Cracca L.; fr. Vesce en épi; vl. AarVitse of - Wikke; ook Vogel-Vitse genaamd. - De vogels zijn verlekkerd op de zaden dezer planten.

Veunshout, o. - W.-Tl. - Boomzwam. Verscheidene soorten; maar vooral de Polyporus igniarius Fr.: fr. Polypore amadouvier. - 't Is van Veunshout dat men zwam (fr. amadou) maakt. - Men zegt ook V'unshout. Veinshout en Veushout.

Veushout. - Z. 't voorg. W.

Vijter, m. - Nederland.- Id. als Hovmsiras (V1. Wk.). 
Vinkoorde, v.- I ${ }^{\circ}$ Oost-Roosebeke.-Id. als VINkdoorn (Vl. Wk.).-2 $2^{\circ}$ Elders, in W.-V1., id. als MaAgDEKENSPALM (Vl. Wk.).

Vinsioen, o. - W.-Vl. - Id. als Sins.Jome en Siensonk (V1. Wk.).

Vischkruid, o.- Heyst-op-den-Berg en omstr.- Nitella flexilis Agardh: fr. Nitelle flexible; vl. Buigzame Nitella. - De visschen schuilen geerne onder deze waterplant.

Vitseboom, m.- W.-Vl. - Id. als BlaAasboom (Vl. Wk.). - De bloemen van dit struikgewas gelijken op die van Vitsen.

Vleugelkesboom, in. - Zwijnaarde en omstr. - Id. als 't volg. w.

Vliegerkesboom, m. - Zwijnaarde en omstr., Eecke, Seeverghem, Sint-Denijs-IVestrem.- Id. als Fuik KERKESвоом (Vl. Wk.). - De gevleugelde vruchten werpt men in de lucht; hun val gelijkt op de vlucht van een vogel (fig. 9).

Vlienderkruid. - Z. 't volg. w.

Vlinderkruid, o. - W.-Vl. - Id. als Vhrender, $\left.2^{\circ}\right)$ (VI. Wk.).

Vlooiekruid, o. - Beeringen, Coursel, Zolder en omstr. - Id. als GAGEL (Vl. Wk.). - De sterke geur van dit struikgewas verjaagt de vlooien, zoo men beweert. Ook ziet men de arme lieden bladeren en takjes er van onder hunnen beddezak steken.

Vlooienhout, o. - Moll, Oolen en omstr. - Id. als 't voorg. W.

Vlotgès, o. - Verb. van - gras. - Zwijnaarde en omstr. - Id. als Flotgers (Vl Wk.).

Vogelwinde, v. - Denderwindeke en omstr. - Id. als STREKBinde (Bijv.)

Vookachtig, bijv.- W.-VI.- IVordt gezegd van appels, wortels, rapen, enz. wier pel verrimpeld eu wier sap verloren is. Appels zijn rookachtig', laat op 't jaar. - In Zuid. Belg.-Limb., zegt men vookak en de zin van dit w. is : te rijp; beginnende te bederven, bijzonder van binnen ('t geen men ook de buikziekte noemt). - Die appel, die peer is vookak; die peren ziju vookak. De uitspr. is eerder fookak. 
Vookak. - Z. 't voorg. w.

Voos, Voosch, Voogsch, Voois, bijv. - Zwijnaarde, Eecke, Seeverghem, Sint-Denijs-Westrem.-Wordt gezegd van rapen en radijzen die, te oud geworden zijnde, geen vast vleesch meer hebben, (J. Paelinck).

Voois. - Z. 't voorg. w.

Vrouwentongen, v. mv. - Nederland. - Id. als VrouwLIÊ-TONGEN (Vl. IVk.).

Vrattekruid, o.- Beeringen en omstr. - Id. als WorTEKRUID (Vl. Wk.).

Vremd-Loof, o. - Verb. van Vreemd -. Zwijnaarde en omstr. - Loof = in deze streek, Rapen; onze gewone Rapen. - Het Vremd-Loof is eene var. met buitengewoon dikke knollen, die Rutabaga genaamd wordt. - Voor verderen uitleg, z. Loof (Vl. Wk.).

Vuilboom, m. - Beeringen en omstr. - Id. als HAverESCH (Vl. Wk.).

Vunshout. - Z. VEUNSHout (Bijv.).

W

Waaiwinde, v. - '/Wijnaarde en omstr. - Id. als WiwiNde (Vl. Wk.).

Wachelter. - Verb. van - teer. - Reckheim en omstr. - Id. als JENEverioom (Vl. Wk.) (fig. 44). - Wachel, wakel (z. 't volg. w.) en wachtel beteekenen, in Limburg, Jeneverbes (fr. baie de Genévrier); dus IVach$(t)$ elteer $=$ Jeneverboom.

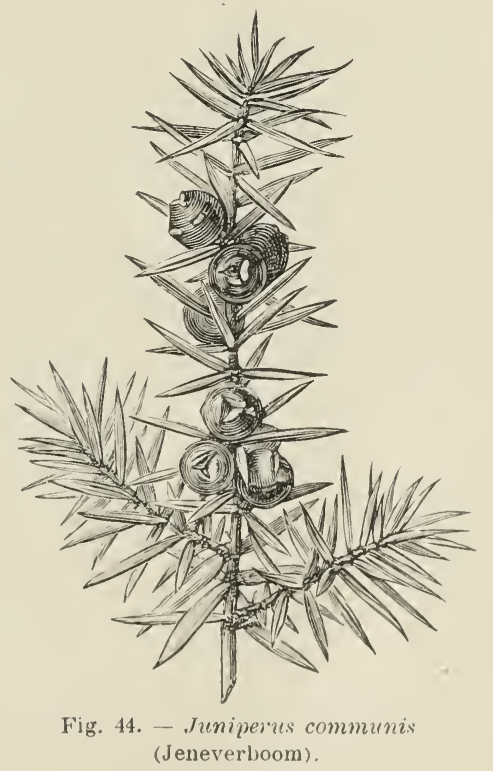

- Aangaande den uitgang teer, z. TeEr (Bijr.). - Elders, in Limburg, heet die boom : Wachalder of Wachholder. 
In 't hoogd. wordt hij ook Wachholder genaamd. Kiliaan vermeldt den naam Wachtelboom, als behoorende tot het oud-geldersch.

Wakel, m. - Nederland. - Id. als 't voorg. w., maar beduidt bijzonder de vrucht.

Wakholder, m. - Nederland. - Id. als WACHELTER (Bijv.).

Walberen, v. mr.- Reckheim en omstr.- Iets zonderlings : de uitspr. is Walberen (korte $e$ ) en niet Walbeeren. - Id. als Boschiezekes (Vl. Wk.). - Verb. van 't duitsch Waldbeeren : Wald $=$ woud, bosch. Deze plant wordt alleen in de bosschen gevonden.

Waldbeeren, v. mv. - Nederland. - Id. als 't voorg. w. Walderik, Wolderik, m. - W.-Vl. - Id. als ERIK (Vl. IVk.).

Walnoot, v. - Nederland. - Id. als OkкEnotex (Vl. Wk.).

Walriet, o. - W.-Vl. - Id. als DekrIET (V1. Wk.).

Watergiroffel, v. - Denderwindeke en omstr. - Hottonia palustris L.; fr. Hottonie des marais; vl. Waterviolier - De plant groeit in 'twater en de bloemen gelijken op die van de Violier of Giroffel, zooals men te Denderwindeke zegt.

Waterkolf, m. - W.-VTl. - Id. als KoLFRIET (Vl. Wk.).

Waterpompe, v. - Z. PoMPE (Bijv.).

Waterridder, m. - Zwijnaarde en omstr. - Stratiotes Aloides L.; fr. Stratiote Faux-Aloès; vl. Valsche Aloës; vulg. Scheeren.- De plant groeit in 't tvater der grachten en der vijvers; zij schijnt, zoo meent het volk, op 't water te rijden.

Watersparretje, o. - W.-VI. - Hippuris vulgaris L.; fr. Pesse commune; vl. Gemeene Lidsteng. - De plant groeit in 't water en heeft het uiterlijke van een kleinen Spar, een Sparretje (fr. Sapin).

Waterspurie, v. - Zwijnaarde, De Pinte, Seeverghem. - Juncus bufonius L.; fr. Jonc des crapauds; vl. PaddeBloembies of Paddebies. - Groeit op vochtige gronden en gelijkt op de Spurie. 
Waterviole, v. - W.-Vl. - Id. als WATERGIROFFEL (Bijv.).

Waterwulge, v. - Oost-Roosebeke en omstr. - Polygonum amphibium L.; fr. Renouée amphibie; vl. I'eenwortel. - De plant groeit gewoonlijk in 't water en de bladeren gelijken op die van den Wilg.

Waulbeeren, v. mv. - Maaseyck en omstr. - Id. als WALDBEEREN (Bijv.) en zelfde uitleg. - Waul=verb. van 't duitsche II ald = bosch, woud.

Wederdood, v.- Nederland.-Asplenium Trichomanes L.; fr. Doradille Polytric; vulg. Capillaire; vl. Steenbreek of IVederdood.

Weiraap, v. - Berthem en omstr. - Id. als EiraAP (Vl. Wk.).

Weit, v. - Nederland. - Synoniem van Tarwe; fr. Froment, Blé; lat. Triticum. - Z. ook BoEкweit (Bijv.).

Werf, Werve. - Z. Wervenhout (Bijv.).

Wervenhout, o. - Naam van verscheidene soorten van groven Wilg (men zegt ook IVerf, Werve, v.). - Te Poperiughe en omstr., noemt men alzoo vooral den Salix aurita L.; fr. Saule à or eillettes; vl. Geoorde Wilg.

Weskroed, m. - Verb. van Wiskruid. - Mastricht en omstr. - Id. als KRUidwesch (Vl. Wk.).

Wettenkruid, o. - Denderwindeke en omstr. - Verb. van Wratten -. Id. als Wertekruid (Vl. Wk.). - Het bijtend geel sap gebr. men om de wratten (hier wetten genaamd) te doen verteren.

Weurft, Weurvenhout. - Vilvoorde en omstr. - Salix caprea L.; fr. Saule Marceau; vl. Ruige of Water-IVilg.

Wieën, werkw. - Verb. van wieden, workw.; wied, o. = onkruid. - Reckheim en omstr. - Wieën, is jong. onkruid uitplukken, om de zaaibedden te zuiveren en de jonge plantjes vrij te zetten (Th. Coenegracht). - In Zuid. Belg.-Limb. zegt men gèjen. - Z. ook Kruien (Bijv.).

Wiegerd, m. - Maastricht en omstr. - Id. als WiJNGAARD (Vl. Wk.).

Wiemeren. - Z. ZWARTE - (Bijv.).

Wiepedoorn, m. - Nederland. - Id. als Hoxdsroos (Vl. Wk.). 
Wijme, v. - W.-Vl.-Id. als WiJu en WiJmen (Vl. Wk.). Wijnknoppen. - Oostham en omstr. - Calycanthis floridus L.; fr. Calycanthe fleuri; vl. Wijnbloem. - De bloem heeft de kleur van wijn en zij blijft gewoonlijk knop (fr. bouton), d. i. zij opent zich maar slecht.

Wijnknupkes, o. mv. - Beeringen en omstr. -- Id. als 't voorg. w. en zelfde uitleg. - Knupkes = verb. van knopkens (fr. petits boutons).

Wild-Koren, o. - Nederland. - Alopecurus agrestis L.; fr. Vulpin des champs; vl. Veld-Vossestaart. - De aar dezer grassoort gelijkt min of meer op die van het Koren (fr. Seigle).

Wilde-Ate, v. mv. - Oost-Roosebeke. - Avena fatua L.; fr. Avoine folle; vulg. Folle-Avoine; vl. Dolle Haver.

Wilde-Door, m. -- Denderwindeke en omstr. - Id. als TruWEeLKen (Vl. Wk.).

Wilde-Geer, m. - Nederland. - Id. als Drijblad (Vl. Wk.). - Geer = verkorting van Geeraard, naam die, in vele plaatsen, aan den Sambucus nigra L.; fr. Sureau noir, gegeven wordt. Het Drijblad gelijkt op den Geer, door den vorm der bladeren en dewijl het onkruid is, dat in 't wild groeit, heeft men het Wilden-Geer gedoopt.

Wilde-Lelietjes, o. mv. - Nederland. - Maianthemum bifolium Schmidt; fr. Maïanthème à deux feuilles; vl. Tweebladig Schaduwbloempje. - De bloemen zien er uit als wilde Lelietjes-van-dalen (fr. Muguet) : zij zijn min schoon en niet welriekend.

Wilde-Mater, v.-Oultre (bij Ninove). - Id. als MoederKRUID (Vl. Wk.).

Wilde-Salie, v.-Denderwindeke en omstr.-Teucrium Scorodonia L.; fr. Germandrée Scorodonie; vulg. Saugedes-bois; vl. Wilde Salie.-De bladeren der plant gelijken op die der gekweekte Salie (Salvia officinalis L.).

Wilde-Vliender, m. - Z wijnaarde en omstr. - Id. als WILDE-GEER (Bijv.).

Wilde-Wettels, v. mv.-Verb. van - Wortels.-Poperinghe en omstr. - Caucalis daucoides L.; fr. Caucalide Fausse-Carotte. - De bladeren en bloemen gelijken op 
die der gekweekte Wortel (fr. Carotte), maar de plant groeit in 't wild. - Z. ook Wortelen (Vl. Wk ).

Wilde-Wijngaard, m. - Oultre (bij Ninove). - Id. als IVitTe-IVIJngaARd (Vl. Wk.).

Wilgenkruid, o. - Berthem en omstr. - Id. als WildeIVILGEN (Vl. Wk.).

Wille-Beete(n), v. mv. - Sint-Joris-Winghe. - Rumex obtusifolius L.; fr. Rumex à feuilles obtuses; vl. Stompbladige Zurkel. - De bladeren gelijken niet slecht op die der gekweekte Beet (fr. Betterave) en de plant leeft in 't wild.

Wille-Klaverkes, o. mv. - Kerkom en in 't Hageland. - Trifolium minus Relhan; fr. Trèfle nain; vl. Dwerg.Klaver. - Deze soort wordt niet gezaaid, maar komt van zelve, in ' $t$ wild.

Wille-Koekoe, m.- Kerkom en omstr.- Id. als SteEnKLAVER (VI. Wk.). - Zelfde uitleg als bij 't voorg. w.

Wille-Koekoeksbloeme(n), v. mv. - Sint-Joris-IVinghe. - Oxalis Acetosella L.; fr. Oxalide Petite-Oseille; vl. Gewone Klaverzuring. - Wilde : tegenover de gekweekte soorten van Oxalis.

Wille-Muzelaar, m. - Kerkom en omstr. - Id. als IVille-PosselaAN; $z$. 't volg. w.

Wille-Posselaan, m. - Verb. van - Postelein. - SintJoris-Winghe en omstr. - Id. als Wilde-Porselein (Vl. Wk.). - De bladeren gelijken eenigszins aan die van Postelein (Portulaca oleracea L.; fr. Pourpier) en de plant groeit soms in 't wild, benevens de moeshoven.

Wille(n)-Dravik, m. - Kerkoin en in 't Hageland. Bromus mollis L.; fr. Brome mou; vl. Dravik.- De plant wordt wild genoemd, in vergelijking met eene andere soort (Bromus secalinus L.), die er min wild nitziet $\mathrm{en}$ bijzonder in de graanakkers groeit.

Windzaad, o. - W.-Vl. - Venkelzaad; fr. semences de Fenouil (Fœniculum capillaceum Gilib.).-In de apotheek verkoopt inen Windzaad: een middel om de winden uit het lijf te drijven. 
Wit-Boksen, v. - Nederland. - Holcus mollis L.; fr. Houlque molle; vl. Zacht Zorggras.

Wit-Sterreken, o. - Lebbeke en omstr. - Id. als StERREKRUID (Vl. Wk.).

Witte-Blagaaize, v. mv. - Oost-Roosebeke en omstr. - Eene var. van Phlox, met witte bloemen.

Witte-Boterstampers, m. mv. - Heyst-op-den-Berg en omstr. - Id. als Witte-Boterstandekes (V1. Wk.).

Witte-Kiek, v. - Nederland. - Thlaspi arvense L.; fr. Tabouret des champs; vl. Veld-Boerenkers. - Onder den naam van Kiek, begrijpt 't volk nog' andere soorten van onkruid (als Sinapis arvensis L., Raphanus Raphanistrun L.), maar aangezien voormelde soort alléén witte bloemen draagt, is zij Witte-Kiek genaamd. - De Sinapis heet Gele-Kiek.

Witte-Krodde, v. - Nederland. - Id. als 't voorg. w.

Witte-Molekens, o. mv. - Denderwindeke en omstr. Melandrium diurnum Gke.; fr. Mélandre blanc; vulg. Compagnon blanc; vl. WitteValsche-Koekoeksbloem. - De bloemkroon is wit en, van boven, rond-plat lijk een molenrad.

Witte-Most, o. - Zwijnaarde en omstr. - Algem. naam van verscheidene soorten van Sphag. num; fr. Sphaigne; vl. Veenmos, die gebruikt worden om de Orchideeën in te planten en die wit zijn, bijzonder als zij droog. worden (fig. 45).

Witte-Heemstwortel, m. Denderwindeke en omstr. - Id. als Witte-Humst (V1. Wk.). Dit laatste $\mathrm{w} .($ Humst $)=$ verb. van Heemst.

Witte-Vodden, v.mv.-Leuven en omstr. - Id. als WoLLEN-

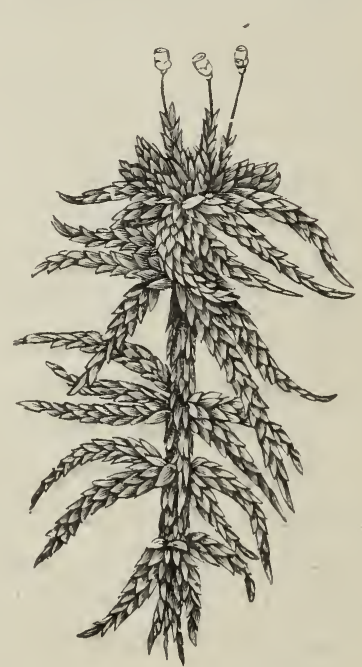

Fig. 45. - Sphugnum (Veenmos).

Vodden (Vl. Wk.). - De bladeren der plant zijn week, 
gelijk vodden, en hebben een witachtigen weerglans.

Witte-Waterroos, v. - Heyst-op-den-Berg. - Id. als Witte-TVaterlelie (Vl. Wk.).

Witte-Weutjes, o. mr.- Maastricht en omstr.- Jonge scheuten en toppen van Labboonen ( $\mathrm{z}$. dit $\mathrm{w}$., in 't V1. Wk.), die als moeskruid gegeten worden.

Witte-Wilde-Winde, v. - Denderwindeke en omstr. Id. als. HAAGLELIE (Vl. Wk.). - De bloemen zijn wit, en de plant is wild in vergelijking met de soorten van Winden die in de hoven gekweekt worden.

Witte-Zeembessenstruik, m. - Denderwindeke en omstr. - Id. als WitTe-BËzekes (Vl. Wk.).

Wolderik. - Z. WALDERIK (Bijv.).

Wolfkers, v. - Lier en omstr. - Id. als Dolle-Kers (Vl. ITk.).

Wolfsveest, r. - Brugge en omstr. - Id. als BonveEsT (V1. IVk.).

Wolveneten, o. - Antwerpen en omstr. - Id. als WoLVENBROOD ( $\mathrm{Vl}$. Wk.).

Wolverlei, v. - Nederland. - Arnica montana L.; fr. Arnique des montagnes; vulg. Tabac-des-Vosges; vl. Berg-Valkruid.

Wrangkruid, o. - Nederland. - Algemeene uaam ran 't geslacht Helleborus I.; fr. Hellébore; vl. Niestruid.

Wrangwortel, m. - Nederland. - Id. als 't voorg. W. Wrattekruid. - Z. VRattekruid (T'1. Wk.).

Wullegès, o. - Zwijnaarde en omstr. - Verb. van Wollegras. - Holcus lanatus L., bijzonder zoolang hij niet in bloeiwijze verkeert. Deze grassoort ziet er zeer wollig uit. - Z. ook Proumgras (Bijv.).

Wulveboontjes, o. mr. - Verb. ran Wolve - OostRoosebeke en omstr. - Lupinus luteus L.; fr. Lupin jaune; vl. Gele Wolfsboon. - Lupinus komt van 't lat. Lupus = wolf.

Wulvekaas, m. - Verb. van Wolven - WT.-T1. - Id.als WoLvenirood ( $\mathrm{Tl}$. Wk.). 


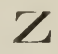

Zaaie. - Zwijnaarde en omstr. - Id. als ZAGGE (V1. Wk.).

Zandvitse, v. - Oost-Roosebeke en omstr. - Lathyrus pratensis L.; fr. Gesse des prés; vl. Weide-Platerwt of Bloemerut.

Zavelboom, r. - Volgens A. De Jaegher, noemt men alzoo, te Poperinghe en omstr., den Juniperus com mun is L.; fr. Genévrier commun; vl. Gewone Jeneverboom (fig. 44). Elders (z. V1. Wk.), beduidt deze naam altijd den Juniperus Sabina L.; fr. Sabine, en waarvan de echte vlaamsche naam Savelboom is.

Zeeandjoen, - anjoen, m. en 0. - W.-V1. - Scilla maritima L.; fr. Scille maritime; v1. Zee-Scilla. - De plant groeit bij de zee en heeft knollen (fr. bulbes) gelijk de ajuinen.

Zeeboon(e), v. - W.-VI. - Id. als LAввооNE(N) (Vl. Wk.).

Zeehaver, v. - W.V1. - Elymusarenarius L.; fr. Élyme des sables; vl. Gewone Zandhaver. - De plant groeit niet dan in zeezand. Zij wordt ook geplant om onze zeeduinen vast te leggen .

Zeekriek, v. - Denderwindeke en omstr. - Id. als KRIEKSKEN-IN-'t HEMD ( Vl. Wk.).

Zeenkruid, o. - Hendersem en omstr. - Heracleum Sphondylium L.; fr. Berce Branc-Ursine; vl. Berentiluw. - Zeen = zenuw; fr. nerf, tendon.-De stengel der plant is gegroefd of geribd; men ziet er verheren lijnen, die als zenuw- of zenenbundels vooruitkomen.

Zeenpijpen, v. mv. - Denderwindeke en omstr. Id. als 't voorg. w. - De pitleg van zeen is als bij 't roorg. w. - De stengels der plant zijn lang, dik en hol; 't zijn waarlijk pijpen (fr. tubes, tuyaux). 
Zevezaad, o. - Oost-Roosbeke en omstr. - Id. als Weurmkraud (Vl. Wk.). - De ware vl. naam is Zeverzaad.

Zeverzaad, o. - W.-Vl. - Id. als 't voorg. W.

Zilverblad, o. - Uitspr. Zelver -. Oost-Roosebeke en omstr. - Id. als ZiLver-Bladeken ( $T$ l. Wk.).

Zineblaren, o. $\mathrm{mv}$. - Zwijnaarde en omstr.. Eecke, Seeverghem, Sint-Denijs-TWestrem. - Id. als ZEENBLAREN (Vl. Wk.). - Verb. van Senneblaren; de bladeren van Cassia-Senna L.; in 't fr. Séné, een wel bekend lichaamzuiverend geneesmiddel.

Zoer-Kruid, o. - Kerkom en in 't Hageland. - Rımex' Acetosa L.; fr. Rumex Oseille; vulg. Oseille de jardin; vl. Hofzurhel. - Z. ook ZuUn-Kruin (V1. Wk.).

Zoermoos. - Z. Moos (Bijv.).

Zoete-Bollen, m. mv. - Zwijnaalde en omstr. - Eene zoete var. van Erwten.

Zolderbloem, v. - Oostmalle en omstr. - Id. als ZoLDERKROLLEN (Vl. Wk.).

Zonderblad, o. - Nederland.-Monotropa Hypopitys L.; fr. Monotrope Sucepin; vl. Woekerend Stofzaad. - Deze woekerplant is zonder bladeren; de stengel draagt alleenlijk eenige witachtige schubben (fr. écailles).

Zulte, v. - Nederland. - Aster Tripolium L.; fr.idem; vl. Zee-Aster of Strand-Aster. - De plant leeft bijzonder in zoutachtige gronden. - Zult en zout hebben dezelfde bet.; men zegt zultvleesch en gezouten vleesch $=$ fr. viande salée, enz.

Zum, m. - Kerkom, Sint-Joris. Winglie en omstr. Id. als DARINK ( $\mathrm{Tl}$. ITk.).

Zwanebloem, v. - W.-VI. - Butomus umbellatus I..; fr. Butome en ombelle; vulg. Jonc-fleuri; vl. Schermdlagende Zwanebloem. - De plant groeit altijd aan den boord van 't water, geliefkoosd verblijf der zuanen (fig. 35).

Zwarte-Haver, v. - Heyst-op-den-Berg. - Avena fatua I.; fr. Avoine folle; vulg. Folle-duoine; vl. DolleHaver, Vloghaver, Even. - De arrtjes (fr. épillets) zijn 
met bruinachtige haren ruw behaard, 't geen hun, tegenorer de andere soorten van Harer, een zwartachtig roorkomen geeft.

Zwarte-Keesten, r. mr. - Zwijnaarde en omstr. Eene Erwtrarieteit met zuarte kiemen (= heesten, in II.-T1.).

Zwarte-Stinknetel, r. - Lier en omstr. - Ballota nigra L.; fr. Ballote noire; rl. Zwarte Stinknetel. - De plant heeft een onaangenamen geur (zij stinkt): hare gedaante gelijkt niet slecht op die ran zekere Netels en de kleur harer bladeren is zwartachtig-groen; om al die redenen werd zij Zwarte-Stinknetel genaamd.

Zwart-Kruid, o. - Berthem en omstr. - Lampsana communis L.: fr. Lampsane commune; rl. Gemeene Atiertiool. - De kleur des stengels is zwart en de bladeren zijn groen-zwartachtig.

Zwijnegras, o. - Starele bij Poperinghe) en omstr. Id. als Verkexsgers ( $\mathrm{Tl}$. Wh.).

Zwijnsooren. o. mr. - Cuerne (bij Kortrijk) en omstr. - Haemanthus albiflos Jacq. - De bladeren dezer gekweekte sieraadplant gelijken aan zwijnsooren

NOTA. - Op bladz. I5, fig. 4 : de woorden "Bloem naturlijke grootte " moeten onder fig. 5 staan en de woorden " Het binnenste der bloem ». onder fig. $千$. 


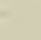




\section{VAN DENZELFDEN SCHRIJ'ER :}

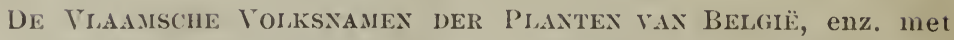
aanduiding der toepassingen en der genezende eigenschappen der planten - 657 figuren. - Werk bekroond door het Kruidkundig Genootschap ran België; goedgekeurd door den Verbeteringsraad. . . . . . . . . . . fr. 10.00

Glide de riferdorisatecr ex Beighqe. - Nieuwe uitgaaf . . . . . . . . . . . . fr.

FLORE ANALYTIQUE ET DESCRIPTIVE DES PROYINCES DE NaMur et dF Luxemboura (plantes indigènes et cultivées), 341 figuren . . . . . . . . . . f $\mathrm{r}$.

Cours de BotaNique: $3^{\text {the }}$ uitgaaf, 1,677 figuren.

Eerste hoekdeel : Botanique générale . .fr." $\mathbf{5 . 0 0}$

Tweede boekdeel: " spéciale. . .fr. $\mathbf{5 . 0 0}$

Notre Col.one - Elude pratique sur le Congo Belge. Talrijke figuren en 1 gekleurde Kaart ran Congoland . . . . . . . . . . . . . . .fr.

Oxze Koronie. - Practische Stuclie over Belgisch Congoland. - Talrijke figuren en 1 gekleurde Kaart ran Congoland. . . . . . . . . . . . fr.

L'Éolution DaNs hes deUx Rignes oRginiques. - Que faut-il en penser aujourl'hui" . . . . . . .fr. 




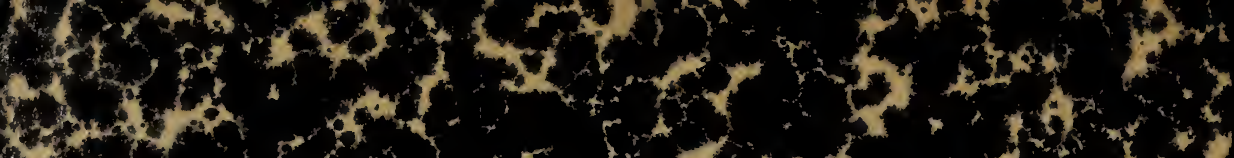

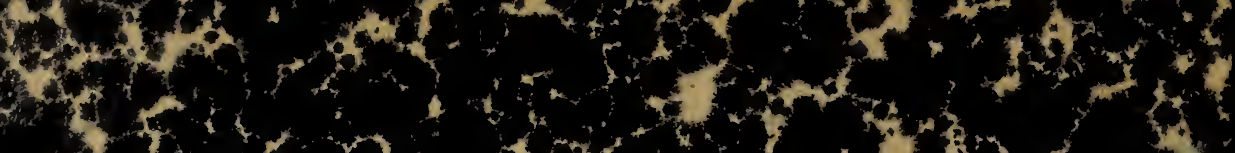

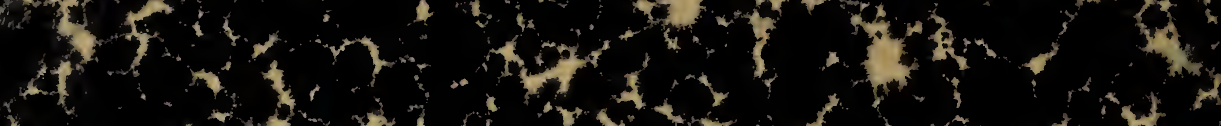

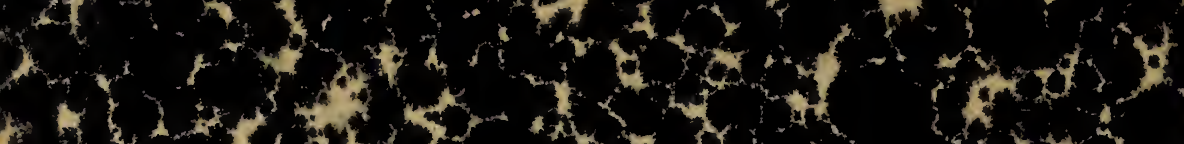

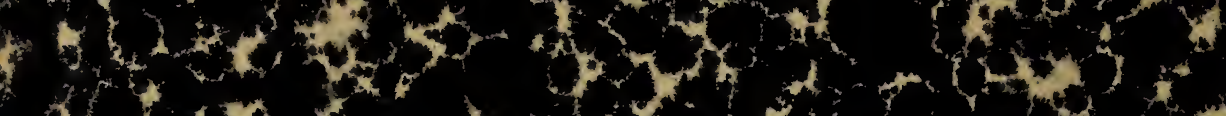

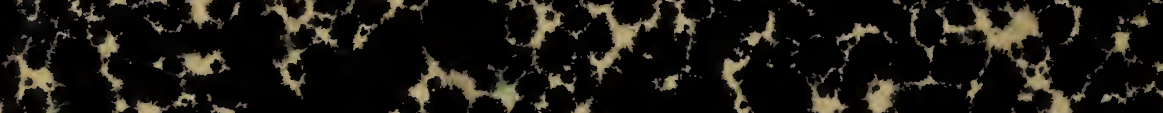
W.

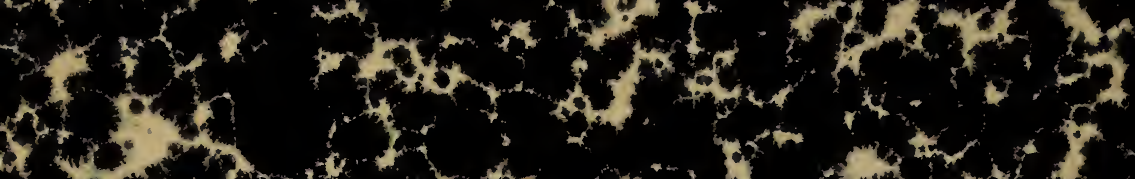
(x)

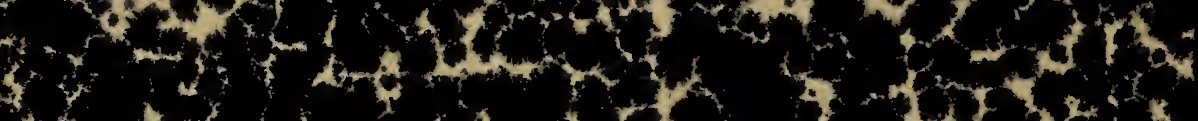

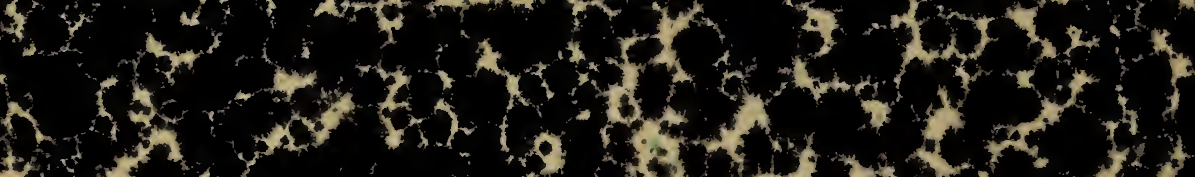

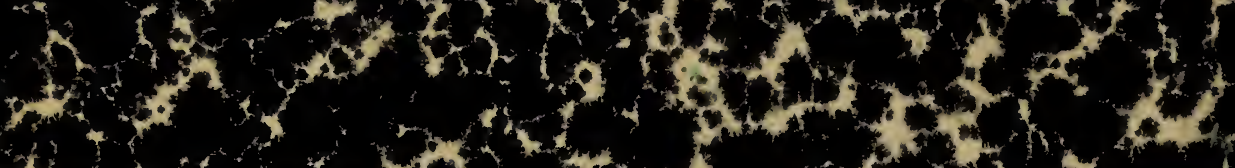

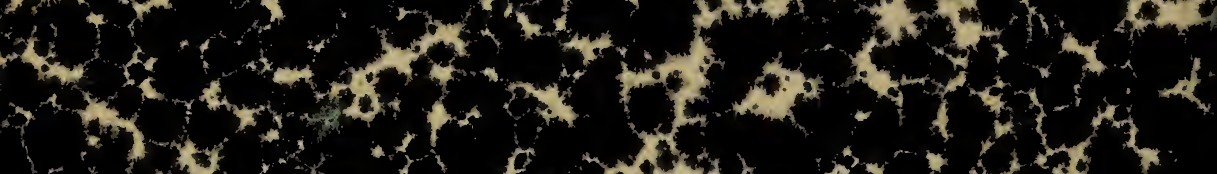
(1)

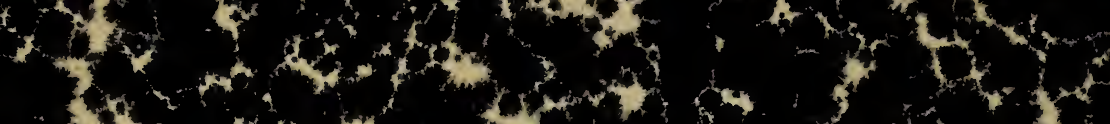

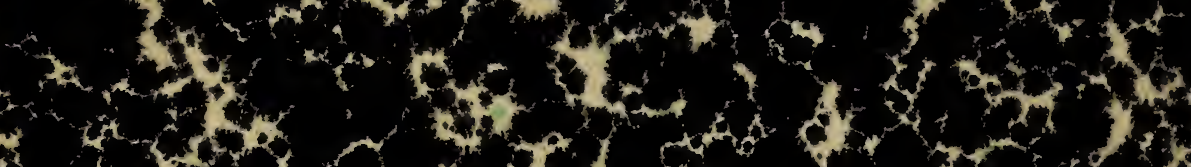
(5)

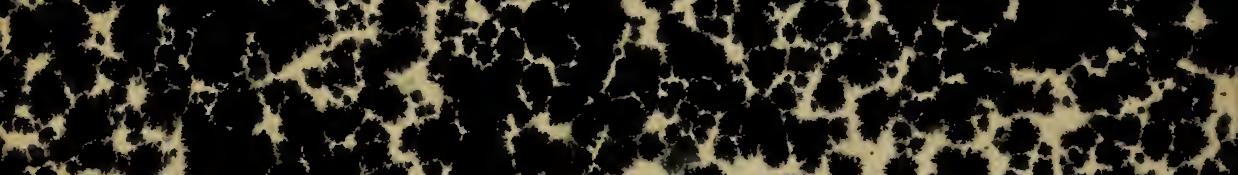

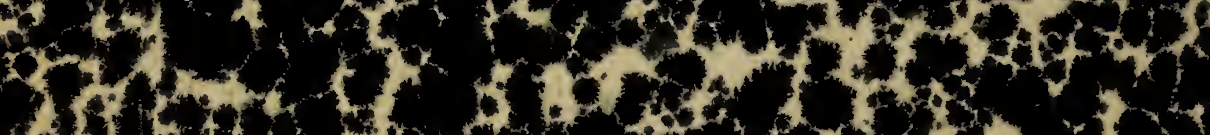

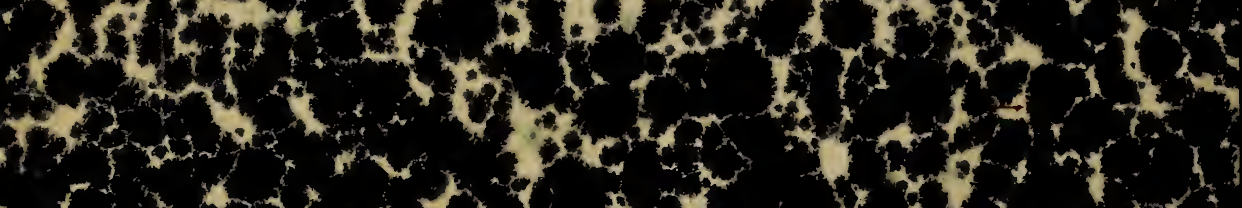

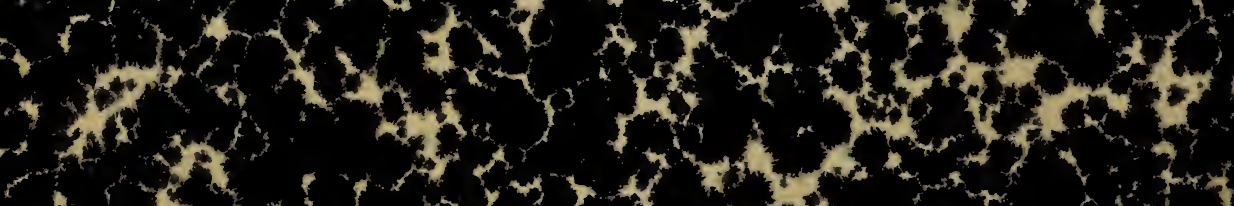

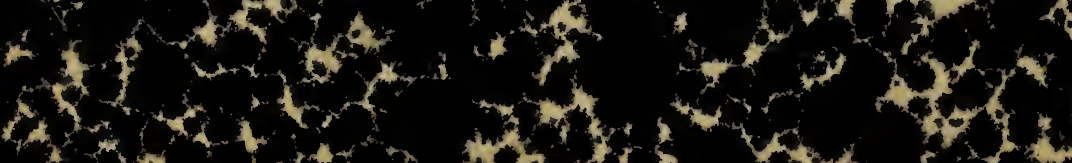

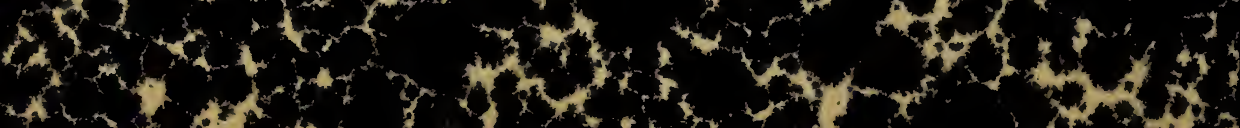
$4+x+y$

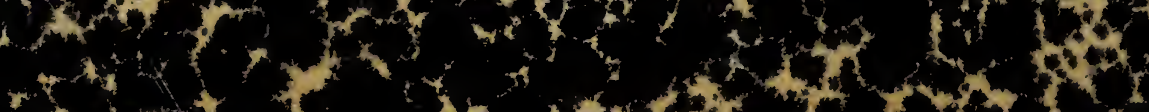

